\title{
Soft EHL based Friction Mechanism of Unreinforced and GF-Reinforced PA66 in Contact with Steel under PA08 Oil Lubrication
}

Takeshi Kunishima ( $\nabla$ takeshi.kunishima@ec-lyon.fr)

LTDS: Laboratoire de tribologie et dynamique des systemes

\section{Gaëtan BOUVARD}

LTDS: Laboratoire de tribologie et dynamique des systemes Jean Christophe ABRY

LTDS: Laboratoire de tribologie et dynamique des systemes

\section{Vincent FRIDRICI}

LTDS: Laboratoire de tribologie et dynamique des systemes

\section{Philippe KAPSA}

LTDS: Laboratoire de tribologie et dynamique des systemes

\section{Research Article}

Keywords: polyamide, friction, PAO8, lubrication, soft EHL

Posted Date: May 11th, 2021

DOl: https://doi.org/10.21203/rs.3.rs-471963/v1

License: (c) (i) This work is licensed under a Creative Commons Attribution 4.0 International License. Read Full License

Version of Record: A version of this preprint was published at Tribology Letters on July 30th, 2021. See the published version at https://doi.org/10.1007/s11249-021-01479-x. 


\title{
Soft EHL based friction mechanism of unreinforced and GF-reinforced PA66 in contact with steel under
} PAO8 oil lubrication

Takeshi Kunishima ${ }^{\text {a, b, * }}$, Gaëtan Bouvard ${ }^{\text {b }}$, Jean-Christophe Abry ${ }^{\text {b }}$, Vincent Fridrici ${ }^{\text {b }}$, Philippe Kapsa ${ }^{\text {b }}$

a JTEKT CORPORATION, 333 Toichi-cho, Kashihara, Nara 634-8555, Japan

${ }^{\mathrm{b}}$ Laboratoire de Tribologie et Dynamique des Systèmes, UMR CNRS 5513, École Centrale de Lyon, Université de Lyon, 36 Avenue Guy de Collongue, F-69134 Écully CEDEX, France

*Corresponding author: Takeshi Kunishima; E-mail: takeshi_kunishima@jtekt.co.jp

Keywords: polyamide, friction, PAO8, lubrication, soft EHL

\begin{abstract}
Polyamide 66 is widely used in polymer sliding parts including polymer gear. These parts are used under lubrication of oil and grease. In this study, the friction mechanism of the contact between polyamide 66 and a steel counterpart lubricated with additive-free polyalphaolefin8 oil was discussed by focusing on various parameters including the sliding surface roughness, normal load (contact pressure), sliding speed, temperature, and hardness of the steel counterpart. To explain the friction coefficient obtained under different test conditions, the theoretical minimum oil film thickness was calculated using the equation of the soft elastic hydrodynamic lubrication regime presented by Hamrock and Dowson considering the temperature dependence of oil viscosity and polymer mechanical properties, and the master curve of the relationship between $\Lambda$ and the friction coefficient was proposed considering the change in the roughness on the sliding surface. In addition, the contributions of the oil film based on the proposed master curve and lubricated solid/solid contact based on the Bowden-Tabor theory to the friction coefficient were discussed. Furthermore, the friction mechanism using the glass fiber-reinforced PA66 composite was investigated and compared to that of the unreinforced PA66.
\end{abstract}

\section{Introduction}

Polyamide 66 (PA66) is widely used in various automobiles and industrial machine parts such as gears [1, 2 , $3,4,5]$, bearing retainers [6, 7, 8], and rollers [9]. Because PA66 exhibits excellent heat resistance and good mechanical or tribological properties, it can be used in automobile engine compartments [10, 11]. When such parts are used under severe conditions, oil or grease lubrication is introduced to the tribosystem to reduce both the sliding heat and the friction coefficient. For example, in a worm reducer, a polymer worm wheel comprised of various plastic meshes with a steel worm shaft under grease lubrication $[12,13,14,15]$. Several studies on the tribology of engineering plastics including PA66 have been conducted under dry conditions owing to the self-lubrication properties of the plastic material, and the effects of each parameter including the contact pressure [16, 17], sliding speed $[16,18]$, and temperature $[19,20,21]$ on the friction or wear properties have been reported. Few works, however, have focused on the typical friction properties of lubricated engineering plastics including PA66 [22, 23 , 24, 25, 26]. Kochi et al. [25] measured the thickness of a lubricant film, on the basis of soft elastic hydrodynamic lubrication (EHL) theory on the contact of bearing steel and polycarbonate (PC). The oil film was thicker using PC (soft EHL) than using glass (hard EHL), irrespective of the sliding speed. A good correlation was observed between the actual measured and theoretically calculated values. Moreover, they demonstrated that the central oil film thickness could be theoretically predicted based on Bauer's model, which was modified based on the analysis 
of Dong and Qian.

In the authors' previous studies, the wear mechanism of GF composites in contact with steel under grease lubrication was elucidated [27, 28]. In addition, the effects of temperature and tribochemistry related to the low friction additives (e.g., zinc carboxylate) in grease were discussed [29]. However, our previous studies focused particularly on the wear or creep resistance of GF composites and steel counterparts under boundary lubricated conditions using grease under fixed high contact pressure and sliding speed to simulate the contact and sliding of a motor-assisted worm reducer. Therefore, the experimental conditions were set so that the tests could be accelerated to quickly evaluate each property. On the other hand, when considering the operating environment of the actual sliding parts including the worm reducer, it is vital to understand the friction properties under a much wider range of load, sliding speed, and temperature conditions. In particular, the mechanical properties of the polymer material and lubricants can be highly influenced by temperature; therefore, understanding the influence of temperature on friction is important.

For polymer worm wheels, it is important to consider tooth formation because it can influence the sliding surface roughness and friction. Polymer worm wheels are fabricated by injection molding and then mechanically forming the teeth by hob cutting. In contrast, the teeth can be fully formed by injection molding without requiring any mechanical cutting, which reduces the cost because the teeth do not have to be mechanically formed. However, the tooth dimensions can be less accurate than the dimensions of mechanically formed teeth. Additionally, runningin is introduced to ensure good matching between the worm wheel and the worm shaft. Considering these tooth formation processes, the roughness of the sliding surface is determined by the hob cutting or running-in conditions or by the surface roughness of the metal die used for injection molding, particularly when the teeth are directly formed using injection molding, and the roughness is supposed to influence the friction. Therefore, it is vital to understand the relationship between the sliding surface roughness and friction properties and to adjust the design of the sliding surface to control the friction of the actual sliding parts, including the polymer worm wheel.

Furthermore, the hardness of the steel counterpart can be an important parameter for understanding the friction mechanism. In the authors' previous work [27], high-hardness steel counterparts induced less wear resistance in the GF composite and more wear resistance in steel, which can be explained by comparing the hardness of the GFs and the steel counterpart. Considering an actual worm reducer, when softer steel not heat-treated after tooth formation is used for the steel worm shaft, the steel wear resistance is supposed to deteriorate despite the good wear resistance of the counterpart GF composites. Conversely, when the steel worm shaft is heat-treated after tooth formation, the wear resistances of the GF composite and steel counterpart can decrease and increase, respectively. In addition, insufficient dimensional stability related to heat-induced distortion results in inadequate worm reducer performance (i.e., increases the sliding torque or short-term durability). Therefore, it is important to understand the effect of steel hardness on the friction between steel and the PA66 or the GF composites under lubrication.

Therefore, the present study focuses on clarifying the friction mechanism between steel and the PA66 or the GF composite under oil lubrication. Polymer sliding parts in contact with steel were used under both oil or grease lubrication. In particular, it is difficult to fundamentally understand the grease lubrication friction mechanism because it is necessary to consider the speed-dependent apparent viscosity of the grease (a non-Newtonian fluid that affects the oil film thickness [25]), the thixotropic properties of the grease, and any possible tribochemical reactions and tribofilm formations, all of which are related to the additives (used to improve the tribological properties [29]) in addition to the lubrication theory of pure oil. Therefore, in this study, the effect of each parameter 
on the friction between the PA66 or GF composite and carbon steel under pure additive-free PAO8 oil lubrication was investigated, and the effects of various parameters including the normal load (contact pressure), sliding speed, temperature, roughness, and hardness of the steel counterpart on the friction were investigated systematically. The results were discussed based on both the EHL and solid-contact theories. Therefore, the study findings form the basis for comprehending the grease lubrication friction mechanism.

\section{Experimental}

\subsection{PA66 and reinforcement fibers}

Ring specimens (i.e., the sample geometry used for the sliding tests described in Section 2.4) were prepared by injection molding of commercially available unreinforced PA66 pellets with normal molecular mass (viscosity number: $145 \mathrm{ml} / \mathrm{g}$ ). To obtain the GF-reinforced PA66 composite test specimens, the raw PA66 and $15 \mathrm{wt} \%$ of GFs (GF diameter: $6.5 \mu \mathrm{m}$ ) were extruded using twin screw extruder and then the GF composite pellets were prepared. Subsequently, the test specimens were fabricated using the obtained GF-extruded pellets (according to the methods described in the authors' previous works [27, 29]). The GF composite specimens were then cut for $3 \mathrm{~mm}$ in the height direction. The objective of this process is to simulate the polymer worm wheel tooth formation by mechanical cutting and to simulate the sliding surface conditions under which the surface GFs were exposed [27]. Fig. 1 presents the scanning electron microscope (SEM) observations of the sliding surface of GF composite after $3 \mathrm{~mm}$ cutting and polishing using \#4,000 polishing paper. Due to the flow of resin inside the metallic die during the injection molding process, the orientation of the fibers compared to the sliding surface are different in the center part of the sliding surface compared to the outer and inner parts, and this was discussed quantitatively in the authors' previous studies [27, 28]. The sliding surface of the ring test specimens using unreinforced PA66 and GF composite was manually polished using a polishing machine and commercial polishing paper with roughness ranging from \#400 to \#4,000 grit to simulate the PA66 sliding surface roughness in the actual worm wheel after hob-cutting and running-in process under different conditions. In addition, nonpolished (i.e., the surface condition just after injection molding) specimens were prepared using unreinforced PA66. The sliding surface roughness $\left(R_{\mathrm{a}}\right)$ was measured using interferometry in the sliding direction of each specimen before and after the sliding tests.

Fig. 2 shows the surface roughness measured before and after the sliding test for the unreinforced PA66 polished using \#800 polishing paper. After the tilt was removed from the obtained image, the average sliding-direction sliding surface roughness $\left(R_{\mathrm{a}}\right)$ was obtained using Vision6 $4^{\circledR}$ software (Bruker). 

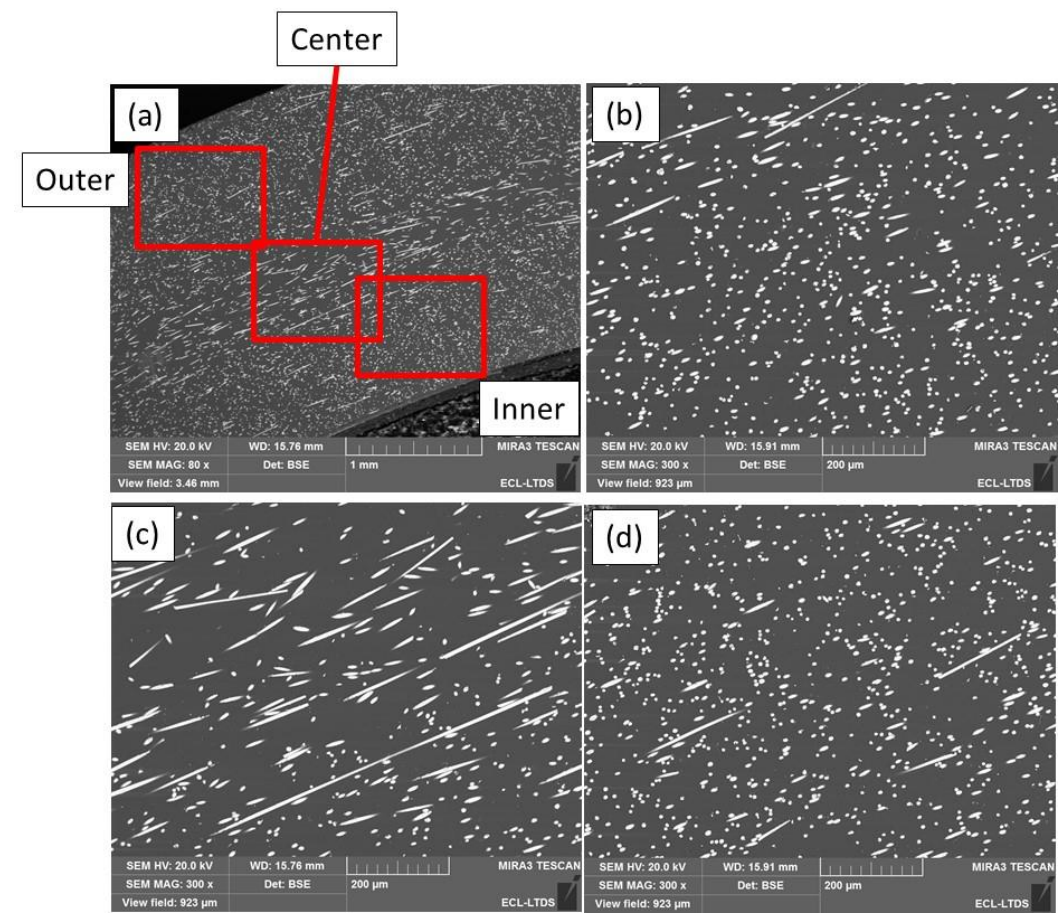

Fig. 1. SEM images of the sliding surface before test of composite in each area: (a) global view; (b) inner position; (c) center position; (d) outer position [27].

(a) Sliding direction
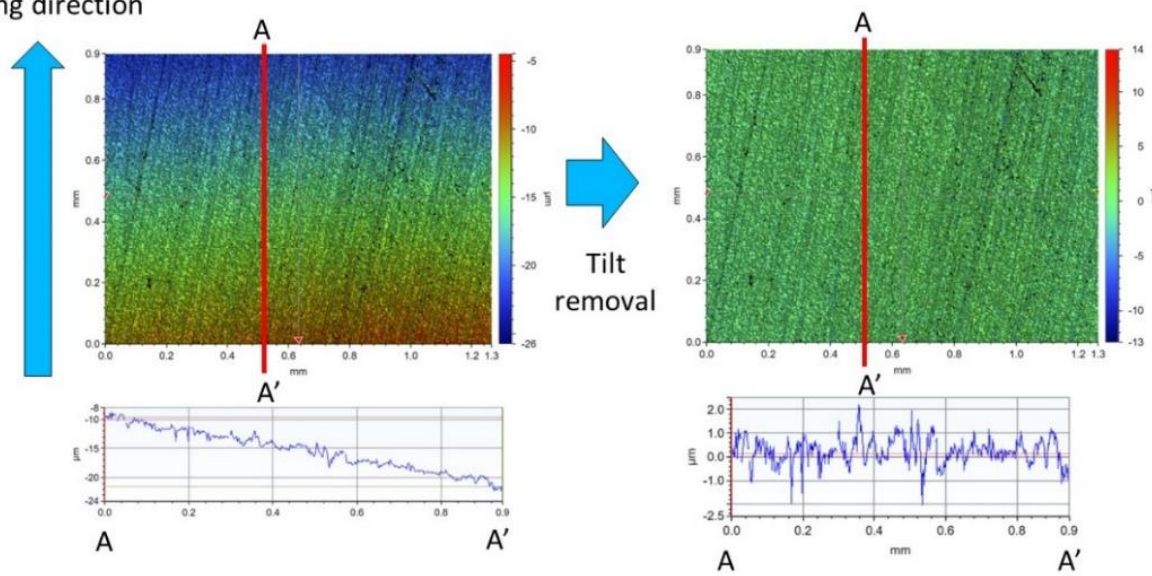

(b) Sliding direction

A
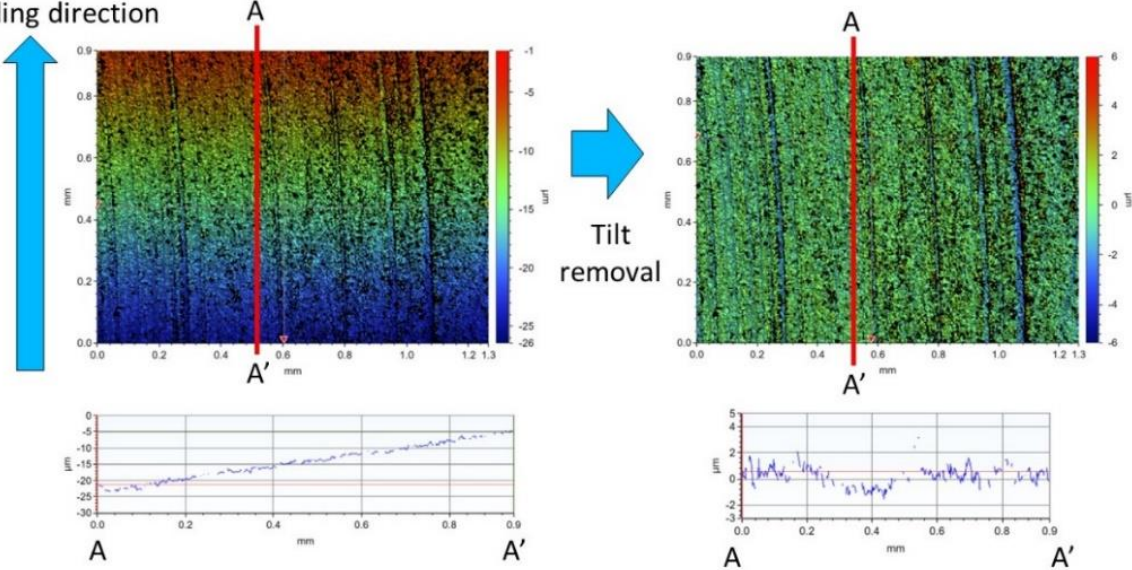

Fig. 2. Sliding surface roughness measured using interferometry (a) before $\left(R_{\mathrm{a}}=0.36 \pm 0.06 \mu \mathrm{m}\right)$ and (b) after $\left(R_{\mathrm{a}}=0.33 \pm 0.06 \mu \mathrm{m}\right)$ sliding test. 


\subsection{Steel cylinders}

S45C steel cylinders showing a Young's modulus of 205 GPa were prepared according to the JIS G 4051 standard and were used for the sliding tests. First, the cylinders were prepared using nonheated steel to simulate a steel worm shaft wherein the formed teeth were not heat treated. These cylinders are hereinafter referred to as "softer" steel cylinders. In contrast, heat-treated cylinders were quench hardened at $890^{\circ} \mathrm{C}$ for $30 \mathrm{~min}$, cooled and tempered in oil at $300^{\circ} \mathrm{C}$ for $60 \mathrm{~min}$, and cooled in ambient air. Then, the cylinder surfaces were polished to obtain a surface roughness similar to that of the nonheated cylinders to simulate a steel worm shaft wherein the formed teeth were heat treated. These cylinders are hereinafter referred to as "harder" steel cylinders. Fig. 3 presents the steel cylinder roughness measured using interferometry before the sliding tests. After the cylindrical shape of the obtained image was removed, the average sliding-direction sliding surface roughness $\left(R_{a}\right)$ were obtained. The steel hardness was measured using microindentation. Table 1 lists the sliding-direction sliding surface roughness $\left(R_{\mathrm{a}}\right)$ and the corresponding hardness of each cylinder. The hardness of the harder steel was higher than that of the softer one (5.9 GPa, as measured using nanoindentation in [27]).

(a) Sliding direction
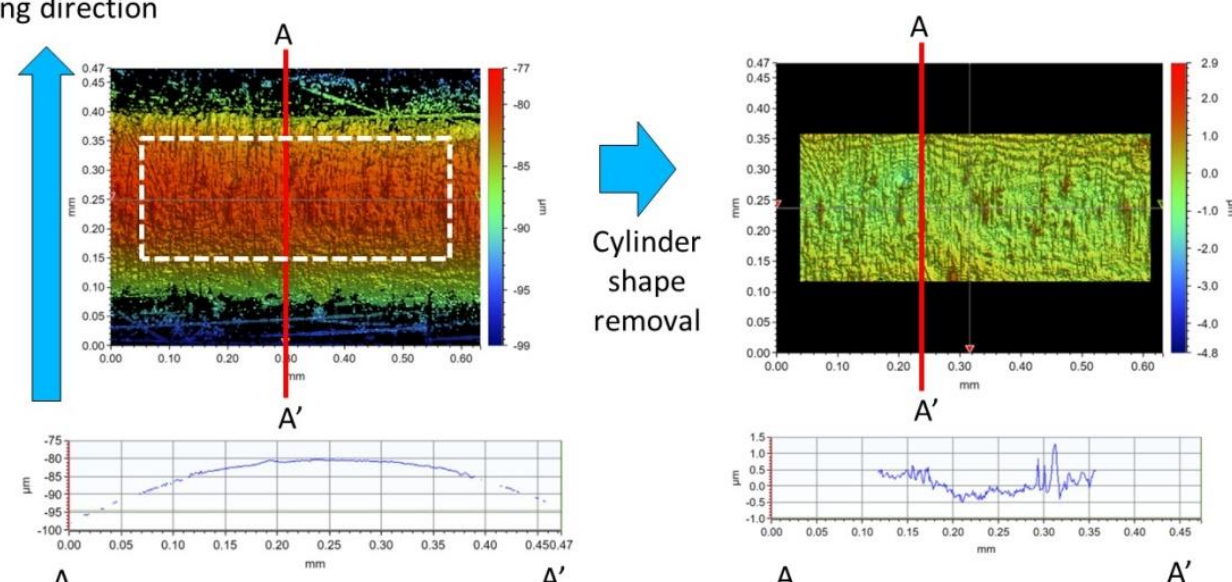

A

$A^{\prime}$

(b)
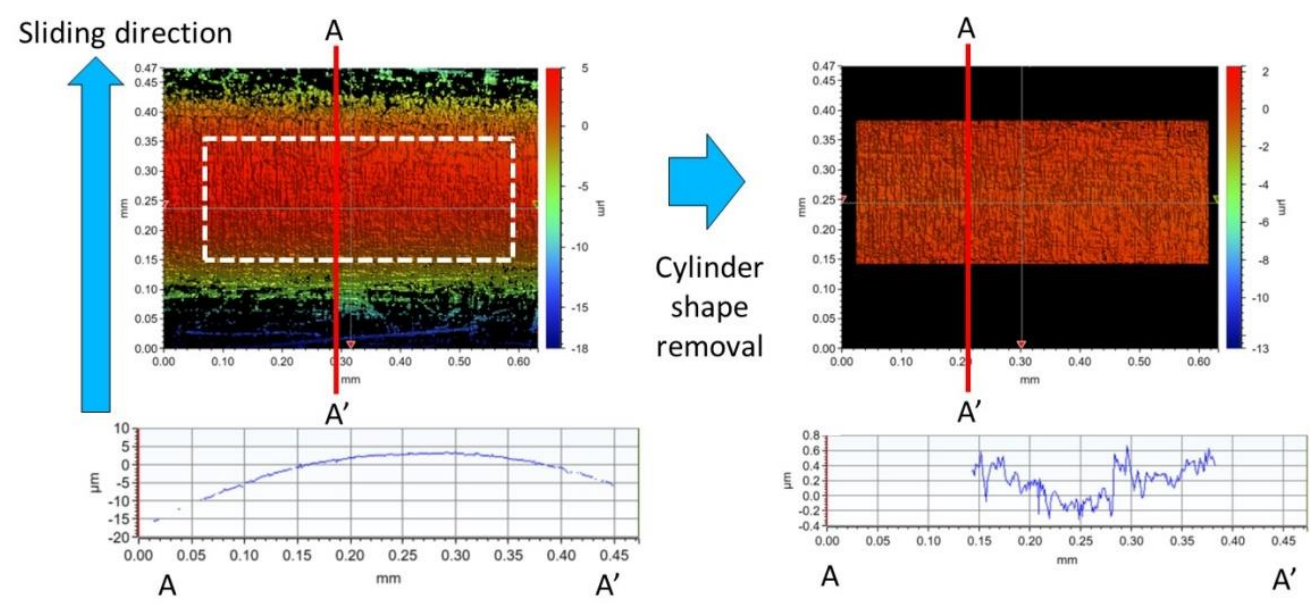

Fig. 3. Surface roughness measured using interferometry before sliding tests: (a) softer steel $\left(R_{\mathrm{a}}=0.12 \pm 0.03\right.$ $\mu \mathrm{m})$ and (b) harder steel $\left(R_{\mathrm{a}}=0.08 \pm 0.02 \mu \mathrm{m}\right)$. 
Table 1. Hardness and roughness of each steel cylinder.

\begin{tabular}{|c|c|c|}
\hline Cylinder & $\begin{array}{c}\text { Hardness measured using } \\
\text { microindentation }(\mathrm{GPa})\end{array}$ & $\begin{array}{c}\text { Roughness }\left(R_{\mathrm{a}}\right) \text { measured in } \\
\text { sliding direction }(\mu \mathrm{m})\end{array}$ \\
\hline Softer & $4.50 \pm 0.13$ & $0.12 \pm 0.03$ \\
\hline Harder & $9.89 \pm 0.17$ & $0.08 \pm 0.02$ \\
\hline
\end{tabular}

\subsection{Lubrication oil}

PAO8 oil (Durasyn ${ }^{\circledR} 168$, INEOS) was used as the lubricating oil in the sliding tests because it does not contain any specific additives such as friction modifiers or extreme pressure additives for improving the tribological properties. Fig. 4 presents the viscosity of the PAO8 oil plotted as a function of temperature, as measured using a corn-rotor rheometer (AR2000, TA Instruments). The measurement shear rate was $1001 / \mathrm{s}$, the cone angle was $4^{\circ}$, and the measurement gap was $111 \mu \mathrm{m}$. Used PAO8 oil has a good compatibility to PA66 to ensure the long-term usage inside the automobile engine compartment at high temperature.

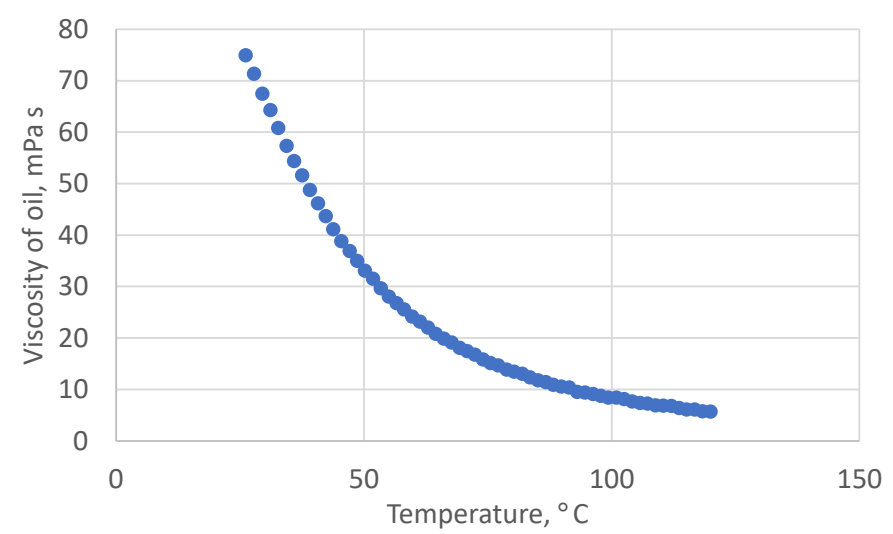

Fig. 4. Temperature dependence of oil viscosity measured using rheometer.

\subsection{Experimental tribological setup and test conditions}

Sliding tests were performed using the unreinforced PA66 or GF composite ring specimens and steel cylinders under PAO8 oil lubrication, according to the same method applied in the authors' previous works [27, 28, 29, 30, 31]. Fig. 5 presents schematics of the test specimens and tribometer setup. Four fixed steel cylinders were placed on the ring specimens, and a normal load was applied. Subsequently, the test specimens were rotated. Before the sliding tests, the sliding surface side of the ring specimens was dipped into the lubrication oil, and the oil lubrication was maintained during the sliding tests. A normal load was applied using the deadweights. When the sliding tests were conducted at 80 or $120^{\circ} \mathrm{C}$, a cartridge heater was inserted into the cylinder sample holder, and a constant temperature was maintained during the sliding tests. The friction coefficient $(\mu)$ was estimated using the measured friction torque $(T)$, normal load $(w)$, and mean rotation radius of the ring specimens $(r=11.4 \mathrm{~mm})$, as shown in the following equation:

$$
\mu=\frac{T}{r w}
$$

One cycle of the sliding tests means one rotation of the ring specimens. 

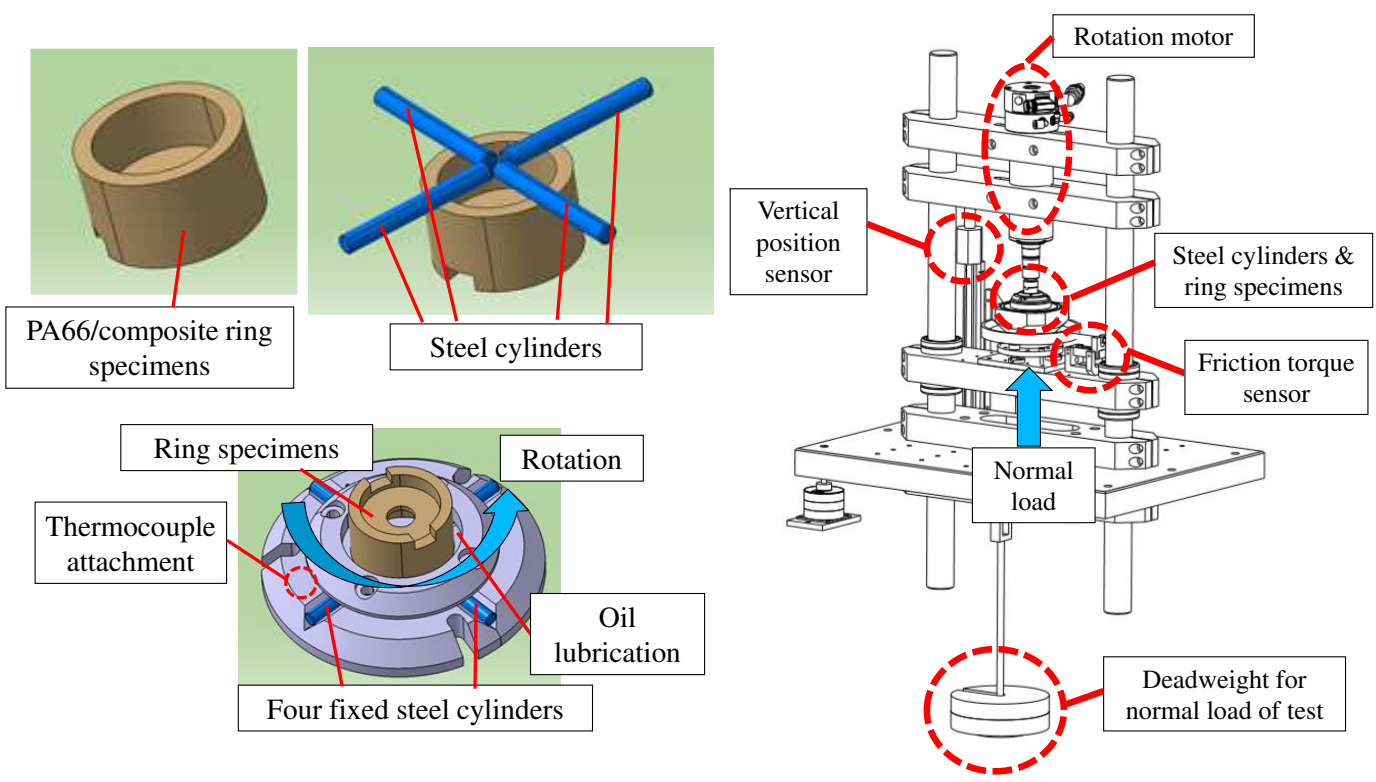

Fig. 5. Schematics of test specimens and sliding-test setup.

To evaluate the friction coefficient, two sliding test profiles were introduced.

\subsubsection{Evaluation of sliding speed dependence}

Software was used to change the rotation speed according to the profile shown in Fig. 6 (a) for the same normal load $(50 \mathrm{~N})$ during the test.

\subsubsection{Evaluation of normal load dependence}

The normal load was changed over the sliding cycles at the same rotation speed (790 rpm) according to the profile presented in Fig. 6 (b) by changing the deadweight; namely, the normal load was increased and decreased three times to investigate the normal load (i.e., contact pressure) dependence of the friction coefficient at the same rotation speed.

(a)

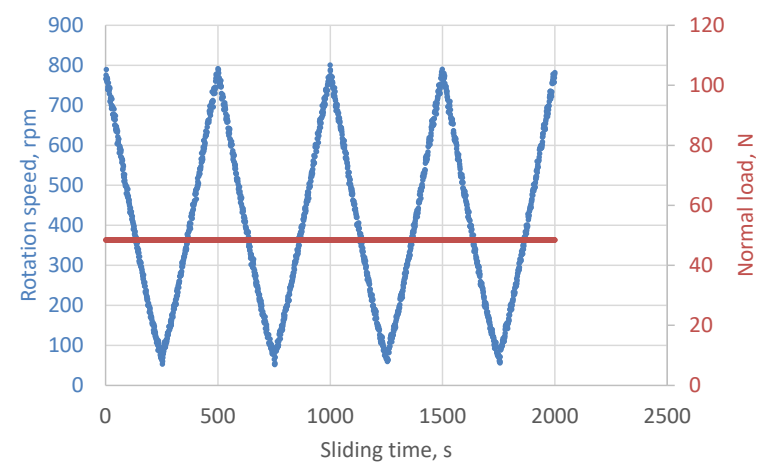

(b)

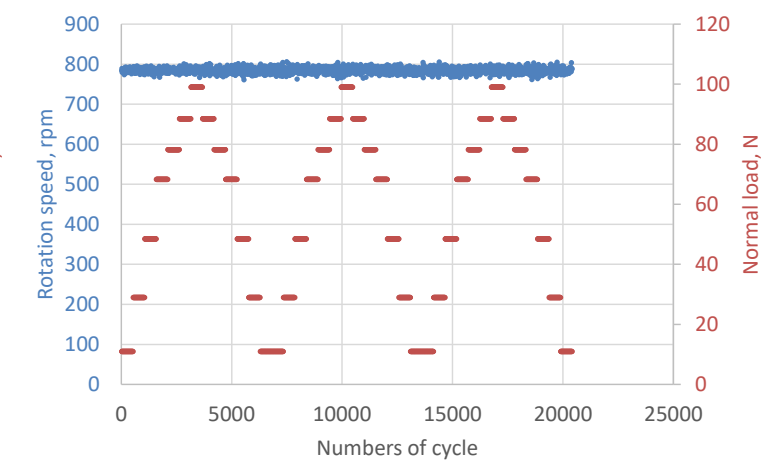

Fig. 6. Sliding test profiles: (a) rotation speed dependence measured under same normal load and (b) normal load dependence measured under same rotation speed. 
Table 2 lists the sliding test conditions. Contact pressure was estimated based on the Hertzian theory considering different Young's modulus of unreinforced and GF-reinforced PA66.

Table 2. Sliding test conditions. RT means room temperature.

\begin{tabular}{|c|c|c|}
\hline \multirow{2}{*}{$\begin{array}{l}\text { Steel cylinders } \\
\qquad(\times 4)\end{array}$} & Diameter & $3.5 \mathrm{~mm}$ \\
\hline & Length & $30 \mathrm{~mm}$ \\
\hline \multirow{4}{*}{$\begin{array}{l}\text { Ring specimen } \\
\text { (JIS K 7218) }\end{array}$} & Outer diameter & $25.6 \mathrm{~mm}$ \\
\hline & Inner diameter & $20 \mathrm{~mm}$ \\
\hline & \multirow{2}{*}{ Height } & $15 \mathrm{~mm}$ (unreinforced PA66) \\
\hline & & 12 mm (GF-reinforced PA66) \\
\hline \multirow{9}{*}{$\begin{array}{c}\text { Test } \\
\text { conditions }\end{array}$} & Rotation speed & up to $1,567 \mathrm{rpm}$ \\
\hline & Mean sliding speed & $\begin{array}{l}\text { up to } 2 \mathrm{~m} / \mathrm{s} \\
\text { (Mean contact-area radius: } 11.4 \mathrm{~mm} \text { ) }\end{array}$ \\
\hline & Normal load & $10-100 \mathrm{~N}$ \\
\hline & \multirow{2}{*}{ Contact pressure } & 23-64 MPa (unreinforced PA66 at RT) \\
\hline & & 30-90 MPa (GF-reinforced PA66 at RT) \\
\hline & Total test duration & $1,560-2,000 \mathrm{~s}$ \\
\hline & Total sliding cycles & $7,800-20,400$ cycles \\
\hline & Environment temperature & $25-120^{\circ} \mathrm{C}$ \\
\hline & Lubricant & PAO8 oil \\
\hline
\end{tabular}

\subsection{Measurement of PA66 and GF composite surface mechanical properties}

The Young's moduli of the PA66 and GF composite ring specimen contact surfaces were measured using microindentation at each temperature according to the same method presented in the authors' previous study [29]. Table 3 lists the test conditions.

Table 3. Test conditions under which Young's moduli of ring specimen contact surfaces were measured using nanoindentation.

\begin{tabular}{|c|c|c|}
\hline Measured sample & GF composite & Unreinforced PA66 \\
\hline Indenter & Berkovich (WC) & Berkovich (WC) \\
\hline $\begin{array}{c}\text { Maximum normal load } \\
\text { and duration }\end{array}$ & $500 \mathrm{mN}$ for $10 \mathrm{~s}$ & $250 \mathrm{mN}$ for $10 \mathrm{~s}$ \\
\hline Temperature & 25,80, and $120^{\circ} \mathrm{C}$ & 25,80, and $120^{\circ} \mathrm{C}$ \\
\hline
\end{tabular}

\subsection{Observation of sliding surfaces after sliding tests}

The sliding surfaces of the ring specimens and steel cylinders were observed using an optical microscope and SEM. In addition, the surface topography and roughness of the ring specimen and steel cylinder sliding surfaces were measured using interferometry after each sliding test, as described in Sections 2.1 and 2.2. 


\section{Results and Discussion}

3.1 Effects of ring surface roughness, sliding speed, and temperature of unreinforced PA66 and harder steel on friction coefficient

To understand the basic friction mechanism of this tribosystem, the effects of the ring surface roughness and sliding speed on the friction coefficient were investigated at room temperature. To eliminate the effect of the steel cylinder wear and the consequent change in the contact geometry, harder steel cylinders were used. In addition, to understand the basic friction mechanism, unreinforced PA66 ring specimens were used. Fig. 7 presents the friction coefficient evolution obtained for different surface roughness obtained at different rotation speeds at room temperature. The initial sliding-direction surface roughness $\left(R_{\mathrm{a}}\right)$ of the unreinforced PA66 ranged from 0.03 to 0.98 $\mu \mathrm{m}$ depending on the polishing process. The global tendency was that the friction coefficient was higher at low rotation speeds and lower at high ones, gradually increasing with decreasing rotation speed and vice versa. The friction coefficient was higher when the initial surface roughness was higher. No remarkable differences were observed between the evolutions obtained for $R_{\mathrm{a}}=0.03$ and $0.07 \mu \mathrm{m}$ or for $R_{\mathrm{a}}=0.40$ and $0.98 \mu \mathrm{m}$. Furthermore, these surface roughness relations did not change until the end of the sliding tests. For $R_{\mathrm{a}}=0.98$ and $0.40 \mu \mathrm{m}$, the friction coefficient decreased gradually during sliding at the same rotation speed. In contrast, the friction coefficient was identical to or higher than the initial ones obtained during sliding at the same rotation speed in the range $R_{\mathrm{a}}=0.03-0.20 \mu \mathrm{m}$. In addition, no remarkable change in the minimum friction coefficient was observed when rotation speed was increased up to 1,567 rpm (see Fig. S1 in Supplementary material).

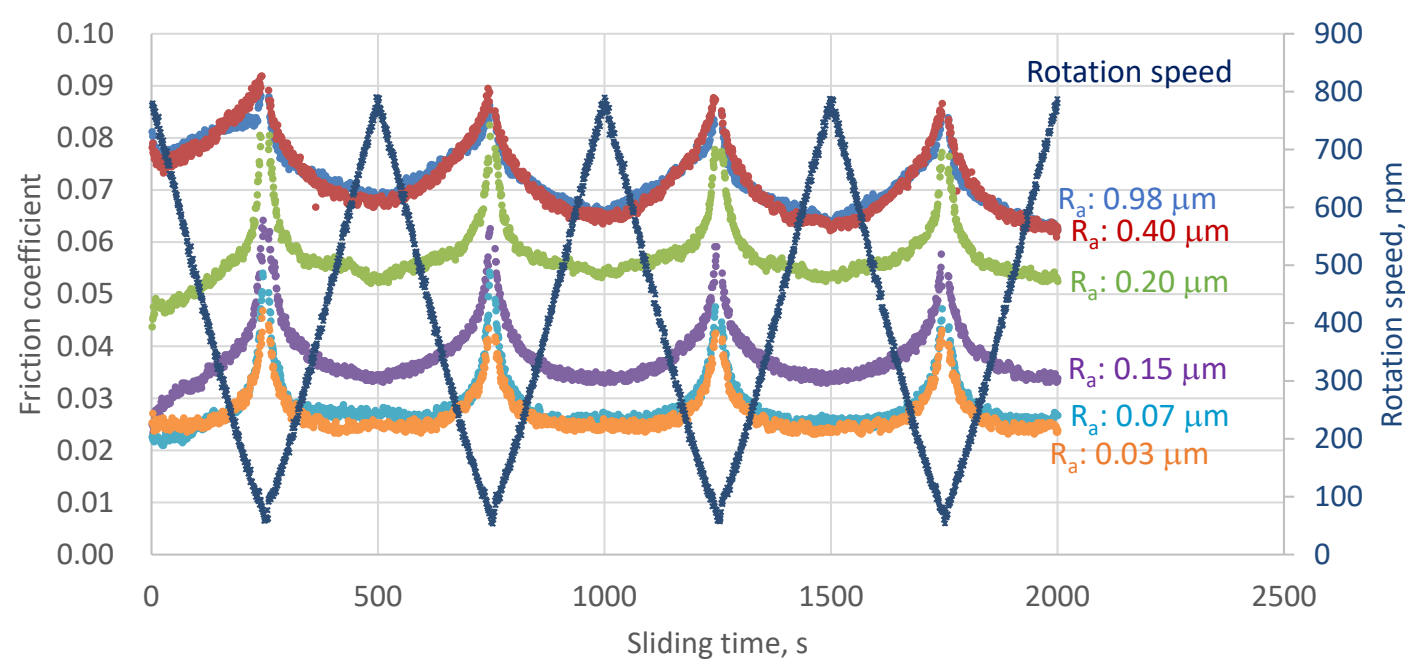

Fig. 7. Friction coefficient evolutions obtained for different surface roughness of unreinforced PA66 ring specimens measured at different rotation speeds at room temperature.

The temperature dependence of the friction coefficient was investigated using samples showing surface roughness $R_{\mathrm{a}}=0.07 \mu \mathrm{m}$ (i.e., polished with \#4,000 paper). Fig. 8 presents the evolution of the friction coefficient at different temperatures and rotation speeds. The initial friction coefficients similarly presented in the range 0.025-0.03 and increased with decreasing sliding speed, as observed in Fig. 7. At room temperature, the low friction coefficients (0.025) stabilized between 200 and $790 \mathrm{rpm}$ during sliding and increased or decreased gradually with decreasing or increasing rotation speed at 80 or $120^{\circ} \mathrm{C}$, respectively. In addition, the global tendency of the friction coefficients gradually increased at the same rotation speed during sliding at 80 or $120^{\circ} \mathrm{C}$ and were higher when the temperature was higher, particularly in the latter part of the sliding tests. 


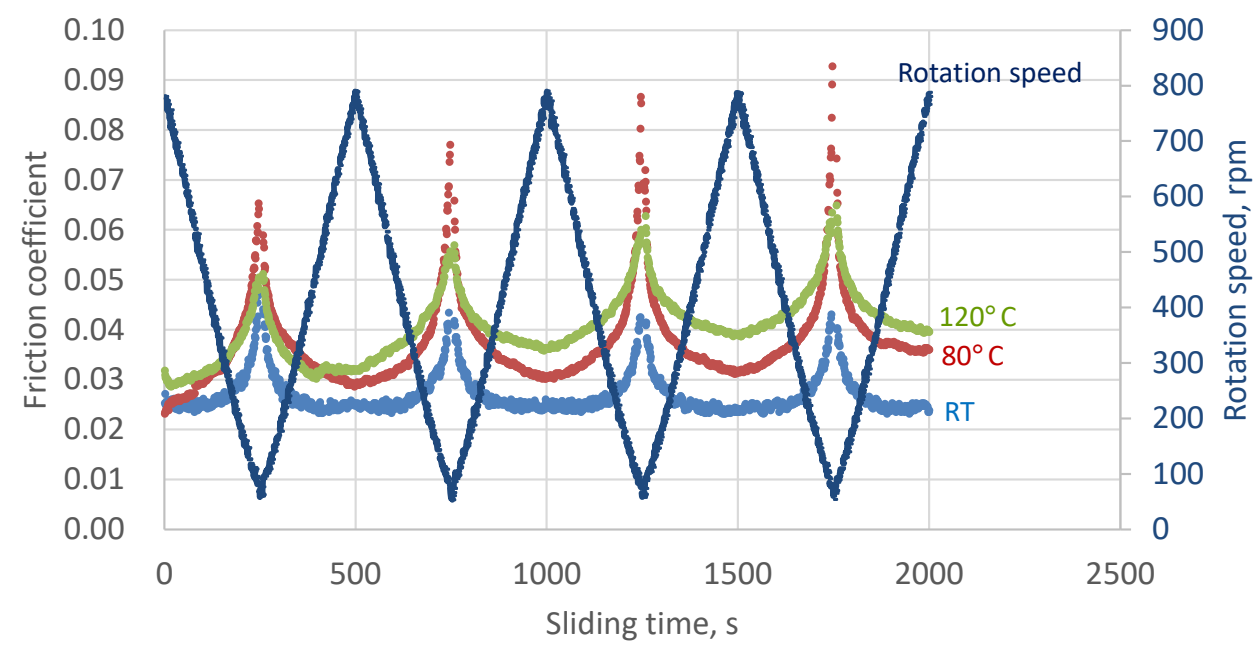

Fig. 8. Friction coefficient evolutions of unreinforced PA66 specimens measured at different temperatures and rotation speeds.

Fig. 9 presents the relationship between the friction coefficient and the sliding speed measured under each test condition. Clearly, the friction coefficient was influenced by each parameter (e.g., roughness and temperature), resulting in different friction coefficients for a given rotation speed.

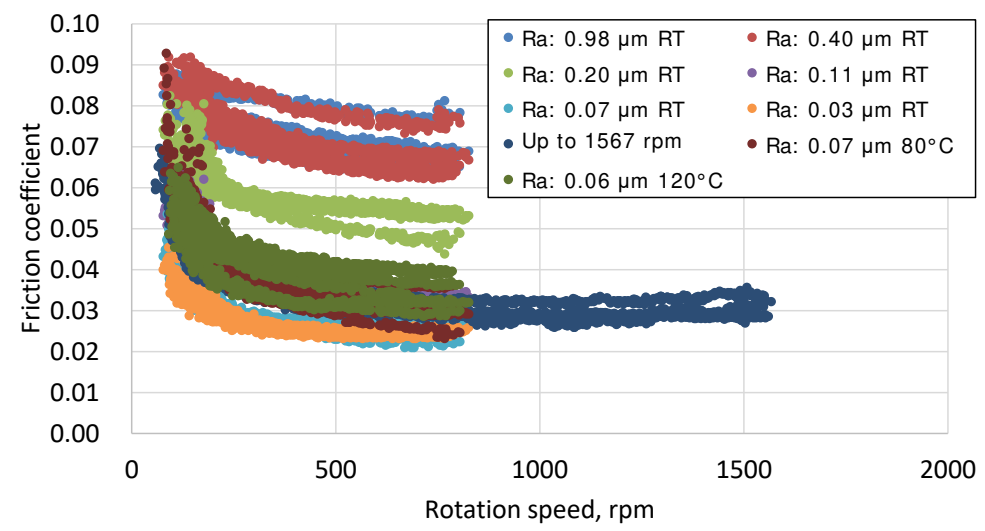

Fig. 9. Relationship between sliding speed and friction coefficient measured under each test condition.

Fig. 10 presents the optical microscope images of the unreinforced PA66 ring specimen (i.e., the specimen with an initial $R_{\mathrm{a}}$ of $0.03 \mu \mathrm{m}$ in Fig. 7) sliding surface before and after the sliding test. Several sliding marks, which are supposed to be steel cylinder asperity-related two-body abrasive wear, are clearly observed in the sliding direction. Table 4 lists the sliding-direction sliding surface roughness $\left(R_{\mathrm{a}}\right)$ of the ring specimens measured using interferometry before and after the sliding tests. $R_{\mathrm{a}}$ decreased after the sliding tests when the initial $R_{\mathrm{a}}$ was above $0.40 \mu \mathrm{m}$, which can be attributed to polishing when the rough PA66 surface slid with a cylinder showing a lower $R_{\mathrm{a}}\left(=0.08 \mu \mathrm{m}\right.$ for the cylinder). In contrast, $R_{\mathrm{a}}$ increased when the initial $R_{\mathrm{a}}$ was low, particularly during the sliding test conducted at room temperature. In addition, the harder steel cylinder did not show any explicit wear. 
(a)

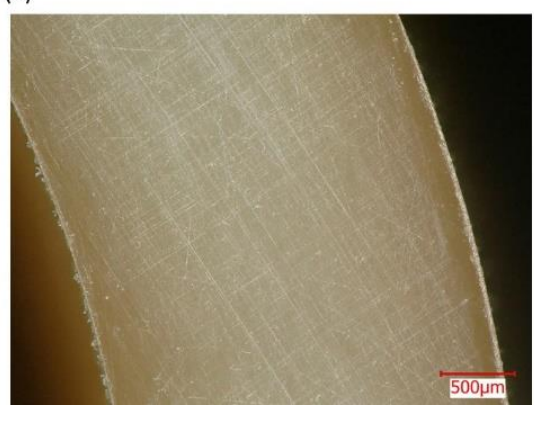

(b)

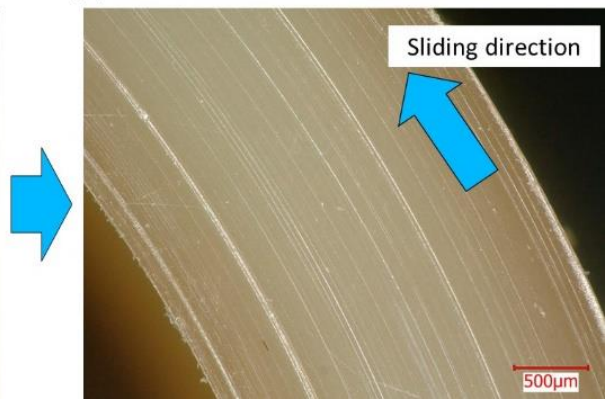

Fig. 10. Optical microscope images taken (a) before and (b) after sliding test.

Table 4. Sliding surface roughness $\left(R_{\mathrm{a}}\right)$ of ring specimens before and after sliding tests.

\begin{tabular}{|c|c|c|c|}
\hline Polishing paper & Temperature $\left({ }^{\circ} \mathrm{C}\right)$ & $\begin{array}{c}\text { Pre-test surface roughness } \\
\left(R_{\mathrm{a}}\right)(\mu \mathrm{m})\end{array}$ & $\begin{array}{c}\text { Post-test surface roughness } \\
\left(R_{\mathrm{a}}\right)(\mu \mathrm{m})\end{array}$ \\
\hline$\# 400$ & RT & $0.98 \pm 0.16$ & $0.46 \pm 0.05$ \\
\hline$\# 800$ & RT & $0.40 \pm 0.05$ & $0.35 \pm 0.10$ \\
\hline No polishing (skin layer) & RT & $0.20 \pm 0.05$ & $0.20 \pm 0.03$ \\
\hline$\# 2,000$ & RT & $0.11 \pm 0.01$ & $0.23 \pm 0.06$ \\
\hline$\# 4,000$ & RT & $0.07 \pm 0.00$ & $0.13 \pm 0.01$ \\
\hline$\# 4,000$ & RT & $0.03 \pm 0.00$ & $0.06 \pm 0.01$ \\
\hline$\# 4,000 *$ & RT & $0.07 \pm 0.00$ & $0.13 \pm 0.01$ \\
\hline$\# 4,000$ & 80 & $0.07 \pm 0.01$ & $0.07 \pm 0.01$ \\
\hline$\# 4,000$ & 120 & $0.06 \pm 0.02$ & $0.07 \pm 0.01$ \\
\hline
\end{tabular}

*Surface roughness measured at higher rotation speeds, as explained in Fig. S1 in Supplementary material.

To analyze these results by systematically considering the sliding conditions and changes in the sliding surface roughness, we focused on the oil film formation and the $\Lambda$ ratio on the sliding surface. The process of estimating the oil film thickness is described in the next section.

\subsection{Oil film thickness estimated based on lubrication regime}

The actual oil film thickness is usually measured using optical interferometry with a steel ball and a transparent glass disk to simulate the rolling-sliding contact of a bearing [25]. To date, few studies have focused on lubrication theories of polymer materials including engineering plastics. However, in the present study, the theoretical oil film thickness was estimated based on EHL for a flat-cylinder pure-sliding contact to discuss the plausible friction mechanism. To estimate the oil film thickness on a sliding surface, it is necessary to determine the lubrication regime of the contact geometry under a given applied load and sliding speed to select the appropriate formula for calculating the oil film thickness $[32,33,34,35]$. Depending on the values of the dimensionless viscosity and elasticity parameters ( $g_{\mathrm{V}}$ and $g_{\mathrm{E}}$, respectively), we can determine the governing lubrication regime of a line contact and the appropriate formula for estimating the oil film thickness by plotting the obtained $g_{V}$ and $g_{E}$ in a lubricationregime map. $g_{E}$ and $g_{\mathrm{V}}$ can be estimated using the following equations.

$$
g_{E}=\left(\frac{w_{l}^{2}}{\eta_{0} E R u}\right)^{1 / 2},
$$




$$
g_{v}=\left(\frac{\alpha^{2} w_{l}^{3}}{\eta_{0} R^{2} u}\right)^{1 / 2},
$$

where $w_{l}$ is the load per unit length, $\eta_{0}$ is the viscosity of the lubrication oil, $E$ is the combined Young's modulus, $R$ is the equivalent contact radius, $u$ is the entrainment speed, and $\alpha$ is the pressure-viscosity coefficient of the oil (20 $\mathrm{GPa}^{-1}$ at room temperature). Furthermore, $w_{l}$ is obtained from the following equation, considering the fourpoint contact between the ring specimen and the steel cylinders and the contact length (i.e., the width of the ring specimens $l=2.8 \mathrm{~mm}$, as presented in Fig. 11).

$$
w_{l}=\frac{w}{4 l}
$$

where $w$ is the normal load applied during the sliding tests.

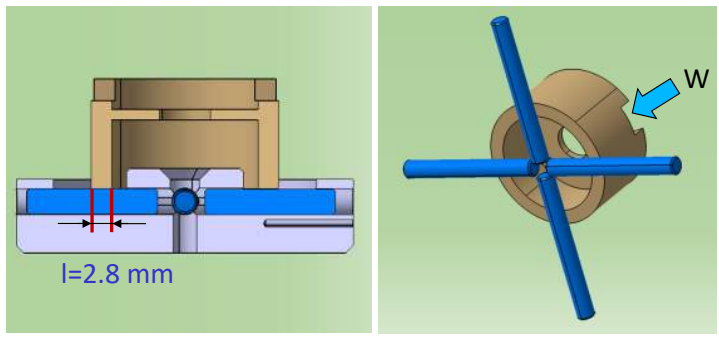

Fig. 11. Contact geometry of sliding test performed with ring specimen and four steel cylinders.

$E, R$, and $u$ are expressed as follows, considering the contact between the two parts presented in Fig. 12 .

$$
\frac{2}{E}=\frac{1-v_{1}{ }^{2}}{E_{1}}+\frac{1-v_{2}{ }^{2}}{E_{2}},
$$

$$
\begin{aligned}
& \frac{1}{R}=\frac{1}{R_{1}}+\frac{1}{R_{2}}, \\
& u=\frac{u_{1}+u_{2}}{2},
\end{aligned}
$$

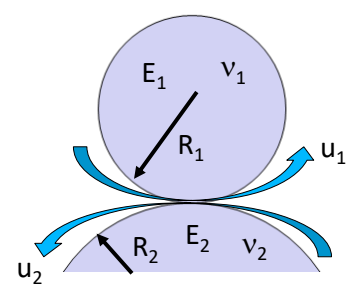

E: Young's modulus

$v$ : Poisson ratio

R: diameter

u: sliding speed

Fig. 12. Schematic of contact between two materials.

where $E_{1}$ and $E_{2}$ are the Young's moduli of the steel cylinder and either the PA66 or the composite ring specimens, respectively; $v_{1}$ and $v_{2}$ are the Poisson ratios of the cylinder and ring, respectively; $R_{1}$ and $R_{2}$ are the contact diameters of the cylinder and ring specimens, respectively (i.e., $R_{2}$ is infinite); and $u_{1}$ and $u_{2}$ are the rotation speeds of the cylinder and ring specimens (i.e., $u_{1}=0$ ), respectively.

In addition, it is necessary to consider the temperature dependence of the oil viscosity and the PA66 mechanical properties to determine the lubrication regime and estimate the theoretical oil film thickness at each temperature. Lubrication oil is a Newtonian fluid; therefore, the viscosity is consistent for different rotation speeds at the same temperature. The viscosity of the PAO8 oil measured using a rheometer at each temperature is shown in Fig. 4. The oil viscosity decreased with increasing temperature, and the measured viscosities were 17.9 and $7.6 \%$ at 80 and $120^{\circ} \mathrm{C}$, respectively, compared to the corresponding viscosities measured at room temperature. 
Fig. 13 shows the Young's moduli of the unreinforced PA66 and GF composite measured using microindentation at each temperature [29]. The GF composite shows a higher Young's modulus than the unreinforced PA66, and the Young's modulus decreased with increasing temperature.

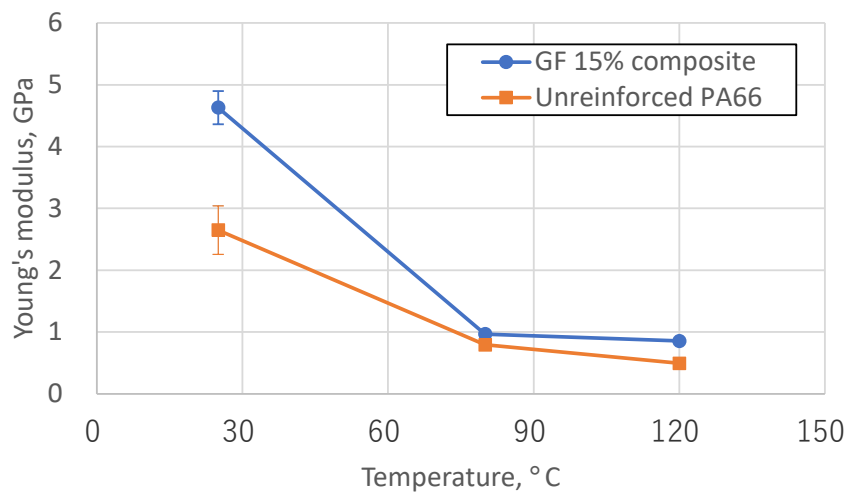

Fig. 13. Young's modulus of unreinforced PA66 and GF composite measured using microindentation at each temperature [29].

From the oil viscosity and Young's modulus obtained for the unreinforced PA66, $g_{\mathrm{E}}$ and $g_{\mathrm{V}}$ were estimated under each test condition (e.g., different rotation speeds, normal loads, and temperatures) and were superimposed on the presented lubrication regime map, as shown in Fig. 14.
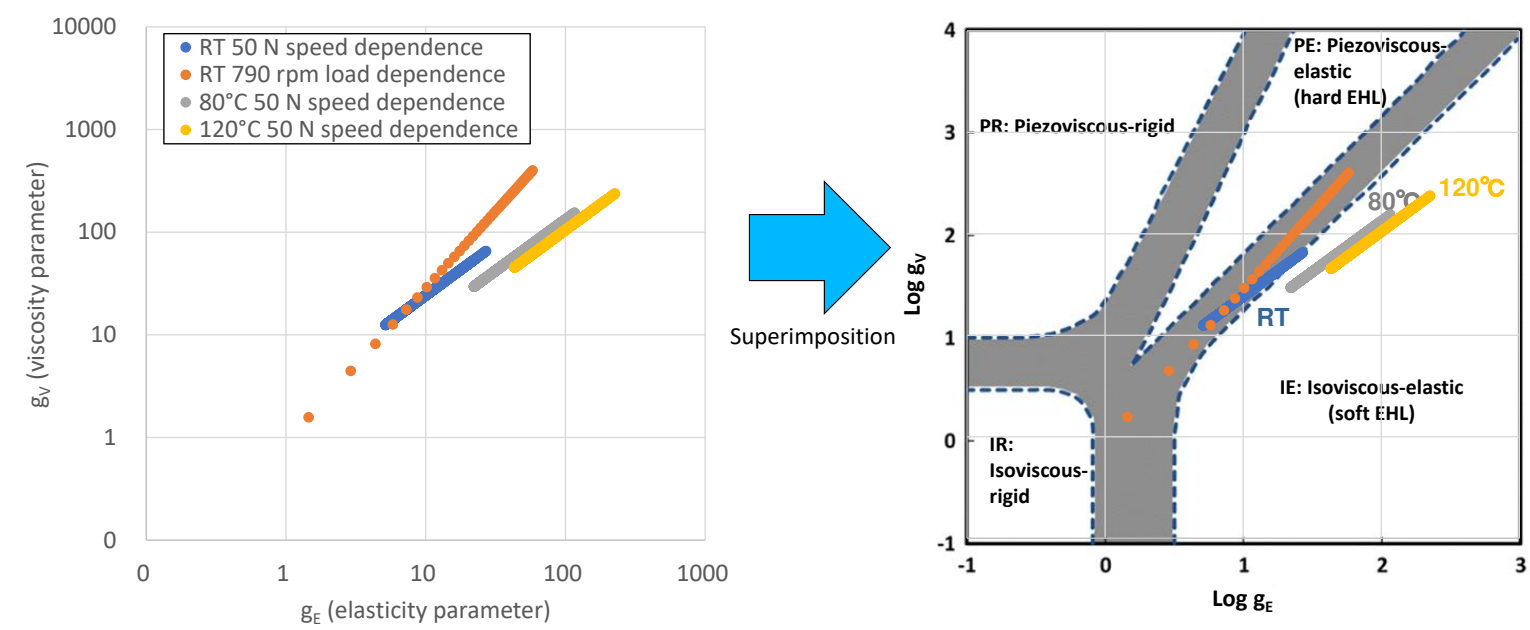

Fig. 14. Lubrication regime map showing $g_{\mathrm{E}}$ and $g_{\mathrm{V}}$ estimated under each sliding condition. Colors in both plots correspond to same data points. This original image of the lubrication regime map was reprinted by the reference [32] and additional explanation was added.

At room temperature, each data point was categorized at the threshold of either the isoviscous-elastic (IE) lubrication regime (dominated by soft EHL) or the piezoviscous-elastic (PE) lubrication regime (dominated by hard EHL). Usually, sliding-polymer materials (e.g., elastomers or plastics used in windscreen wipers, seals, or bearing polymer cages) are categorized in the IE lubrication regime $[25,34,36]$ wherein although the elastic deformation must be considered, the contact pressure is too low to enhance the oil viscosity. However, it is assumed that the lubrication regime in the current study more likely approached PE because the small-diameter steel cylinder induced high contact pressure and because the Young's modulus of the PA66 was one order of magnitude 
higher than that of the elastomer. In contrast, the lubrication regime approached IE with increasing temperature because the PA66 softened with decreasing Young's modulus and became much more plastic-like with increasing temperature.

Several equations for estimating the theoretical oil film thickness in the IE and PE lubrication regimes have been proposed, and the present study uses the more common Hamrock and Dowson equations [33, 37]. The following equations were used to estimate the theoretical minimum oil film thickness in each lubrication regime: In the IE lubrication regime,

$$
H_{\min }=\frac{h_{\min }}{R}=7.43 U^{0.65} W^{-0.21}\left(1-0.85 e^{-0.31 k}\right),
$$

In the PE lubrication regime,

$$
H_{\min }=\frac{h_{\min }}{R}=3.63 U^{0.68} G^{0.49} W^{-0.073}\left(1-e^{-0.68 k}\right),
$$

where $H_{\min }$ is the minimum dimensionless film thickness, $h_{\min }$ is the minimum film thickness, $U$ is the dimensionless speed parameter, $W$ is the dimensionless load parameter, $G$ is the material parameter, and $k$ is the ellipticity parameter ranging from 1 (for a circular configuration such as a ball-on-plate configuration) to 12 (for a configuration approaching a rectangular contact). The dimensionless parameters $U, W$, and $G$ are defined as follows.

$$
\begin{gathered}
U=\frac{u \eta_{0}}{E R}, \\
W=\frac{w_{l}}{E R}, \\
G=\alpha E .
\end{gathered}
$$

Although few studies have actually measured the oil film thickness of line contacts fabricated using engineering plastics including PA66, the oil film thickness measured at the point contact between a transparent PC disk (instead of a transparent glass disk used to measure the oil film thickness by interferometry) and a steel ball in the rollingsliding contact presented by Kochi et al. [25] and the corresponding oil film thickness estimated based on the Hamrock and Dowson soft EHL theories were well correlated. Therefore, the theoretical oil film thickness estimated based on EHL for a line contact fabricated using PA66 should be reliable. Considering equations shown above, minimum oil film thickness under each condition was estimated (detailed estimated minimum oil film thickness: see Figs. S2 and S3 in Supplementary material). Then $\Lambda$ is estimated using the oil film thickness calculated under each condition, and the influence on the friction coefficient is discussed in the next section.

\subsection{Development of $\Lambda$-friction coefficient master curve}

The estimated oil film thicknesses can be used to determine the likelihood and severity of asperity contacts by calculating the lambda ratio $(\Lambda)$, which is the ratio of the minimum oil film thickness to the combined surface roughness of two sliding materials $\left(R_{\mathrm{a} 1}\right.$ and $\left.R_{\mathrm{a} 2}\right) . \Lambda$ can be calculated as follows [38, 39]:

$$
\Lambda=\frac{h_{\min }}{\sqrt{R{a_{1}}^{2}+R{a_{2}}^{2}}},
$$

where $\Lambda<1$ indicates boundary lubrication, $\Lambda>3$ indicates the fluid-film lubrication setup, and $1 \leq \Lambda \leq 3$ indicates a partial or mixed lubrication regime [40]. Because the sliding surface roughness changed during the sliding test (as discussed in Section 3.1), roughness $R_{\mathrm{a}}$ was assumed to change (increase or decrease) linearly during sliding to calculate $\Lambda$ at each sliding time. Fig. 15 shows the relationship between the measured friction 
coefficient and $\Lambda$ calculated under different test conditions (e.g., various initial surface roughness, rotation speed, and temperatures; that is, the same friction data as those shown in Fig. 9). The obtained master curve shows that the friction coefficient could be approximated by $\Lambda$ regardless of the test conditions or surface roughness for the same normal load when unreinforced PA66 and harder steel were used under oil lubrication. In the low- $\Lambda$ regime (between 0 and 1.5), the friction coefficient decreased with increasing $\Lambda$, which is typical in the boundary and mixed lubrication regimes wherein the contact is affected by the solid direct points of contact. Conversely, in the high- $\Lambda$ regime (above 1.5), the low friction coefficient was very similar (in the range $0.025-0.035$ ) because the proportion of the contact separated by the oil film increased (i.e., fluid lubrication), and the direct contact effect should be mitigated. This tendency is consistent with the Stribeck curve.

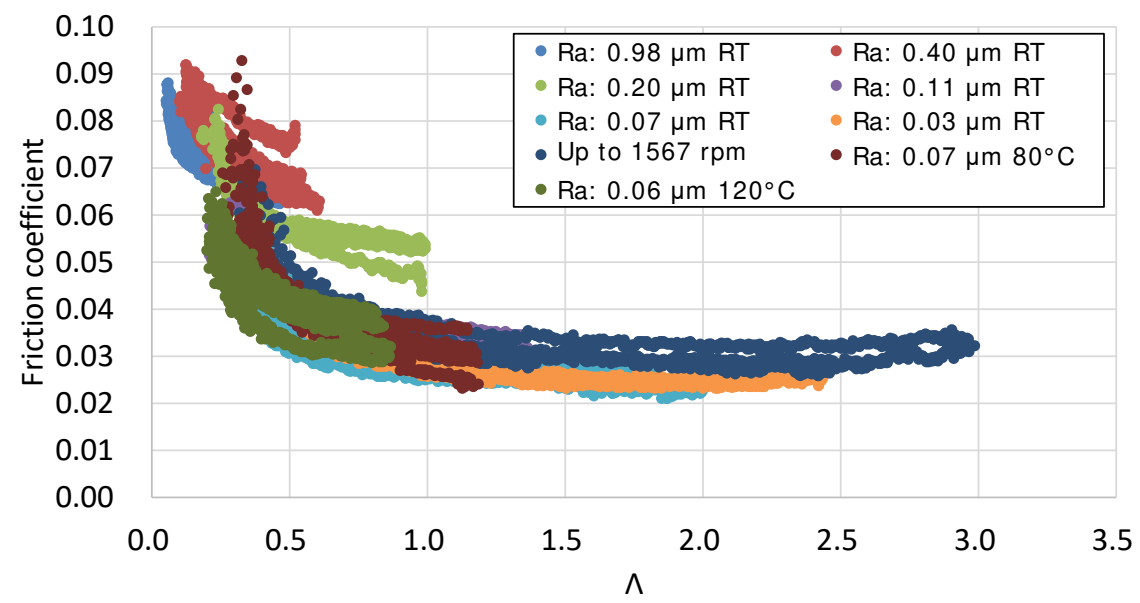

Fig. 15. Obtained master $\Lambda-\mu$ curve.

\subsection{Effect of normal load (contact pressure) on friction coefficient}

In addition, the effect of the normal load (and thus contact pressure) on the friction coefficient was investigated, and the obtained results were analyzed using the proposed theories. Fig. 16 presents the evolution of the friction coefficient obtained for different normal loads and sliding surface roughness of the unreinforced PA66 ring specimens with the harder steel. As previously observed, a higher surface roughness led to a higher friction coefficient for any normal load. When the initial surface roughness was low $(0.03 \mu \mathrm{m})$, the friction coefficient remained low and stabilized in the range 0.02-0.03. Conversely, when the initial surface roughness was high (e.g., 0.23 or $0.68 \mu \mathrm{m}$ ), the friction coefficient decreased with increasing normal load. In addition, when the initial $R_{\mathrm{a}}=$ 0.23 or 0.68 , the difference between the friction coefficients was smaller in the last stage of the sliding test than in the initial stage. 


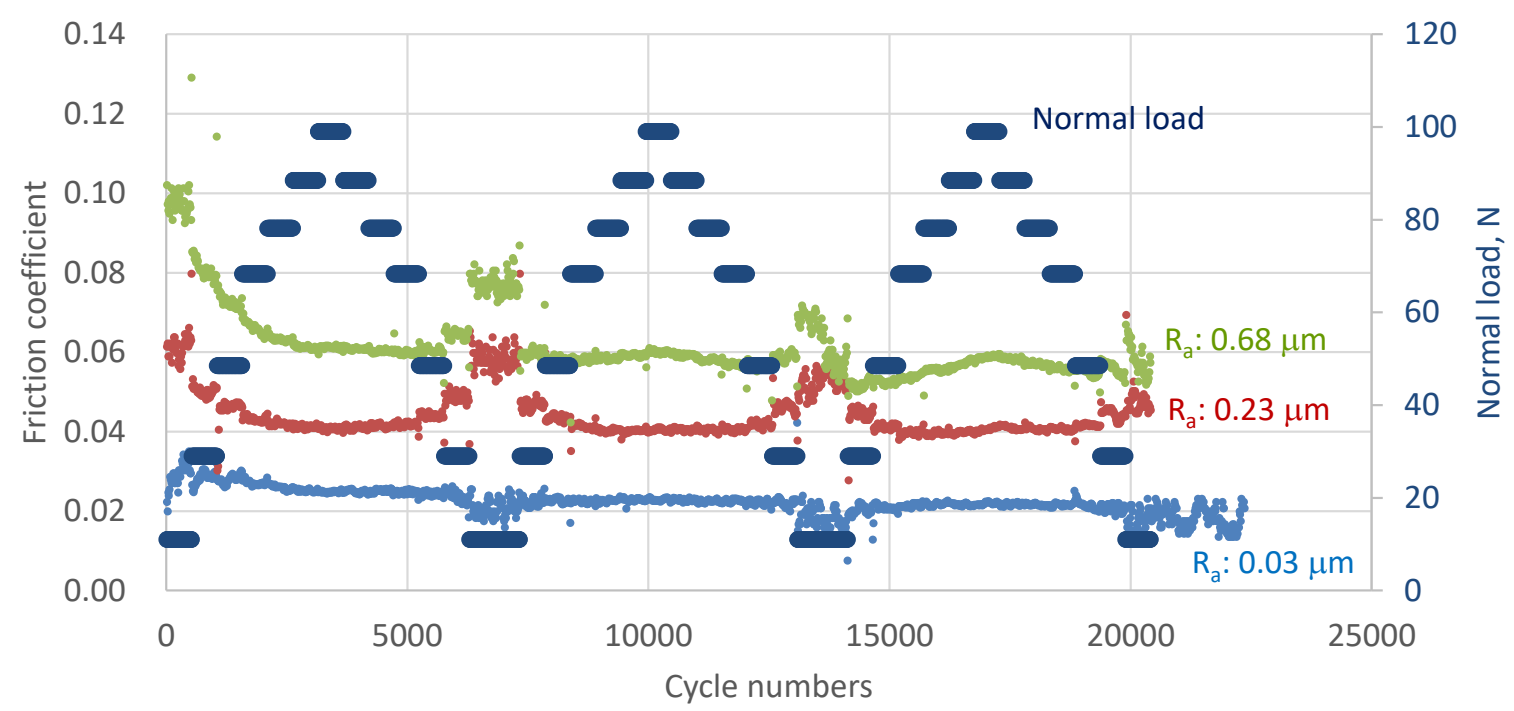

Fig. 16. Friction coefficient evolutions obtained for unreinforced PA66-ring specimens under different normal loads and sliding surface roughness.

To further discuss these results, the theoretical oil film thickness was calculated for different normal loads, as presented in Error! Reference source not found.Fig. S3 (b), to obtain the relation between $\Lambda$ and the friction coefficient by postulating that the surface roughness $\left(R_{\mathrm{a}}\right)$ changed linearly during the sliding test. Then, the obtained relation was superimposed on the previously obtained master $\Lambda \square$-friction coefficient curve, as shown in Fig. 17 (The master curve from Fig. 15 is shown in gray.). The results obtained when $R_{\mathrm{a}}=0.03 \mu \mathrm{m}$ were consistent with the master $\Lambda$-friction coefficient curve, meaning that these contacts are under fluid or mixed lubrication. Therefore, the constant friction coefficient for each normal load can be explained by the few contact points between the PA66 and the steel. The results obtained when $R_{\mathrm{a}}=0.23$ or $0.68 \mu \mathrm{m}$, on the other hand, did not coincide with the master $\Lambda$-friction coefficient curve. These results showed that the friction coefficient decreased with increasing normal load, which is opposite to the Stribeck curve observed in the mixed lubrication regime.

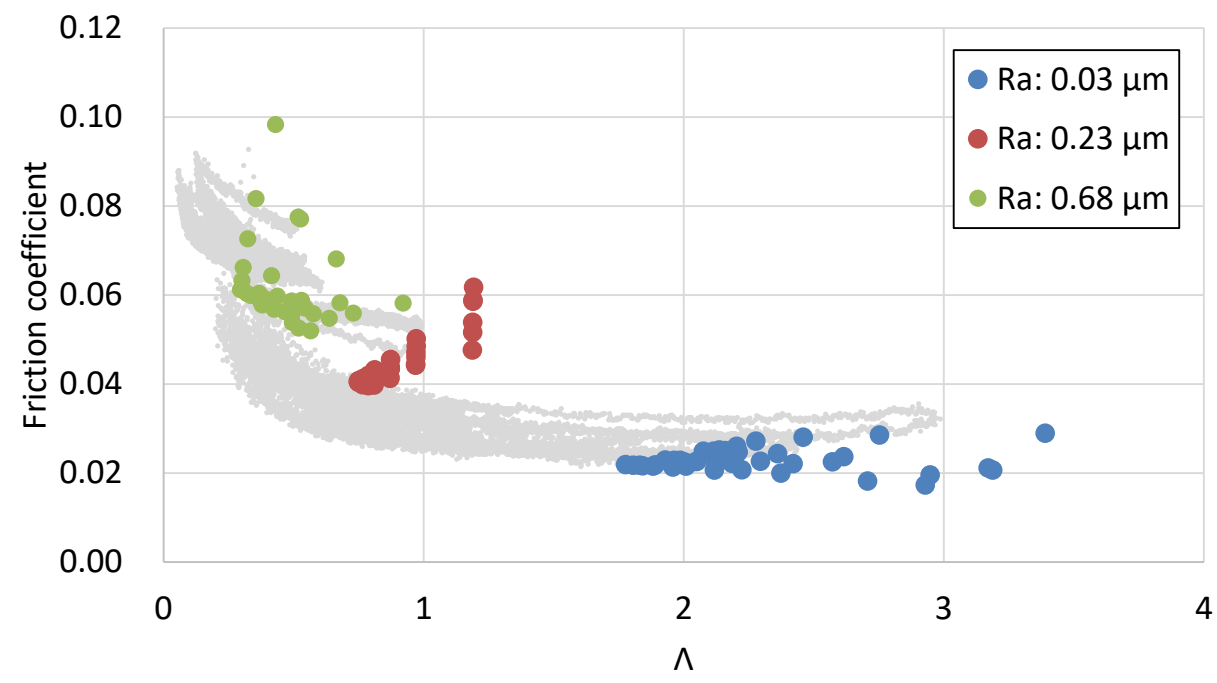

Fig. 17. Relationship between $\Lambda$ and friction coefficient superimposed on $\Lambda-\mu$ master curve (gray) shown in Fig. 
To explain the normal load dependence of the friction coefficient, the Bowden and Tabor laws were applied to these results. As presented by Bowden and Tabor [41], on the direct (nonlubricated) contact of any two materials, two mechanisms that contribute to friction should be considered. First, the adhesion at the regions of actual contact is usually remarkable. The adhesion originates from the adhesive bonds formed between the surfaces in the sliding contact [42]. Furthermore, the actual contact area is remarkably smaller than the apparent one. Therefore, the adhesion-related friction can be expressed as the product of the actual contact area and the average shear strength. The second factor is related to the plowing, grooving, and cracking of one surface (usually the softer polymer material) by the hard asperities on the other surface (usually the harder metallic material). Therefore, the total friction $F$ (i.e., the resistance to movement along the contact surface) can be expressed by the following equation:

$$
F=F_{\text {adhesion }}+F_{\text {deformation }}=A \cdot \tau+F_{\text {deformation }},
$$

where $A$ is the total actual contact area, and $\tau$ is the shear strength of the polymer material. In reality, $F$ is quite similar to $F_{\text {adhesion }}$ because $F_{\text {deformation }}$ is far smaller than $F_{\text {adhesion }}$ [43]. Considering the relation among the friction, the friction coefficient $(\mu)$, and the normal load $(W)$, friction coefficient can be expressed by the following equation:

$$
\mu=\frac{F}{w}=\frac{A \tau}{w}=\frac{\tau}{P}
$$

where $P$ is the mean contact pressure $(=W / A)$. For polymers, $\tau$ increases linearly with increasing mean contact pressure.

$$
\tau=\tau_{0}+\mu_{\infty} P,
$$

where $\tau_{0}$ is the constant intrinsic characteristic shear strength, and $\mu_{\infty}$ is the pressure coefficient for an infinite pressure. Considering equations (15) and (16), the friction coefficient can be expressed as follows:

$$
\mu=\frac{\tau}{P}=\frac{\tau_{0}}{P}+\mu_{\infty}
$$

Therefore, $\mu$ is a function of the pressure in the contact and can be determined by the shear strength of the material. The shear strength linearly increases with increasing contact pressure, as shown in equation (16). The pressure coefficient $\left(\mu_{\infty}\right)$ can be determined from the bulk-polymer sliding tests performed under various contact pressures because $\mu_{\infty}$ is the friction coefficient when the contact pressure is infinite [44].

Considering the proposed Bowden and Tabor law, Fig. 18 shows the relationships between the normal load and inverse contact pressure and the friction coefficient for unreinforced PA66 ring specimens showing different surface roughness and under different normal loads. Each contact pressure was estimated based on Hertzian theory. When $R_{\mathrm{a}}=0.03 \mu \mathrm{m}$, the friction coefficient was approximately identical for each contact pressure, and the slope $\left(\tau_{0}\right)$ in the linear approximation equation (i.e., the relation between the inverse of $P$ and the friction coefficient) was negative, meaning that the normal-load dependence of the friction coefficient cannot be explained by the Bowden and Tabor law (i.e., the direct-solid-contact-based theory). Therefore, the lubrication-theory-based explanation (i.e., the $\Lambda-\mu$ curve) is reasonable (Fig. 15). In contrast, when the initial $R_{\mathrm{a}}$ was higher, the slope $\left(\tau_{0}\right)$ in the linear approximation equation was positive, which is supposed to depend on the polymer mechanical properties and in fact, high correlation coefficients $\left(R^{2}>0.9\right)$ were observed, meaning that the normal load dependence of the friction coefficient can be explained using the Bowden and Tabor law. Therefore, it is reasonable that these results cannot be discussed through lubrication theory. 
(a)

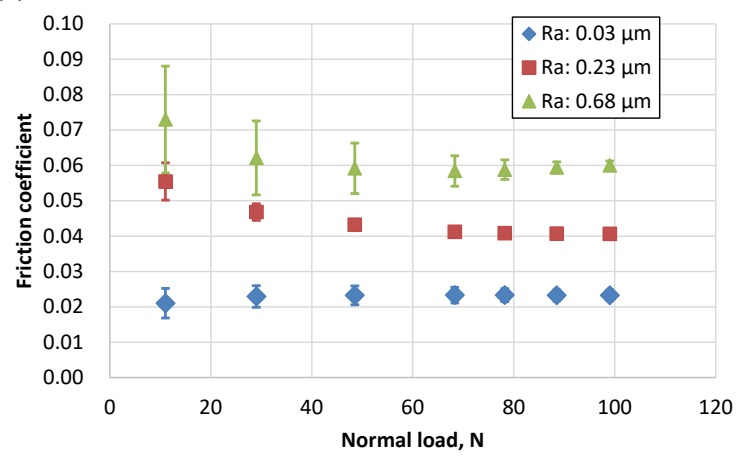

(b)

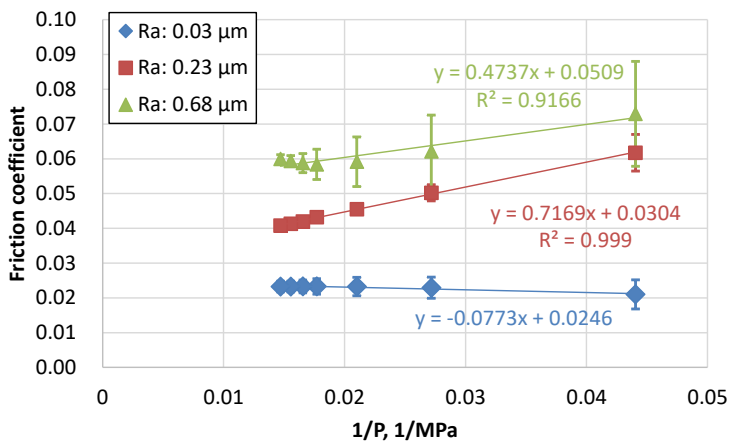

Fig. 18. Relationships between (a) normal load friction coefficient and (b) inverse contact pressure and friction coefficient for different normal loads and surface roughness of unreinforced PA66 ring specimens.

\subsection{Effect of steel counterpart hardness on friction coefficient}

As mentioned in Section 1, it is necessary to investigate the effect of the steel counterpart hardness on the friction coefficient because the counterpart hardness is determined by the heat treatment conditions; therefore, they should be selected appropriately. First, the effect of the steel hardness on the rotation speed dependence of the friction coefficient was investigated, as presented in Fig. 19, using the unreinforced PA66 ring specimens showing roughness $R_{\mathrm{a}}=0.05 \mu \mathrm{m}$ under a normal load of $50 \mathrm{~N}$. No typical differences were observed between the friction coefficient evolutions of the softer and harder steels. In addition, the steel counterpart did not show any visible wear, even on the surface of the softer steel. Considering these results, severe direct contact, which induces the wear of the steel counterpart, was not supposed to occur. Therefore, the influence of the oil film formation was remarkable, and the steel hardness negligibly affected the friction coefficient. Next, the rotation speed dependence of the friction coefficient was similarly investigated using unreinforced PA66 showing a much rougher $\left(R_{\mathrm{a}}=0.20\right.$ $\mu \mathrm{m})$ sliding surface. Unlike the results obtained using the harder steel or at $R_{\mathrm{a}}=0.05 \mu \mathrm{m}$, the friction coefficient suddenly and reproducibly increased after the surfaces had slid for $400 \mathrm{~s}$. In addition, the softer steel cylinder partially wore after sliding for $750 \mathrm{~s}$, as shown in Fig. 21. The steel wore even when using the unreinforced PA66, which did not contain any reinforcement fibers such as GFs that show abrasion on the steel counterpart. Furthermore, the steel wear was influenced by the roughness (i.e., surface asperities) of the PA66. Worn steel can be evidence of the direct contact between the PA66 and steel, and steel wear is supposed to suddenly increase the friction coefficient. In addition, although the steel surface was partly worn, the friction coefficient of the softer steel exhibited the same tendency as that of the harder steel by suddenly increasing after the surfaces had slid for $400 \mathrm{~s}$. 


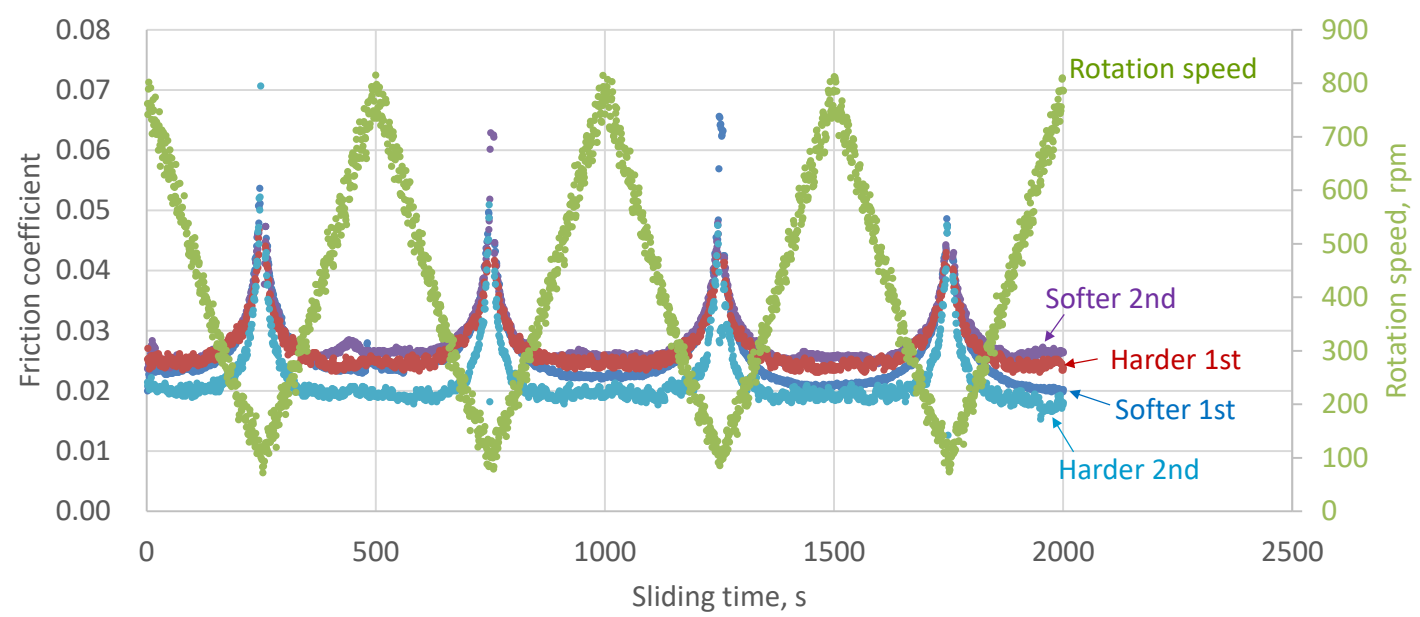

Fig. 19. Friction coefficient evolutions obtained for different rotation speeds and counterpart steel harnesses measured using unreinforced PA66. Initial surface $R_{\mathrm{a}}=0.05 \mu \mathrm{m}$ (two tests were conducted for each steel hardness).

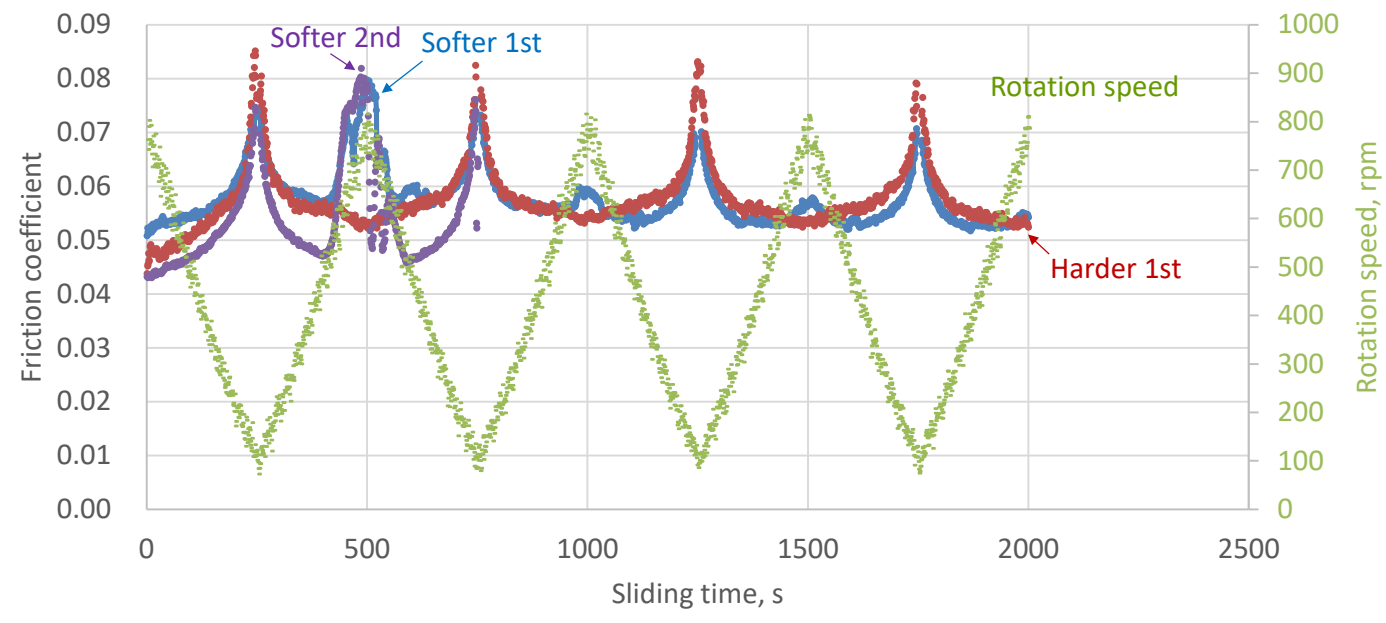

Fig. 20. Friction coefficient evolutions obtained for different rotation speeds and counterpart steel harnesses measured using unreinforced PA66. Initial surface $R_{\mathrm{a}}=0.20 \mu \mathrm{m}$.

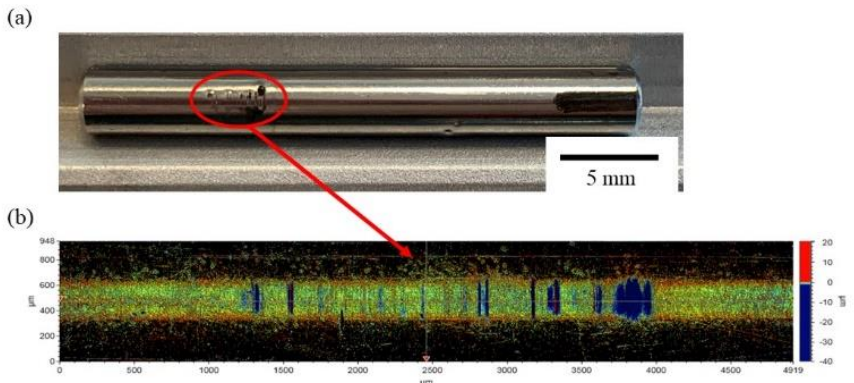

Fig. 21. (a) Optical microscope image and (b) interferometric measurement (after cylinder shape was removed) after softer steel cylinder had slid for $750 \mathrm{~s}$. 


\subsection{Effect of GF reinforcement on friction coefficient}

In the actual application of PA66 sliding parts, reinforcement fibers including GFs can improve the mechanical properties. Therefore, it is vital to consider the GF composite friction mechanism and compare it to that of the unreinforced PA66. To discuss the lubrication theory for the GF composite as for the unreinforced PA66, the lubrication regime and theoretical oil film were investigated by considering the different mechanical properties (e.g., the Young's modulus of the sliding surface measured by microindentation) of the GF composite, as presented in Fig. 13. Fig. 22 shows $g_{\mathrm{E}}$ and $g_{\mathrm{V}}$ obtained under each sliding test condition and superimposed on the lubrication regime map. Analogous to the unreinforced PA66, each data point was categorized at the boundary between the IE (soft EHL) and PE (hard EHL) regimes at room temperature and slightly approached the hard EHL regime because the fiber reinforcement had increased the Young's modulus compared to that of the unreinforced PA66. Meanwhile, each data point obtained at 80 and $120^{\circ} \mathrm{C}$ was still categorized in the soft EHL regime.
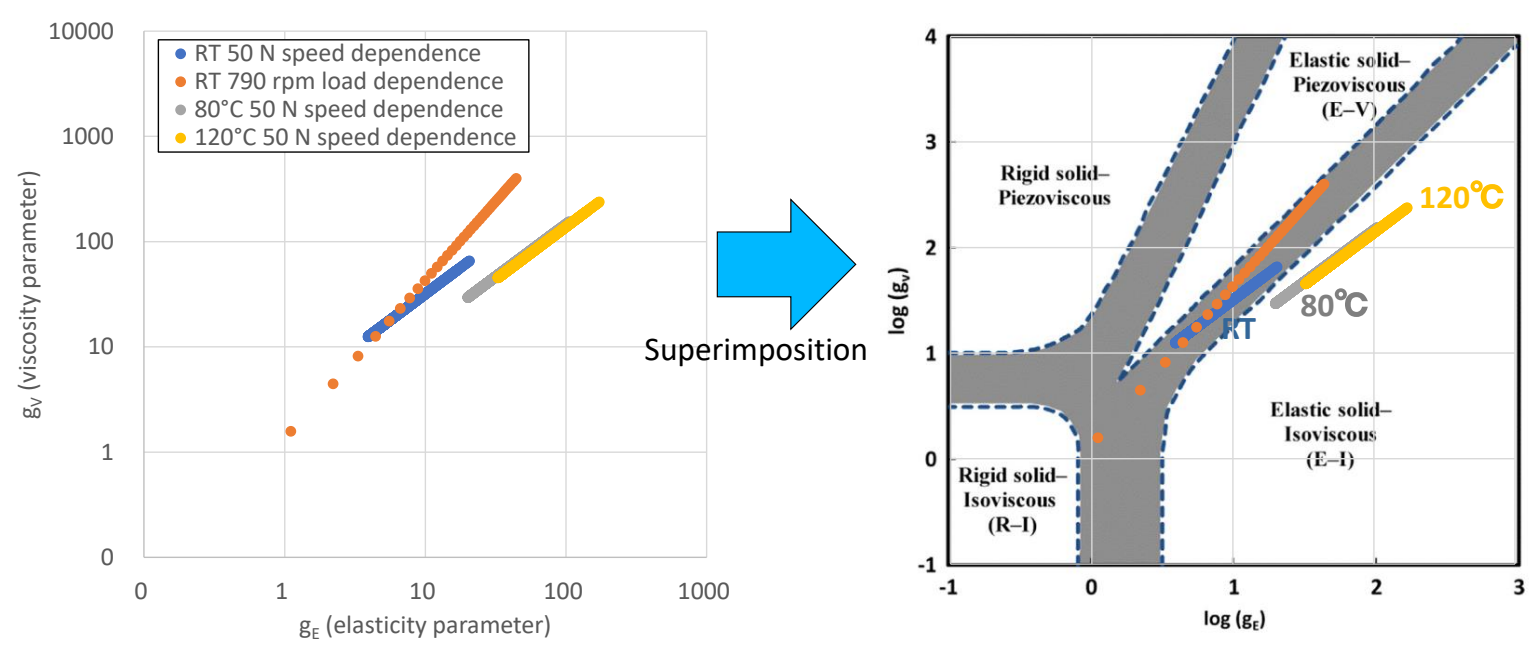

Fig. 22. $g_{\mathrm{E}}$ and $g_{\mathrm{V}}$ obtained under each sliding-test condition for GF composite and superimposed on lubrication regime map presented in Fig. 9. Colors in both plots correspond to same data points. This original image of the lubrication regime map was reprinted by the reference [32] and additional explanation was added.

Then, the theoretical oil film thickness was calculated using the equation for the IE lubrication regime (equation (8), as presented in Fig. S4 in supplementary material. Fig. 23 presents the rotation speed, sliding surface roughness, and temperature dependences of the friction coefficients obtained using the GF composite and the harder steel, and Table 5 lists the sliding surface roughness obtained before and after each sliding test. The initial sliding surface roughness of the GF composite was higher than that of the unreinforced PA66 polished under the same conditions, which is supposed to be owing to the GFs exposed on the sliding surface. The GF composite hardness (5.9 GPa [27]) was lower than that of the harder steel $(9.9 \mathrm{GPa})$, and the steel cylinder did not show any visible wear after each sliding test. The global tendency was that the friction coefficient increased with increasing composite sliding surface roughness, decreasing rotation speed, and increasing temperature. The GF composite friction coefficient obtained at each temperature and rotation speed was similar to that obtained using the unreinforced PA66 and polished using the same polishing paper $(\# 4,000)$. Furthermore, the GF composite and unreinforced PA66 both showed similar initial surface roughness $(\sim 0.06 \mu \mathrm{m})$ even if the theoretical minimum oil film thickness obtained using the GF composite was thinner than that obtained using the unreinforced PA66. Although the friction 
coefficient under dry conditions usually decreases when reinforcement fibers including GFs are added [19], the friction coefficient did not explicitly decrease when the fiber composites are used under oil lubrication. Furthermore, as observed for the unreinforced PA66, $R_{\mathrm{a}}$ increased for the smooth samples after the sliding tests, whereas polishing decreased $R_{\mathrm{a}}$ when the initial $R_{\mathrm{a}}$ was above $0.47 \mu \mathrm{m}$.

(a)

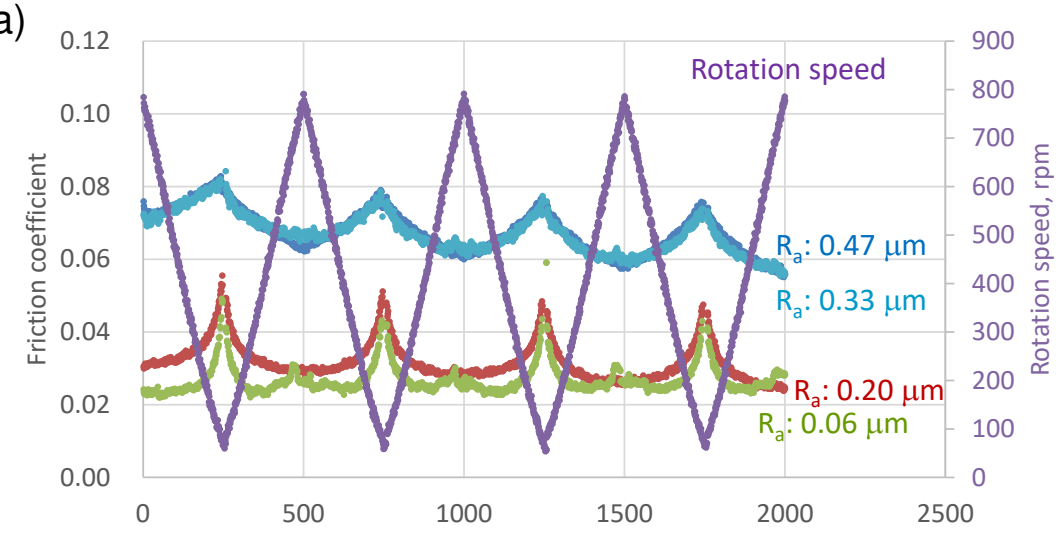

(b)

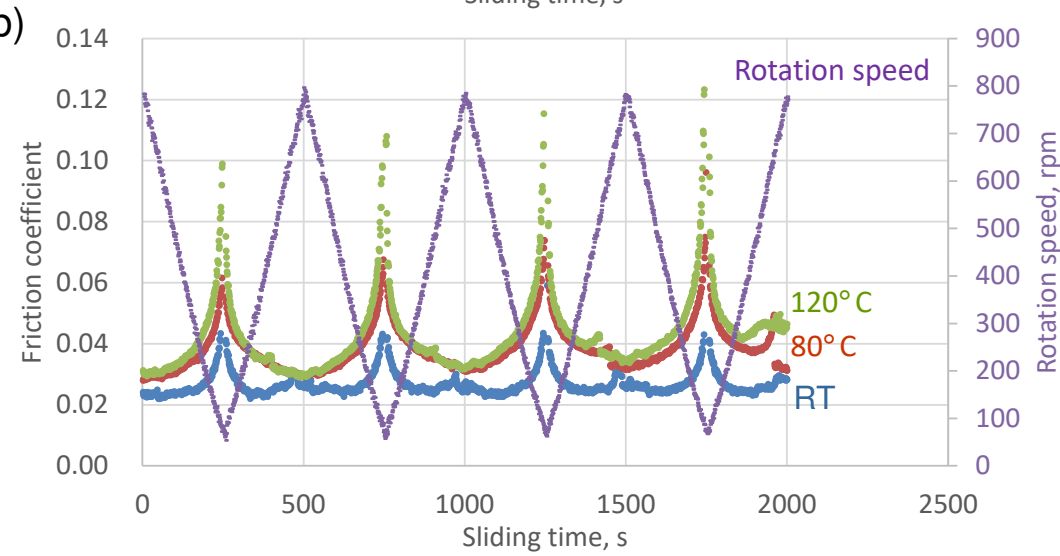

Fig. 23. (a) Rotation speed and sliding surface roughness dependences obtained at room temperature and (b) rotation speed and temperature dependences of friction coefficient obtained using smooth GF composite and harder steel.

Table 5. Sliding surface roughness $\left(R_{a}\right)$ measured before and after each sliding test.

\begin{tabular}{|c|c|c|c|}
\hline Polishing paper & Temperature $\left({ }^{\circ} \mathrm{C}\right)$ & Pre-test $R_{a}(\mu \mathrm{m})$ & Post-test $R_{a}(\mu \mathrm{m})$ \\
\hline$\# 4000$ & RT & $0.06 \pm 0.00$ & $0.07 \pm 0.01$ \\
\hline$\# 2000$ & RT & $0.20 \pm 0.07$ & $0.24 \pm 0.08$ \\
\hline$\# 800$ & RT & $0.33 \pm 0.02$ & $0.27 \pm 0.08$ \\
\hline$\# 800$ & RT & $0.47 \pm 0.02$ & $0.42 \pm 0.08$ \\
\hline$\# 4000$ & 80 & $0.07 \pm 0.01$ & $0.08 \pm 0.01$ \\
\hline$\# 4000$ & 120 & $0.08 \pm 0.01$ & $0.08 \pm 0.02$ \\
\hline
\end{tabular}

Considering the composite sliding surface roughness obtained before and after the sliding tests (as listed in Table 5), the effect of the calculated $\Lambda$ on the friction coefficient is discussed by postulating that the surface roughness changed linearly during the sliding tests. Fig. 24 presents the relationship between $\Lambda$ and the friction coefficient obtained using the GF composite. For comparison, the relationship is superimposed on the master curve obtained using the unreinforced PA66 (Fig. 15). As observed for the unreinforced PA66, the friction coefficient 
decreased with increasing $\Lambda$ (for low $\Lambda$ ). In addition, the GF composite friction coefficients were lower than the unreinforced PA66 ones for the same $\Lambda$; namely, the GF composite could show lower friction coefficients than the unreinforced PA66 for smaller $\Lambda$. This can be explained by the relatively low direct contact area between the GF composite and the steel, which is related to the exposed GF. The friction coefficient obtained using the GF composite, however, did not become lower than that of the unreinforced PA66 polished using the same polishing paper. The sliding surface roughness of the GF composite was much higher than that of the unreinforced PA66, and the theoretical minimum oil film thickness obtained using the GF composite became thinner owing to the higher Young's modulus compared to that of the unreinforced PA66. Therefore, the effect of the lower contact area, which decreased the friction coefficient, was supposed to be canceled by the oil film formation weaker than that of the unreinforced PA66.

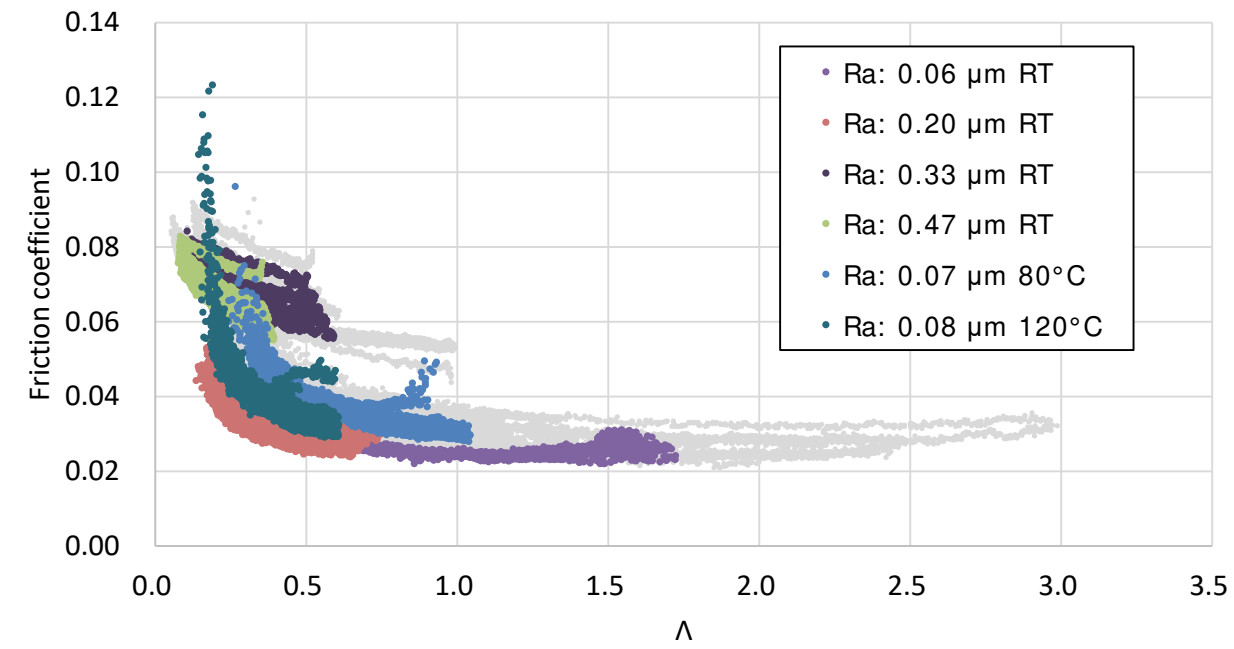

Fig. 24. Relationship between calculated $\Lambda$ and friction coefficient obtained using GF composite compared to same relationship obtained using master $\Lambda \square-\mu$ curve (gray) for unreinforced PA66.

Fig. 25 shows the SEM observations of the sliding surface after sliding tests. No explicit wear scar, including scratch or severe peeling of PA66 and damage of GFs as observed under much higher normal load conditions [27, 28], can be observed on the sliding surface with initial $R_{\mathrm{a}}=0.06 \mu \mathrm{m}$ tested at room temperature. This is because the effect of oil film formation is high and direct contact was reduced on the sliding under lower contact pressure. Even on the sliding surface polished with initial $R_{\mathrm{a}}=0.47 \mu \mathrm{m}$ tested at room temperature, no severe damage on the sliding surface was observed, whereas polishing scar which was also observed on the sliding surface before sliding test (see Fig. S5 in Supplementary file) can be observed. 
(a)

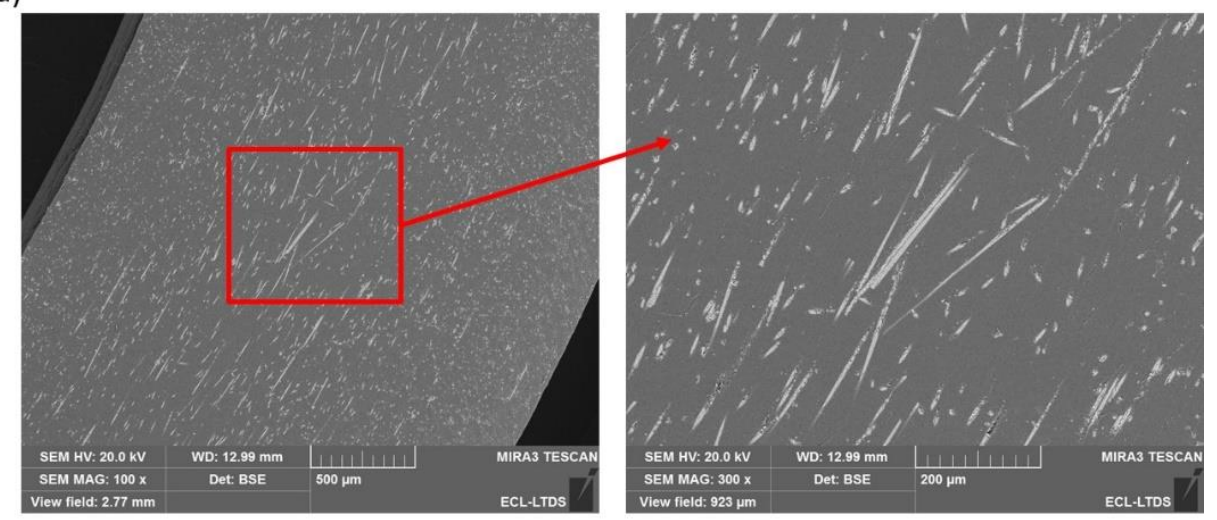

(b)

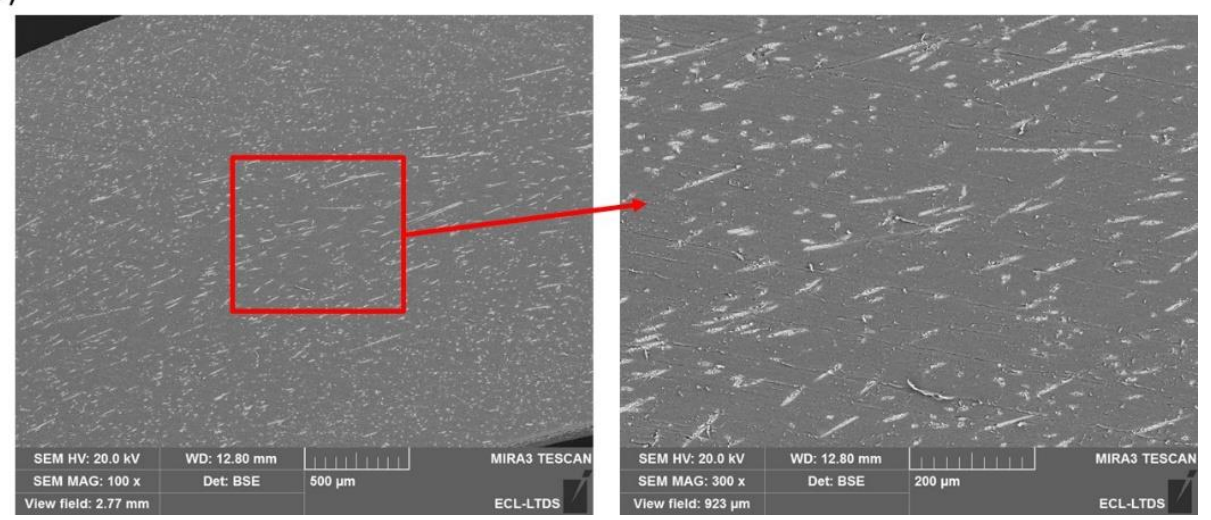

Fig. $25 \mathrm{SEM}$ observations of the sliding surface after sliding tests; (a) initial $\mathrm{R}_{a}=0.06 \mu \mathrm{m}$, (b) initial $\mathrm{R}_{\mathrm{a}}=0.47$

$\mu \mathrm{m}$.

Furthermore, the effect of the steel cylinder hardness on the friction coefficient obtained using the GF composite was investigated. GF shows abrasion on steel counterparts, particularly when the counterpart is softer than the GF. In the authors' previous studies, the effects of the fiber orientation, diameter, and the GF surface treatment on the wear resistance of steel and the GF composite were elucidated under grease lubrication [27,]. Therefore, in the present study, the effect of the steel hardness on the friction coefficient obtained for a lower normal load (i.e., contact pressure) was investigated. Fig. 26 presents the friction coefficient evolutions obtained using either the GF composite or the unreinforced PA66 and either the softer or harder steel at different rotation speeds. For each specimen, the sliding surface was polished using $\# 800$ polishing paper before the sliding tests. As observed for the unreinforced PA66 (Fig. 20, where the $R_{\mathrm{a}}$ of the ring specimens is much lower), the friction coefficient suddenly increased with increasing rotation speed (400, 900, 1400, and $1850 \mathrm{~s})$ only when the softer steel was used. In addition to the suddenly increased friction coefficient, neither the absolute values nor the rotation speed dependence of the friction coefficients obtained using the unreinforced PA66 and the GF composite were explicitly different. Fig. 27 presents the interferometric measurements and Table 6 lists the roughness and wear volume of the softer steel cylinder (after the cylindrical shape was removed) after the sliding tests performed using the unreinforced PA66 and the GF composite. The steel counterpart showed a wear scar on the steel cylinder surface tested in contact with both the unreinforced PA66 and the GF composite. The roughness of the sliding surface and wear volume of the cylinder tested with GF composite were higher than those tested with unreinforced PA66, confirming that the GF composite containing hard fibers showed more severe abrasion on the steel 
counterpart than the unreinforced PA66 did.

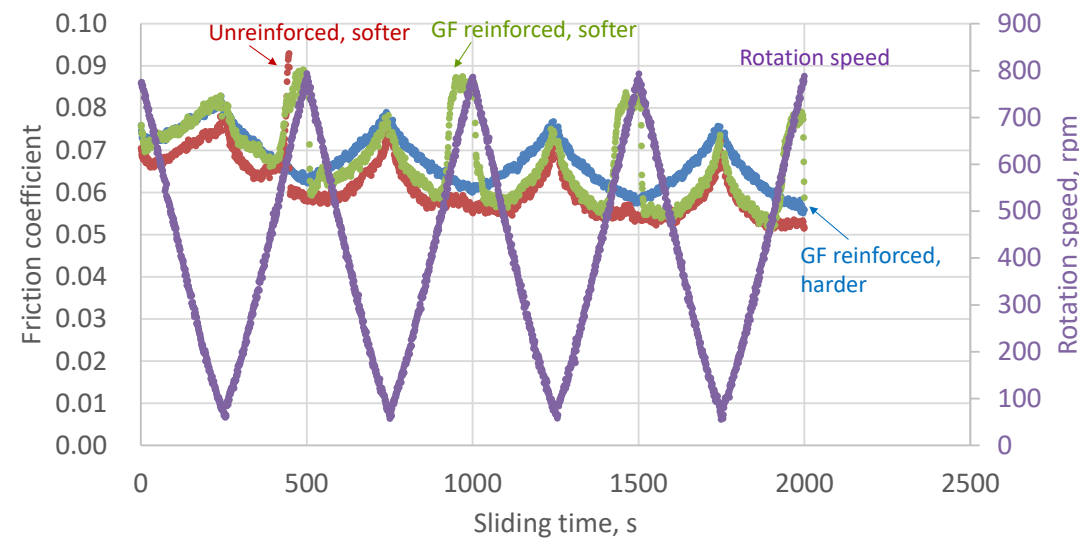

Fig. 26. Friction coefficient evolutions obtained at different rotation speeds for either GF composite or unreinforced PA66 and either softer or harder steel.

(a)

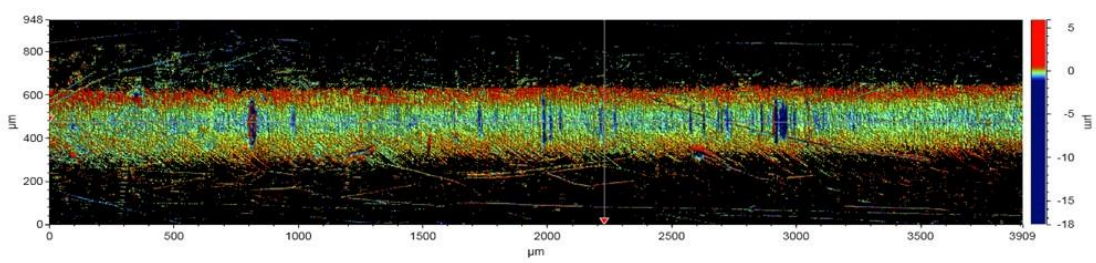

(b)

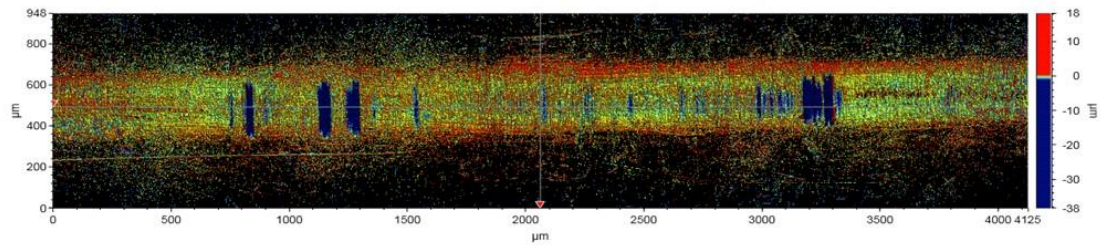

Fig. 27. Interferometric measurements of steel cylinder (after cylindrical shape was removed) after sliding tests in contact with (a) unreinforced PA66 and (b) GF composite.

Table 6. Roughness and wear volume of softer steel cylinder measured after sliding tests.

\begin{tabular}{|c|c|c|c|}
\hline Ring specimen & $\mathrm{S}_{\mathrm{a}}(\mu \mathrm{m})$ & $\mathrm{R}_{\mathrm{a}}(\mu \mathrm{m})$ & Wear volume* $\left(\mathrm{mm}^{3}\right)$ \\
\hline Unreinforced PA66 & $0.29 \pm 0.070$ & $0.09 \pm 0.04$ & $5.3 \times 10^{-4}$ \\
\hline GF-reinforced PA66 & $0.38 \pm 0.046$ & $0.17 \pm 0.03$ & $11.0 \times 10^{-4}$ \\
\hline
\end{tabular}




\section{Conclusions}

The friction mechanisms of unreinforced and GF-reinforced PA66 in contact with steel under PAO8 oil lubrication were elucidated based on soft EHL. The following points should be highlighted.

1) Effects of ring surface roughness, sliding speed, and temperature of unreinforced PA66 and harder steel on friction coefficient

The friction coefficient increased with increasing initial surface roughness of the sliding surface PA66-ringspecimen sliding surface, decreasing sliding speed, and increasing temperature.

\section{2) Friction coefficient obtained using estimated oil film thickness and $\Lambda$}

The theoretical minimum oil film thickness was estimated considering various sliding conditions and the temperature dependence of the oil viscosity and Young's modulus of unreinforced PA66 using the equation for soft EHL presented by Hamrock and Dowson. In addition, the $\Lambda-\mu$ master curve was presented considering the change in the sliding surface roughness during the sliding test under different test conditions.

\section{3) Effect of normal load on friction coefficient}

The normal load dependence of the friction coefficient can be explained by the proposed $\Lambda \square-\mu$ curve when the initial surface roughness is lower. The Bowden and Tabor law, on the other hand, explained the normal load dependence well, and the results did not coincide with the proposed $\Lambda-\mu$ curve when the initial surface roughness was higher because the effect of the direct contact between the PA66 and steel became more remarkable than the influence of the oil film formation.

\section{4) Effect of steel hardness on friction coefficient}

The use of softer steel suddenly increased the friction coefficient only when the initial PA66 roughness was higher, which is related to the direct contact between the PA66 and steel counterpart and the degree of steel wear.

\section{5) Effect of GF reinforcement on friction coefficient}

The effects of the sliding speed, initial sliding surface roughness, and temperature on the friction coefficient were investigated for the GF composite, and they showed the same tendencies as observed for the unreinforced PA66. The minimum oil film thickness was calculated considering the higher Young's modulus of the GF composite. The $\Lambda-\mu$ master curve was obtained for the GF composite and compared to that obtained for the unreinforced PA66, thereby confirming that a lower friction coefficient can be obtained using the GF composite compared to the unreinforced PA66 for the same $\Lambda$. 


\section{Declarations}

Funding: This work does not receive any funding.

Conflict of interest: The authors declare that they have no competing interests.

Availability of data: The raw data can be obtained from the authors upon request.

Authors' contribution: Takeshi Kunishima: Conceptualization, Validation, Investigation, Writing - original draft, Gaëtan Bouvard: Methodology, Software, Writing - review \& editing, Jean Christophe ABRY: Methodology, Writing - review \& editing, Vincent Fridrici: Conceptualization, Writing - review \& editing, Project administration, Supervision, Philippe Kapsa: Conceptualization, Writing - review \& editing, Project administration, Supervision

Ethical Approval: Ethical approval was obtained from JTEKT CORPORATION and Laboratoire de Tribologie et Dynamique des Systèmes.

Consent to Publish: All authors have seen the manuscript and approved to submit to your journal, and we would greatly appreciate for your attention and consideration.

References

${ }^{1}$ S. Senthilvelan, R. Gnanamoorthy, Damage Mechanisms in injection molded unreinforced, glass and carbon reinforced nylon 66 spur gears, Appl. Compos. Mater. 11 (2004) 377-397. https://doi.org/10.1023/B:ACMA.0000045313.47841.4e

${ }^{2}$ B. Sarita, S. Senthilvelan, Effects of lubricant on the surface durability of an injection molded polyamide 66 spur gear paired with a steel gear, Tribol. Int. 137 (2019) 193-211.

$\underline{\text { https://doi.org/10.1016/j.triboint.2019.02.050 }}$

3 J. Tavčar, G. Grkman, J. Duhovnik, Accelerated lifetime testing of reinforced polymer gears, J. Adv. Mec. Des., Sys., and Man. 12 (2018) 1-13.

https://doi.org/10.1299/jamdsm.2018jamdsm0006

${ }^{4}$ Y. Zhang, C. Purssell, K. Mao, S. Leigh, A physical investigation of wear and thermal characteristics of 3D printed nylon spur gears. Tribol. Int., 141 (2020) 105953.

$\underline{\text { https://doi.org/10.1016/j.triboint.2019.105953 }}$

${ }^{5}$ N. M. Mehat, H. M. Noor, S. Kamaruddin, Optimization of multiple quality characteristics for injection moulded polyamide helical gear via integration of Taguchi method and Grey relational analysis, Mater. Sci. Eng., 932 (2020) 012122.

https://doi.org/10.1088/1757-899X/932/1/012122

${ }^{6}$ H. Oh, M.H. Azarian, C. Morillo, M. Pecht, E. Rhem, Failure mechanisms of ball bearings under lightly loaded, non-accelerated usage conditions, Tribol. Int. 81 (2015) 291-299.

https://doi.org/10.1016/j.triboint.2014.09.014

7 Z. Wenhu, D. Sier, C. Guoding, C. Yongcun, Impact of lubricant traction coefficient on cage's dynamic characteristics in high-speed angular contact ball bearing, Chin. J. Aeronaut. 30 (2017) 827-835.

$\underline{\text { https://doi.org/10.1016/j.cja.2016.08.019 }}$ 
${ }^{8}$ D.V. Butorin, N.G. Filippenko, A.V. Livshits, S.I. Popov, Analysis of failures of bearings of axle box unit with polyamide cages and prospects of increasing their service life, IOP Conference Series: Mat. Sci. Eng. 760 (2019) https://doi.org/10.1088/1757-899X/760/1/012010

${ }^{9}$ M. Harrass, K. Friedrich, A.A. Almajid, Tribological behavior of selected engineering polymers under rolling contact. Tribol. Int. 43 (2010) 635-646.

https://doi.org/10.1016/j.triboint.2009.10.003

10 J. Wesołowski, K. Płachta, The Polyamide Market, Fibres \& textiles in eastern Europe 120 (2016) 12-18. https://doi.org/10.5604/12303666.1215537

11 J.J. Rajesh, J. Bijwe, U.S. Tewari, Abrasive wear performance of various polyamides, Wear 252 (2002) 769 776.

https://doi.org/10.1016/S0043-1648(02)00039-X.

12 P. Poirel, Prospects for electric power steering, ATZ Worldwide 114 (2012) 10-14.

https://doi.org/10.1007/s38311-012-0170-4

${ }^{13}$ G.H. Kim, J.W. Lee, T.1. Seo, Durability characteristics analysis of plastic worm wheel with glass fiber reinforced polyamide, Mater. 6 (2013) 1873-1890.

https://doi.org/10.3390/ma6051873

${ }^{14}$ S.H. Kim, M.C. Shin, J.W. Byun, K.H. O, C.N. Chu, Efficiency prediction of worm gear with plastic worm wheel. Int. J. Precis. Eng. Manuf. 13 (2012) 167-174.

https://doi.org/10.1007/s12541-012-0021-7

15 T. Kunishima, K. Miyake, T. Kurokawa, H. Arai, Clarification of tribological behavior on tooth surface of resin worm gear for electric power steering, JTEKT Eng. J. English Ed. 1013E (2016) 27-33.

http://eb-cat.ds-navi.co.jp/enu/jtekt/tech/ej/img/no1013e/1013e_05.pdf

${ }^{16}$ L. Xu, Z. Zhu, G. Chen, C. Qu, Effect of load and sliding velocity on tribological behaviors of aramid fiber reinforced PA1010 composites, Indus. Lubr. Tribol. 62 (2010) 46-51.

https://doi.org/10.1108/00368791011012461

${ }^{17}$ F.V.D. Velde, P.D. Baets, The friction and wear behaviour of polyamide 6 sliding against steel at low speed under very high contact pressures, Wear 209 (1997) 106-114.

https://doi.org/10.1016/S0043-1648(96)07500-X

18 A. Horovistiz, S. Laranjeira, J.P. Davim, Influence of sliding velocity on the tribological behavior of PA66GF30 and PA66 $+\mathrm{MoS}_{2}$ : an analysis of morphology of sliding surface by digital image processing, Polym. Bull. 75 (2018) 5113-5131.

https://doi.org/10.1007/s00289-018-2314-1

19 M.W. Shin, S.S. Kim, H. Jang, Friction and wear of polyamide 66 with different weight average molar mass, Tribol. Lett. 44 (2011) 151-158. https://doi.org/10.1007/s11249-011-9833-3

${ }^{20}$ M.T. Lates, R. Velicu, C.C. Gavrila, Temperature, pressure, and velocity influence on the tribological properties of PA66 and PA46 Polyamides, Mater. 12 (20) (2019) 3452. https://doi.org/10.3390/ma12203452

${ }^{21}$ P. Samyn, G. Schoukens, I.V. Driessche, J.V. Craenenbroeck, F. Verpoort, Softening and melting mechanisms of polyamides interfering with sliding stability under adhesive conditions, Polymer 47 (2006) 5050-5065. https://doi.org/10.1016/i.polymer.2006.05.034

${ }^{22}$ G. Tatsumi, M. Ratoi, Y. Shitara, K. Sakamoto, B.G. Mellor, Effect of organic friction modifiers on lubrication of PEEK-steel contact, Tribol. Int. 151 (2020) 106513.

https://doi.org/10.1016/j.triboint.2020.106513 
${ }^{23}$ G. Tatsumi, M. Ratoi, Y. Shitara, K. Sakamoto, B.G. Mellor, Effect of lubrication on friction and wear properties of PEEK with steel counterparts, Tribol. Online 14 (2019) 345-352. https://doi.org/10.2474/trol.14.345

${ }^{24}$ S. Zhang, C. Cui, G. Chen, Tribological behavior of MC Nylon6 composites filled with glass fiber and fly ash, J. Wuhan University of Technol. Mater. Sci. Ed. (2012) 290-295.

$\underline{\text { https://doi.org/10.1007/s11595-012-0455-x }}$

25 T. Kochi, R. Ichimura, M. Yoshihara, D. Dong, Y. Kimura, Film thickness and traction in soft EHL with grease, Tribol. Online 12 (4) (2017) 171-176.

https://doi.org/10.2474/trol.12.171

${ }^{26}$ B.B. Jia, T.S. Li, X.J. Liu, P.H. Cong, Tribological behaviors of several polymer-polymer sliding combinations under dry friction and oil-lubricated conditions, Wear 262 (2007) 1353-1359. https://doi.org/10.1016/j.wear.2007.01.011

${ }^{27}$ T. Kunishima, Y. Nagai, T, Kurokawa, G. Bouvard, J-C. Abry, V. Fridrici, Ph. Kapsa, Tribological behavior of glass fiber reinforced-PA66 in contact with carbon steel under high contact pressure, sliding and grease lubricated conditions, Wear 456-457 (2020) 203383.

https://doi.org/10.1016/j.wear.2020.203383

${ }^{28}$ T. Kunishima, Y. Nagai, S. Nagai, T, Kurokawa, G. Bouvard, J-C. Abry, V. Fridrici, Ph. Kapsa, Effects of glass fiber properties and polymer molecular mass on the mechanical properties and tribological properties of a polyamide-66-based composite in contact with carbon steel under grease lubrication, Wear 462-463 (2020) 203500.

https://doi.org/10.1016/j.wear.2020.203500

${ }^{29}$ T. Kunishima, S. Nagai, T. Kurokawa, J. Galipaud, G. Guillonneau, G. Bouvard, J.-Ch. Abry, C. Minfray, V. Fridrici, Ph. Kapsa, Effects of temperature and addition of zinc carboxylate to grease on the tribological properties of PA66 in contact with carbon steel, Tribol. Int. 153 (2021) 106578. https://doi.org/10.1016/j.triboint.2020.106578

30 T. Kunishima, T. Kurokawa, H. Arai, V. Fridrici, Ph. Kapsa, Reactive extrusion mechanism, mechanical and tribological behavior of fiber reinforced polyamide 66 with added carbodiimide, Mater. Des. 188 (2020) 108447. https://doi.org/10.1016/i.matdes.2019.108447

31 T. Kunishima, Y. Nagai, G. Bouvard, J-C. Abry, V. Fridrici, Ph. Kapsa, Comparison of the tribological properties of carbon/glass fiber reinforced PA66-based composites in contact with steel, with and without grease lubrication, Wear in press.

https://doi.org/10.1016/j.wear.2021.203899

32 J. Takabi, M.M. Khonsari, On the dynamic performance of roller bearings operating under low rotational speeds with consideration of surface roughness, Tribol. Int. 86 (2015) 62-71.

https://doi.org/10.1016/j.triboint.2015.01.011

${ }^{33}$ B.J. Hamrock, D. Dowson, Minimum film thickness in elliptical contacts for different regimes of fluid-film lubrication, NASA Technical paper 1342 (1978) 1-22.

${ }^{34}$ N. Marx, J. Guegan, H.A. Spikes, Elastohydrodynamic film thickness of soft EHL contacts using optical interferometry, Tribol. Int., 99 (2016) 267-277.

https://doi.org/10.1016/j.triboint.2016.03.020

${ }^{35}$ M. Esfahanian, B.J. Hamrock, Fluid-film lubrication regimes revisited, Tribol. Trans. 34 (1991) 628-632. https://doi.org/10.1080/10402009108982081

${ }^{36}$ J. Vicente, J.R. Stokes, H.A. Spikes, The frictional properties of Newtonian fluids in rolling-sliding soft-EHL contact. Tribol. Let. 20 (2005) 273-286.

https://doi.org/10.1007/s11249-005-9067-3

37 B.J. Hamrock, D. Dowson, Elastohydrodynamic lubrication of elliptical contacts for materials of low elastic 
modulus I—fully flooded conjunction, J. Lubr. Technol. 100 (1978) 236-245.

https://doi.org/10.1115/1.3453152

${ }^{38}$ K.D. Dearn, T.J. Hoskins, L. Andrei, D. Walton, Lubrication regimes in high-performance polymer spur gears, Adv. Tribol. 2013 (2013) 987251.

https://doi.org/10.1155/2013/987251

${ }^{39}$ P. Cann, E. Ioannides, B. Jacobson, A.A. Lubrecht, The lambda ratio — a critical re-examination, Wear 175 (1994) $177-188$.

https://doi.org/10.1016/0043-1648(94)90181-3

${ }^{40}$ T. Joyce, Handbook of polymer tribology: chapter 4: Biopolymer Tribology, (2018) 111-152.

${ }^{41}$ F.P. Bowden, D. Tabor, Friction, lubrication and wear: a survey of work during the last decade, British J. Appl. Phys., 17 (1966) 1521-1544.

https://doi.org/10.1088/0508-3443/17/12/301

${ }^{42}$ N. Myshkin, A. Kovalev, Handbook of polymer tribology: chapter 1: Adhesion and friction of polymers and polymer composite, (2018) 3-45.

${ }^{43}$ Y. Yamaguchi, Tribology of plastic materials: Their characteristics and applications to sliding components, Elsevier (1990) 1 .

${ }^{44}$ M.M. Hossain, H.J. Sue, Handbook of polymer tribology: chapter 6: FEM modeling of scratch-induced deformation in polymers, (2018) 183-219. 


\section{Figures}

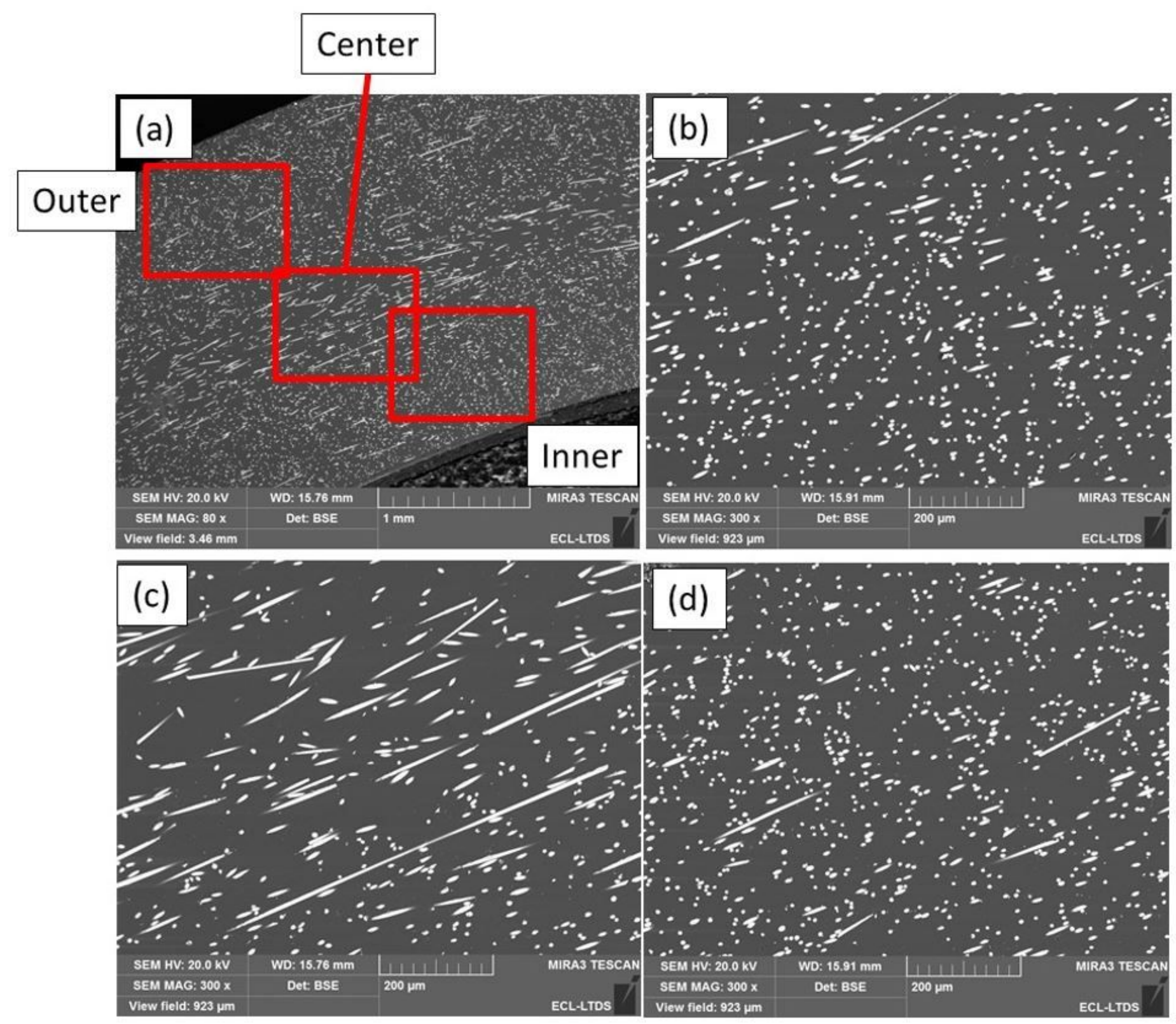

Figure 1

SEM images of the sliding surface before test of composite in each area: (a) global view; (b) inner position; (c) center position; (d) outer position [27]. 
(a) Sliding direction
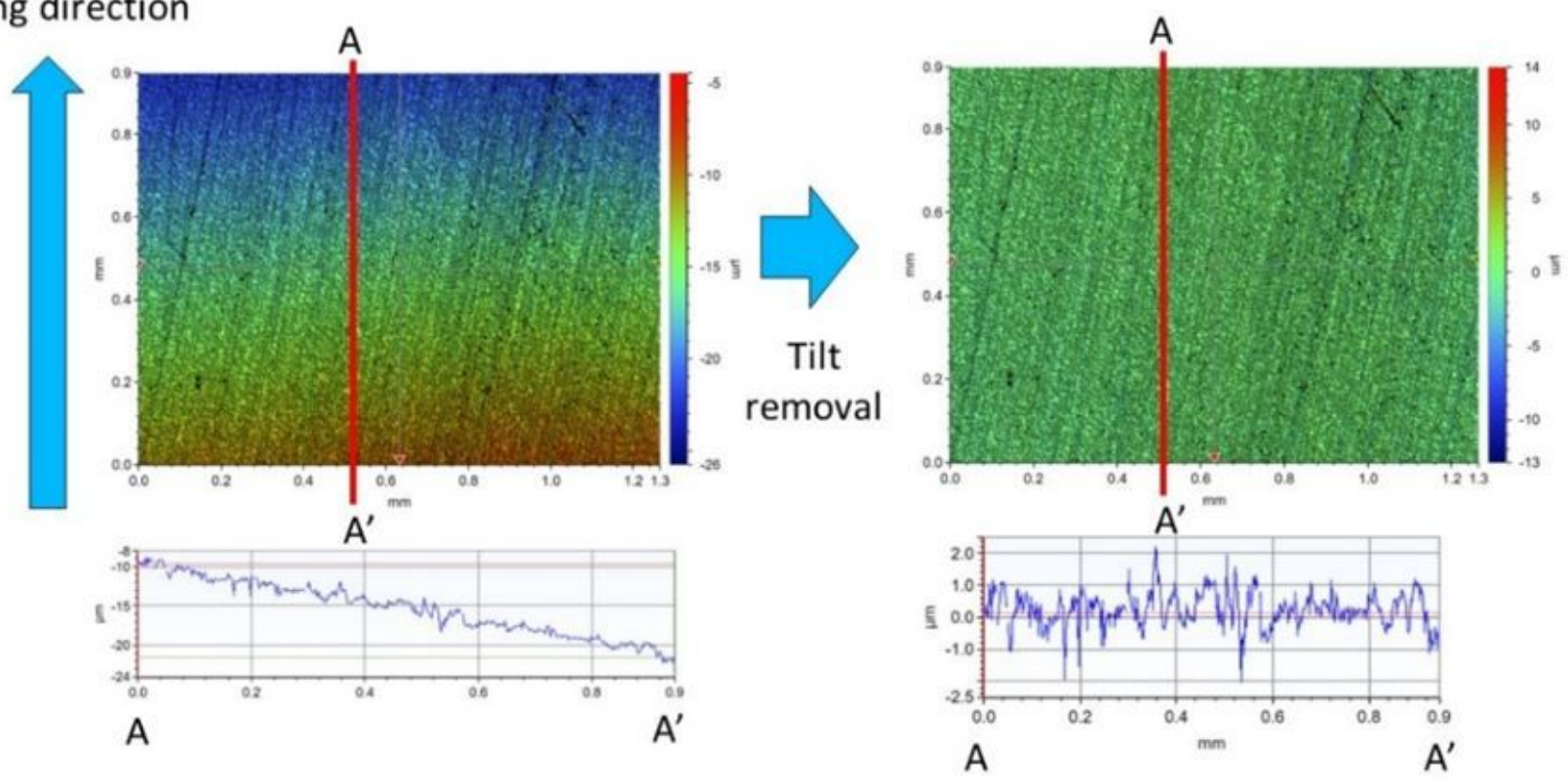

(b) Sliding direction
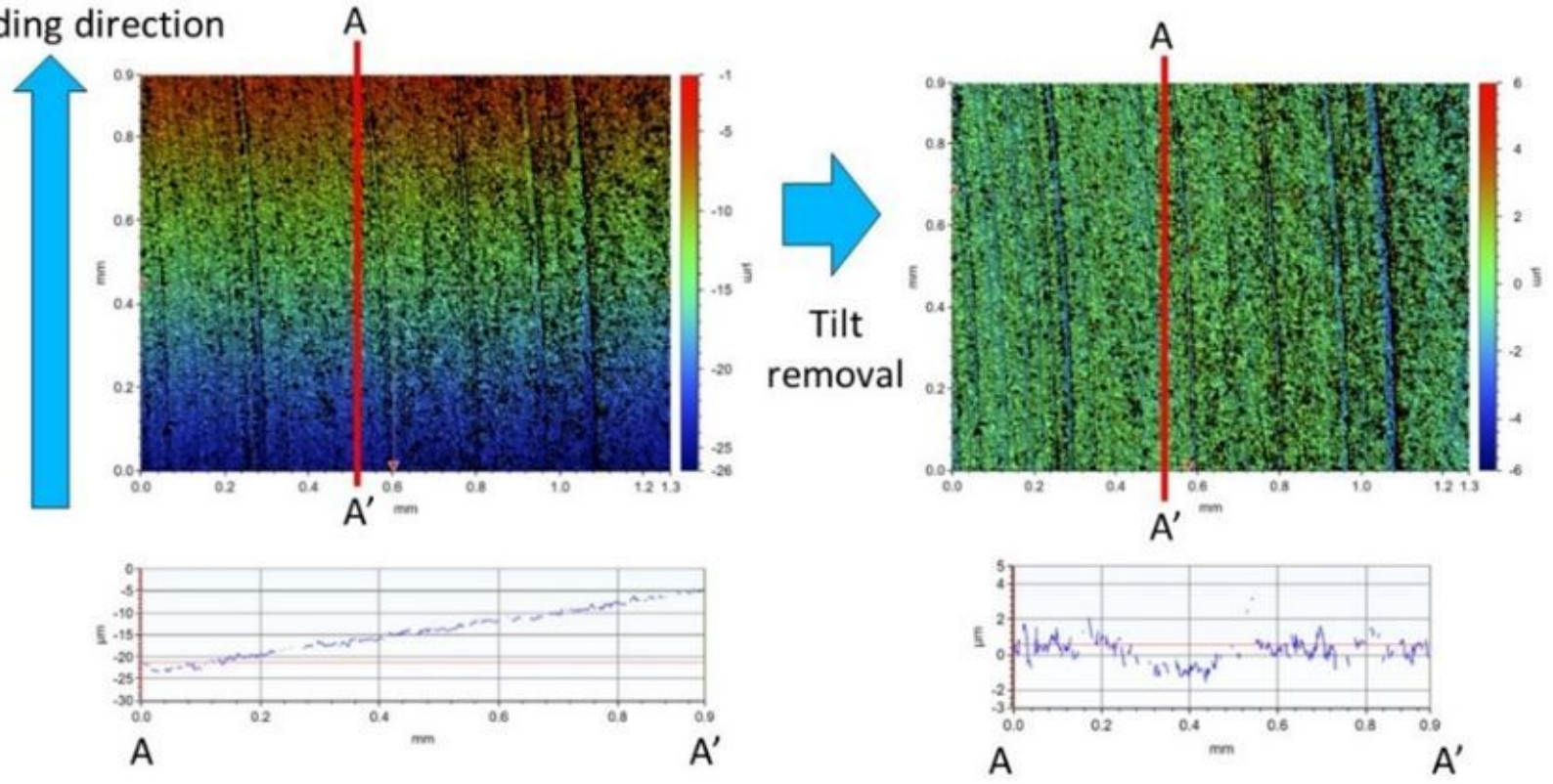

Figure 2

Sliding surface roughness measured using interferometry (a) before ( $\mathrm{Ra}=0.36 \pm 0.06 \mu \mathrm{m})$ and $(\mathrm{b})$ after $(\mathrm{Ra}=0.33 \pm 0.06 \mu \mathrm{m})$ sliding test. 
(a) Sliding direction
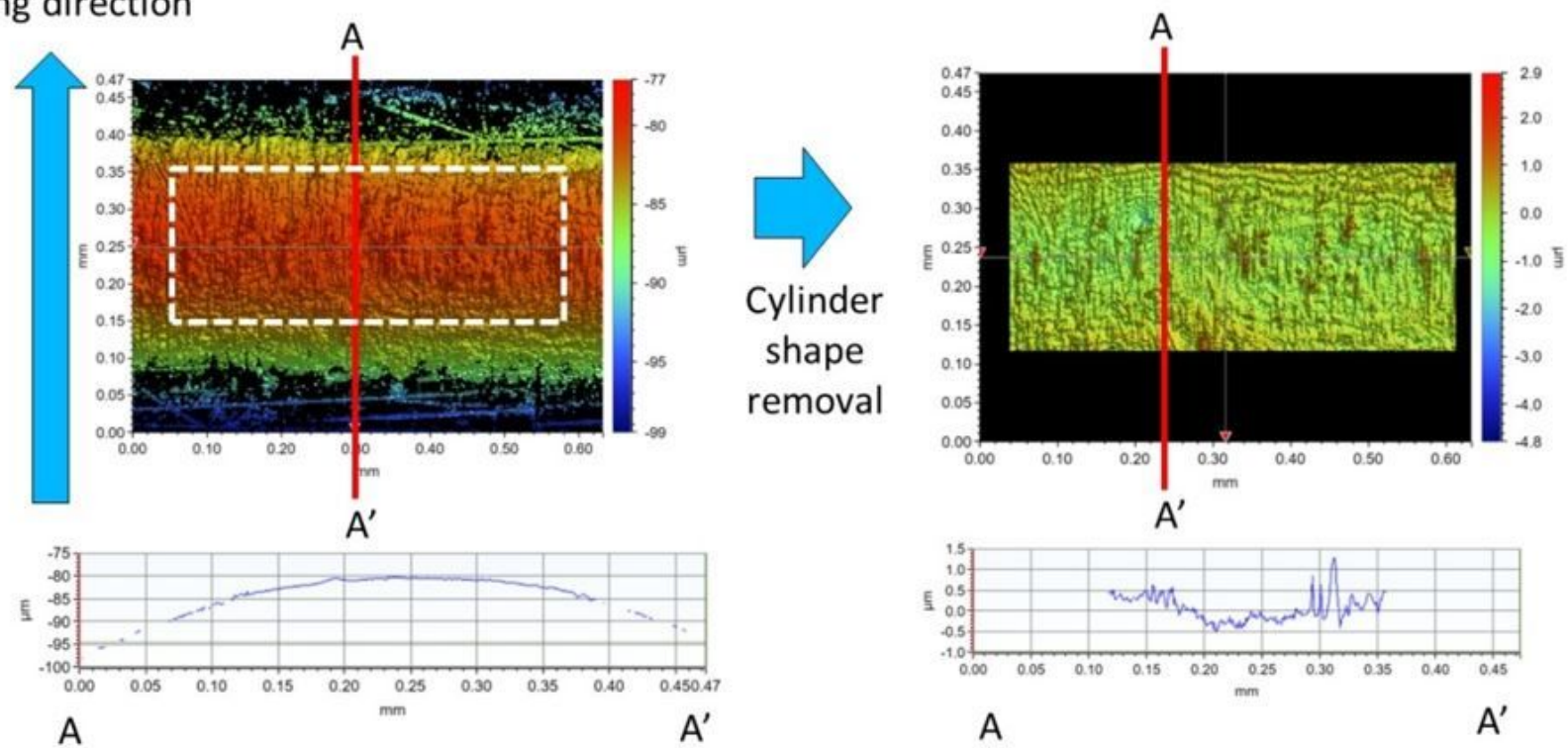

(b)
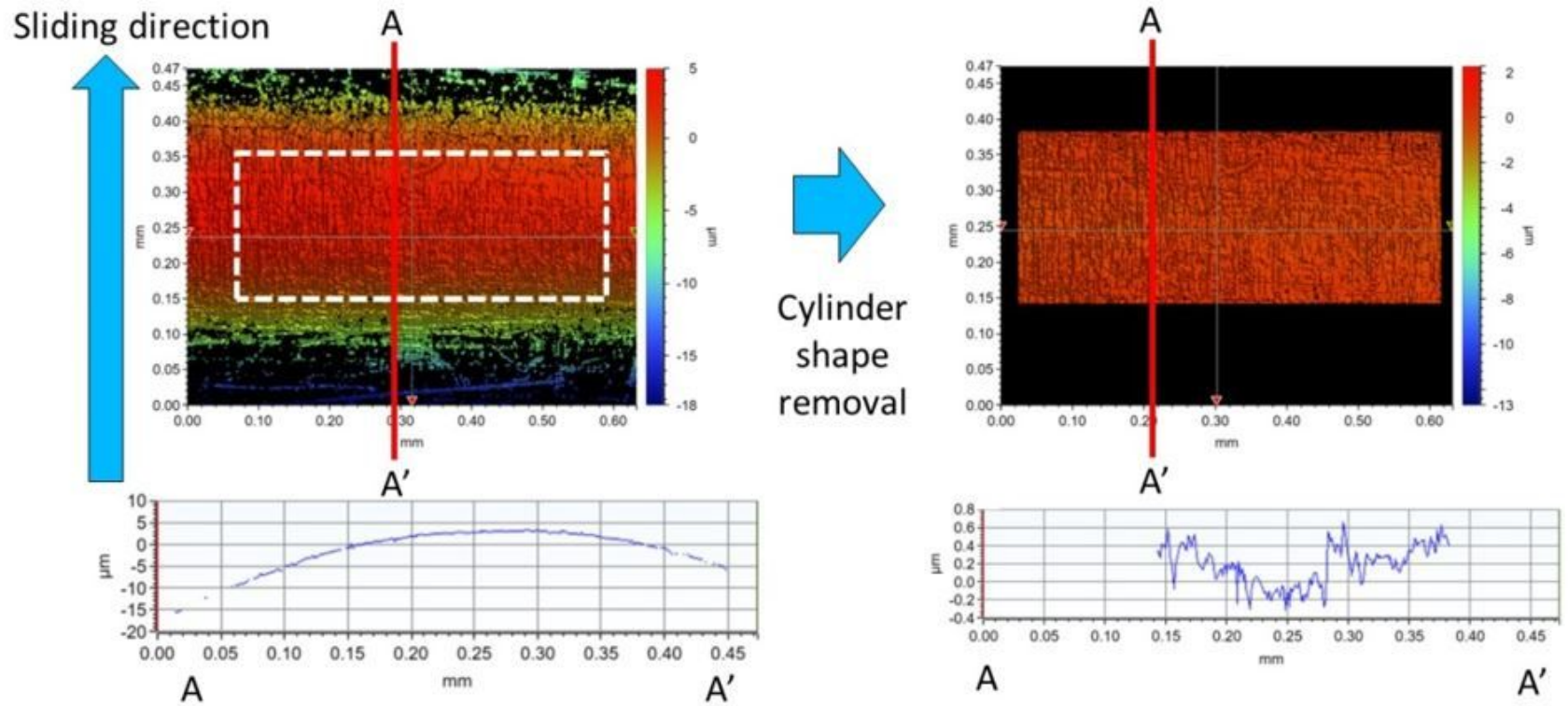

Figure 3

Surface roughness measured using interferometry before sliding tests: (a) softer steel $(\mathrm{Ra}=0.12 \pm 0.03$ $\mu \mathrm{m})$ and $(\mathrm{b})$ harder steel $(\mathrm{Ra}=0.08 \pm 0.02 \mu \mathrm{m})$. 


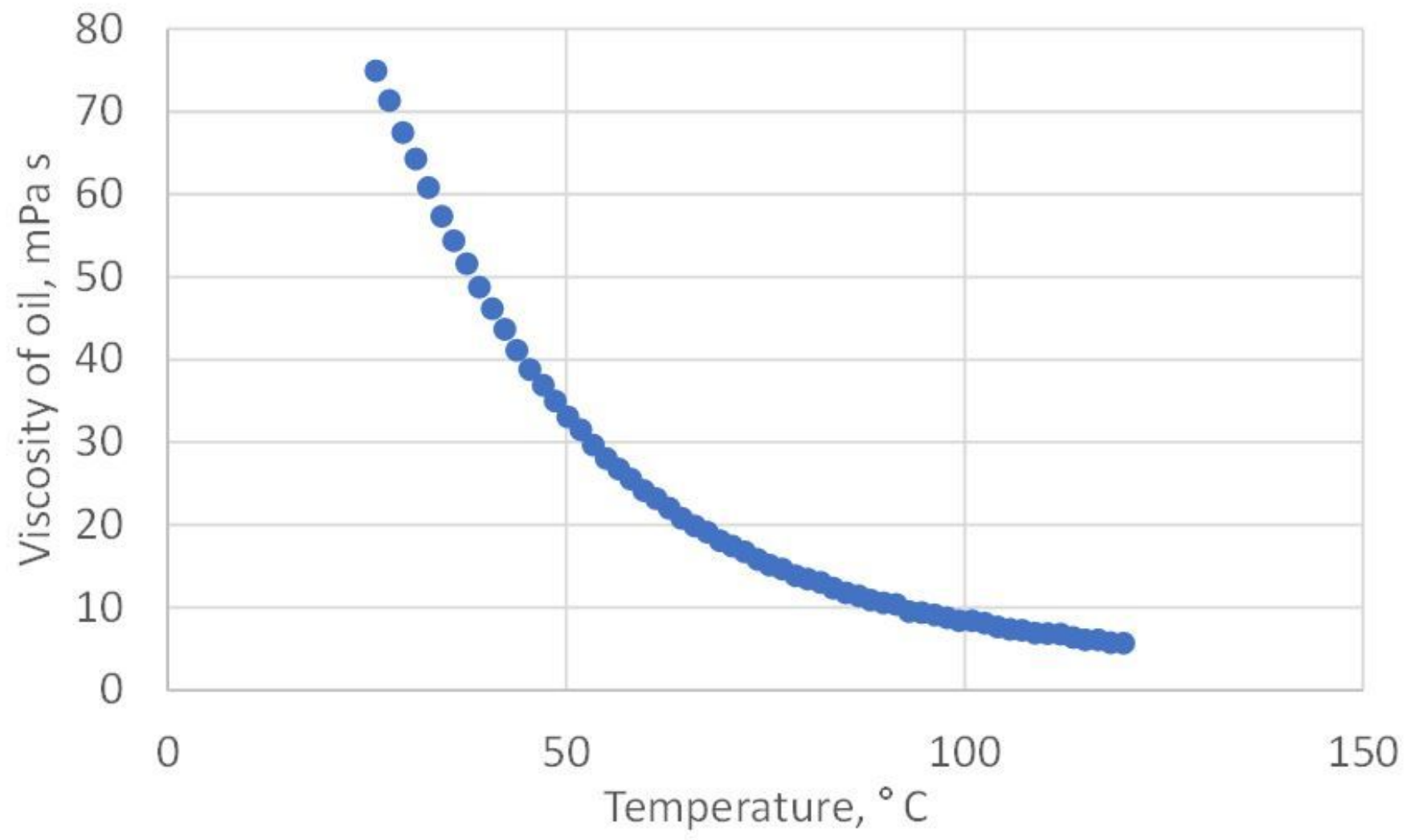

\section{Figure 4}

Temperature dependence of oil viscosity measured using rheometer.
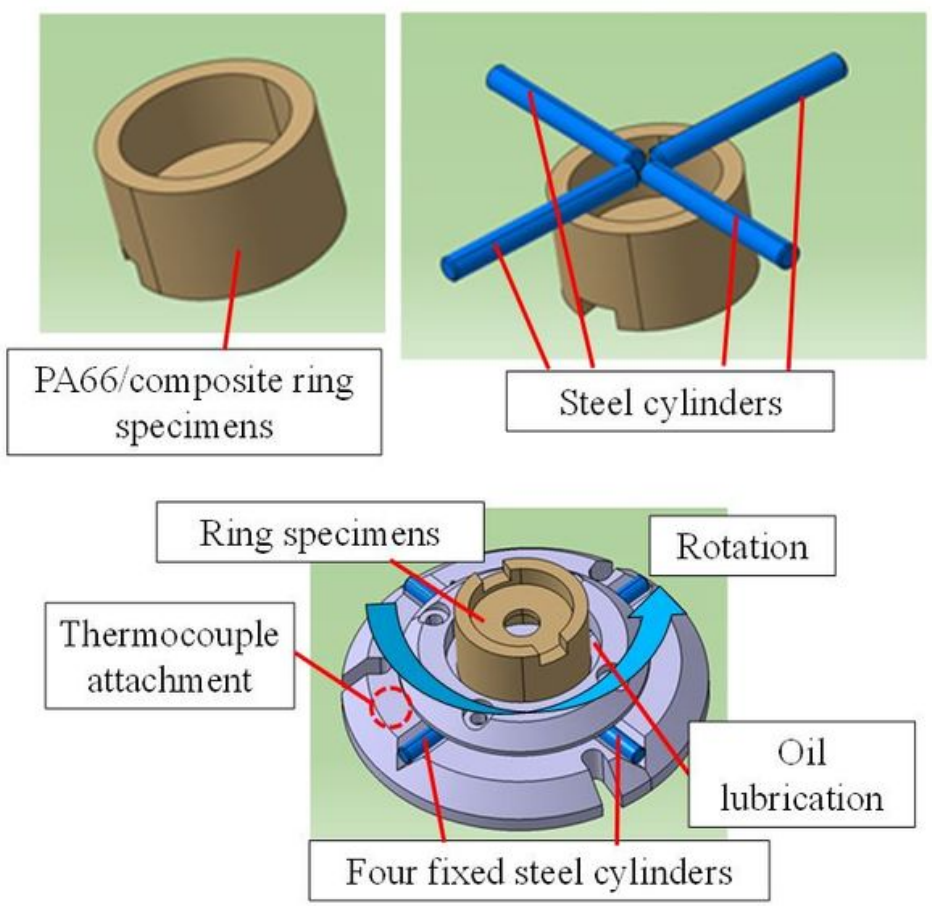

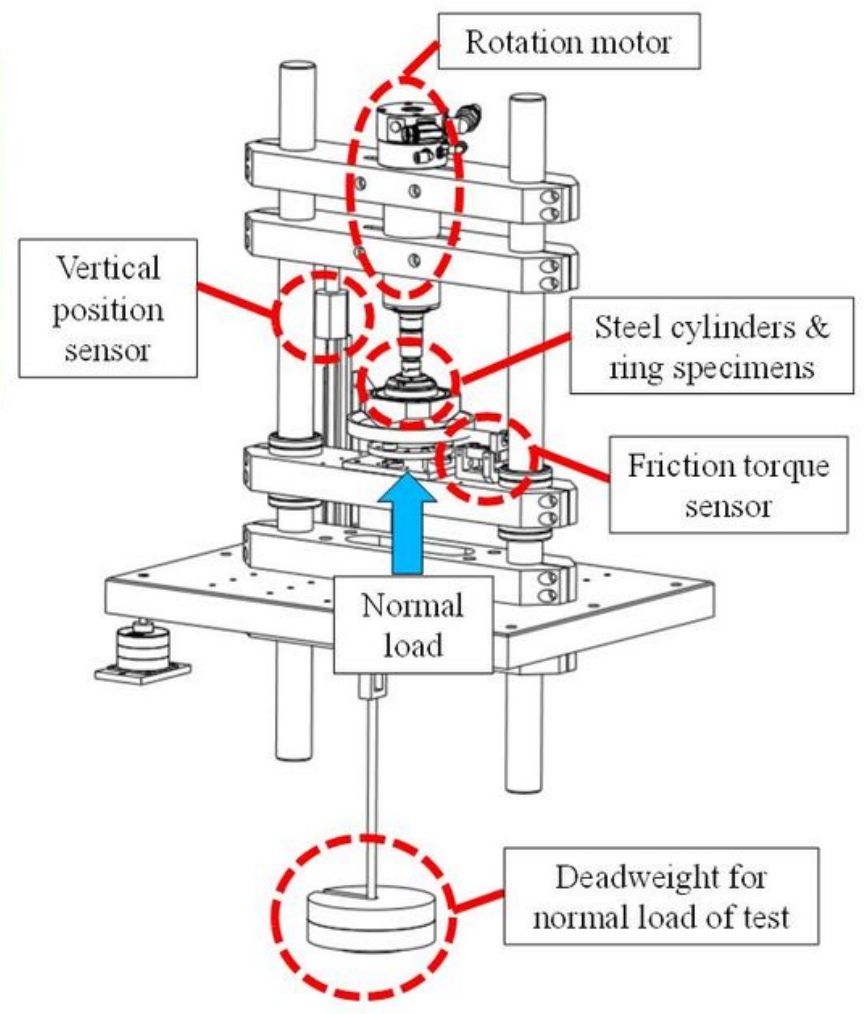


Schematics of test specimens and sliding-test setup.

(a)

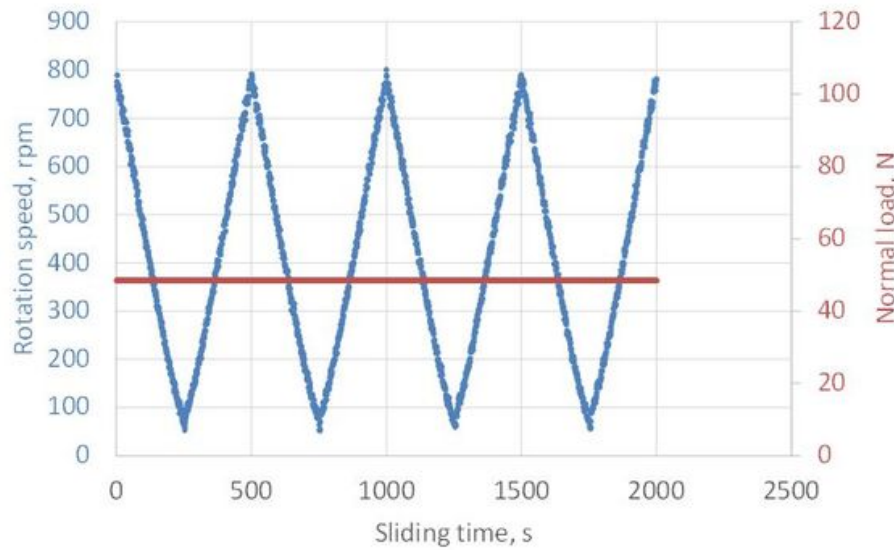

(b)

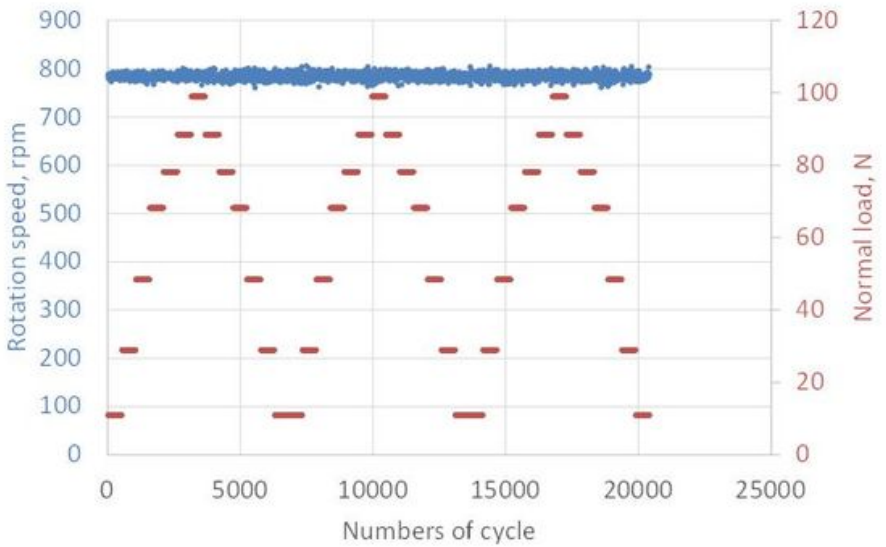

\section{Figure 6}

Sliding test profiles: (a) rotation speed dependence measured under same normal load and (b) normal load dependence measured under same rotation speed.

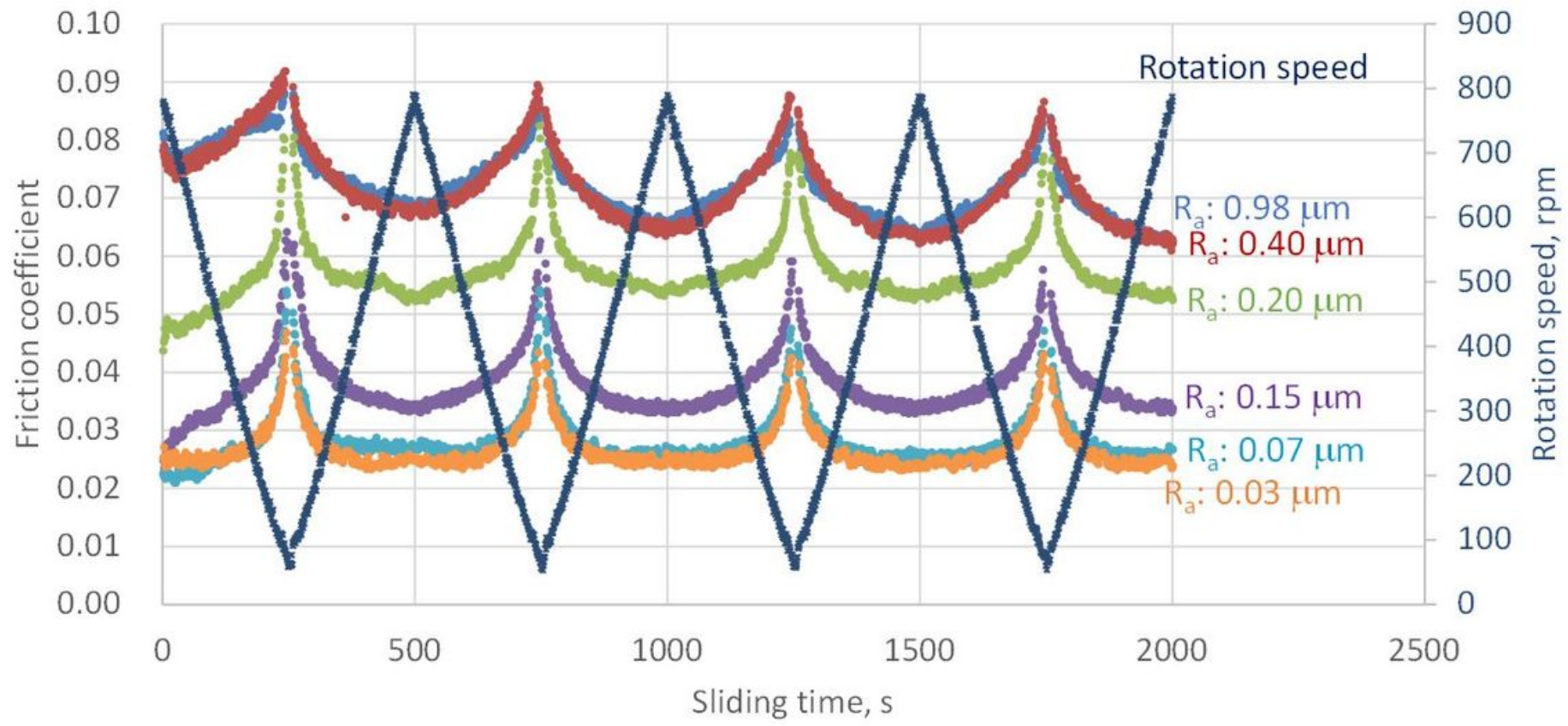

Figure 7

Friction coefficient evolutions obtained for different surface roughness of unreinforced PA66 ring specimens measured at different rotation speeds at room temperature. 


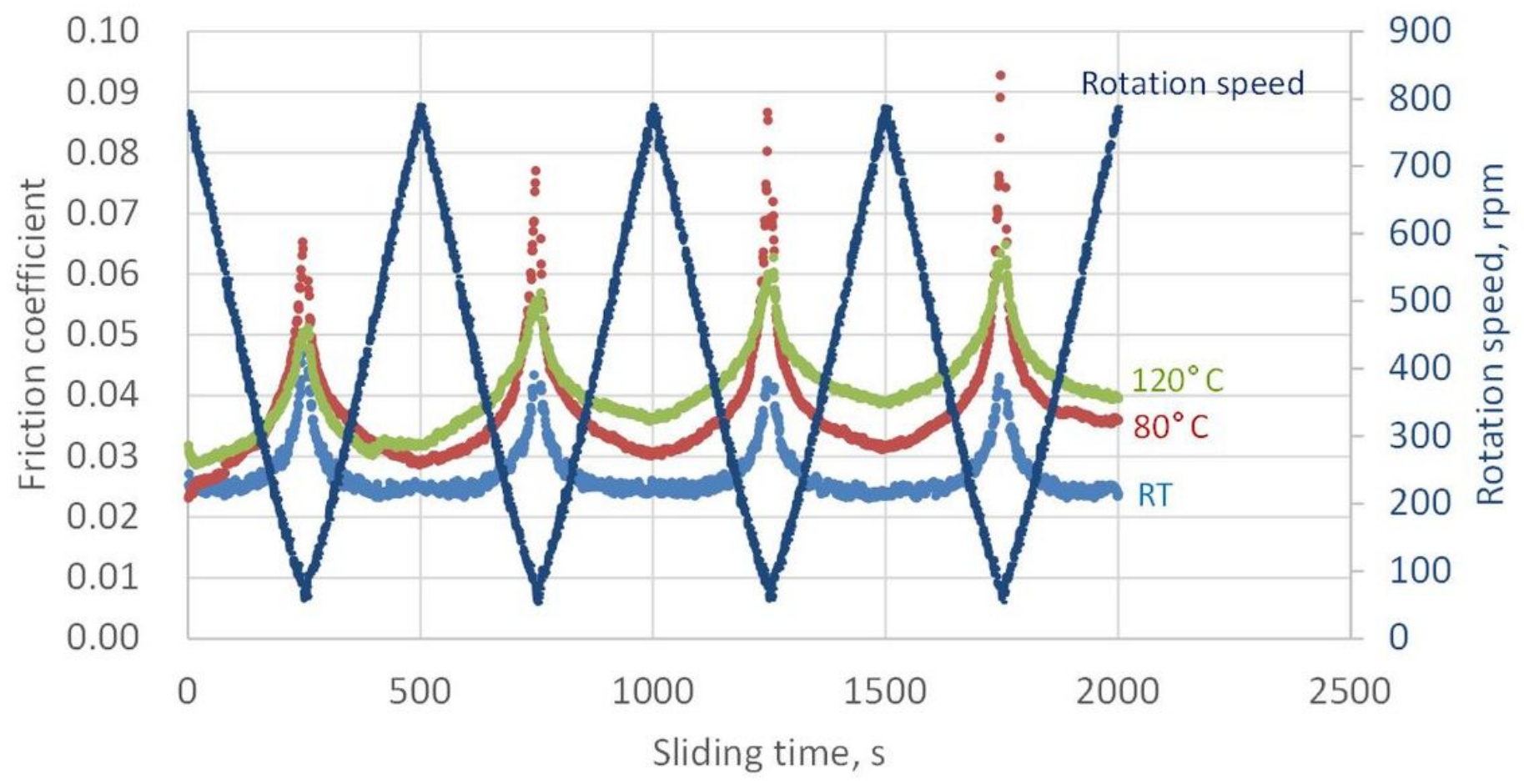

Figure 8

Friction coefficient evolutions of unreinforced PA66 specimens measured at different temperatures and rotation speeds.

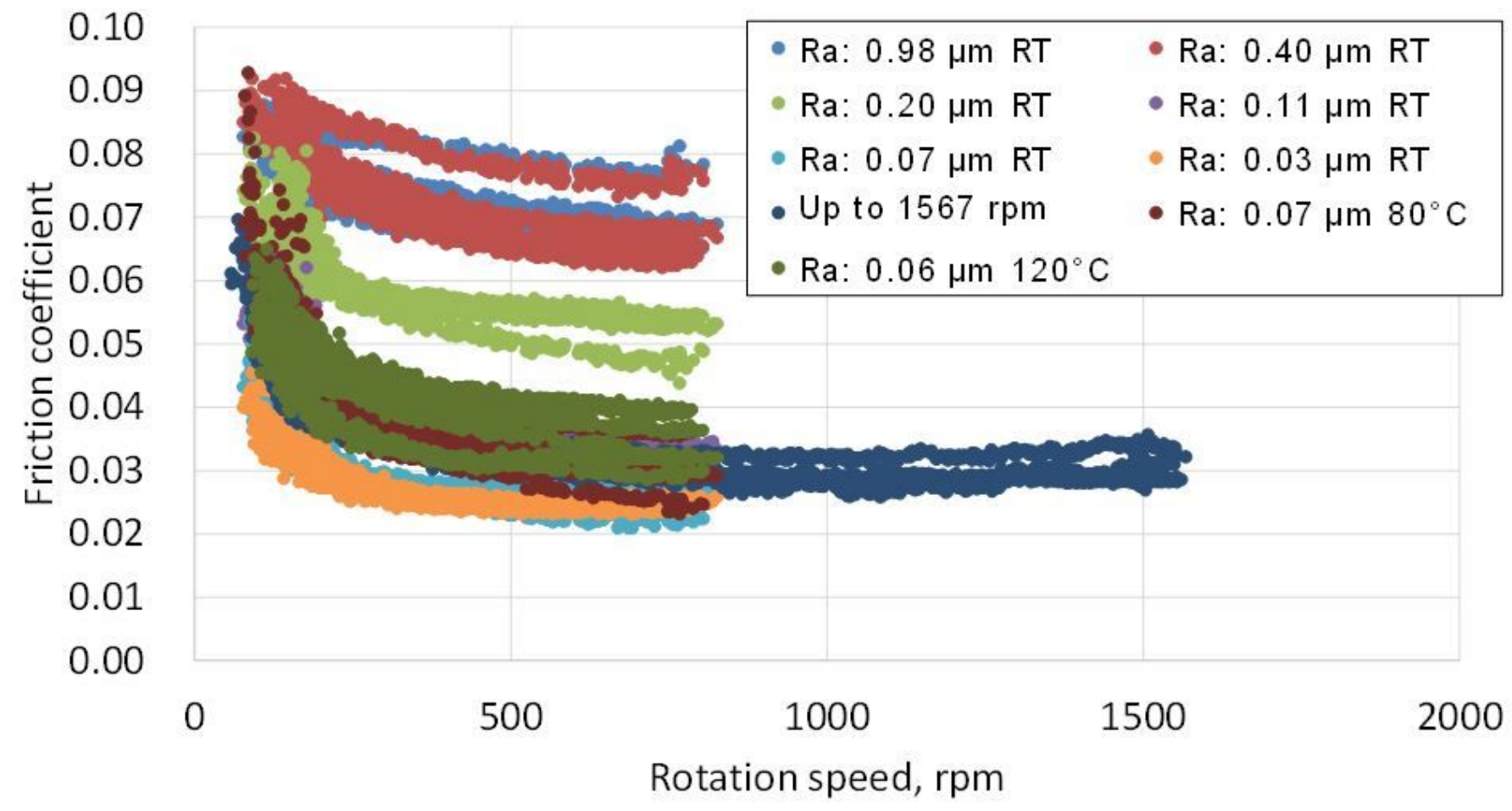

Figure 9

Relationship between sliding speed and friction coefficient measured under each test condition. 
(a)

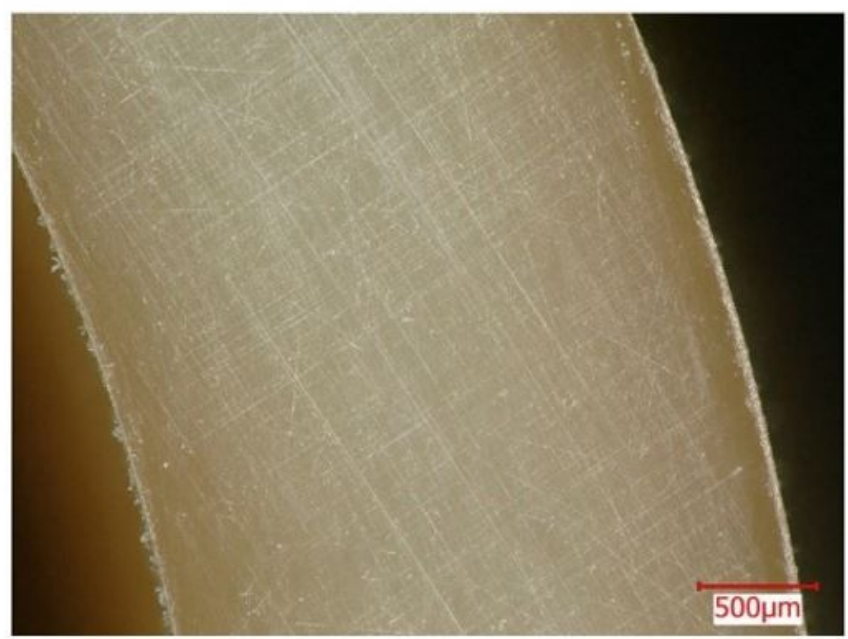

(b)

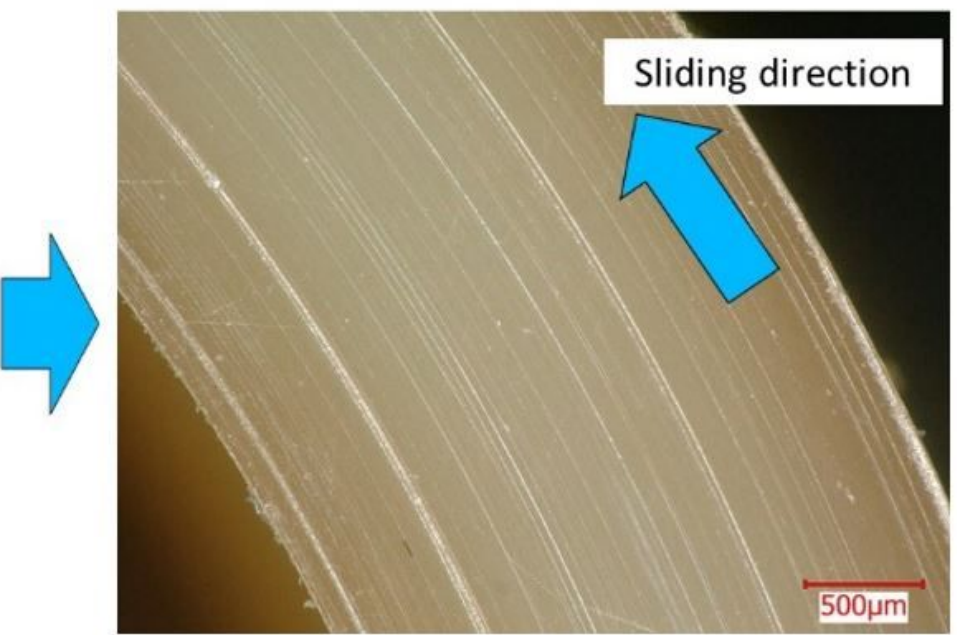

\section{Figure 10}

Optical microscope images taken (a) before and (b) after sliding test.
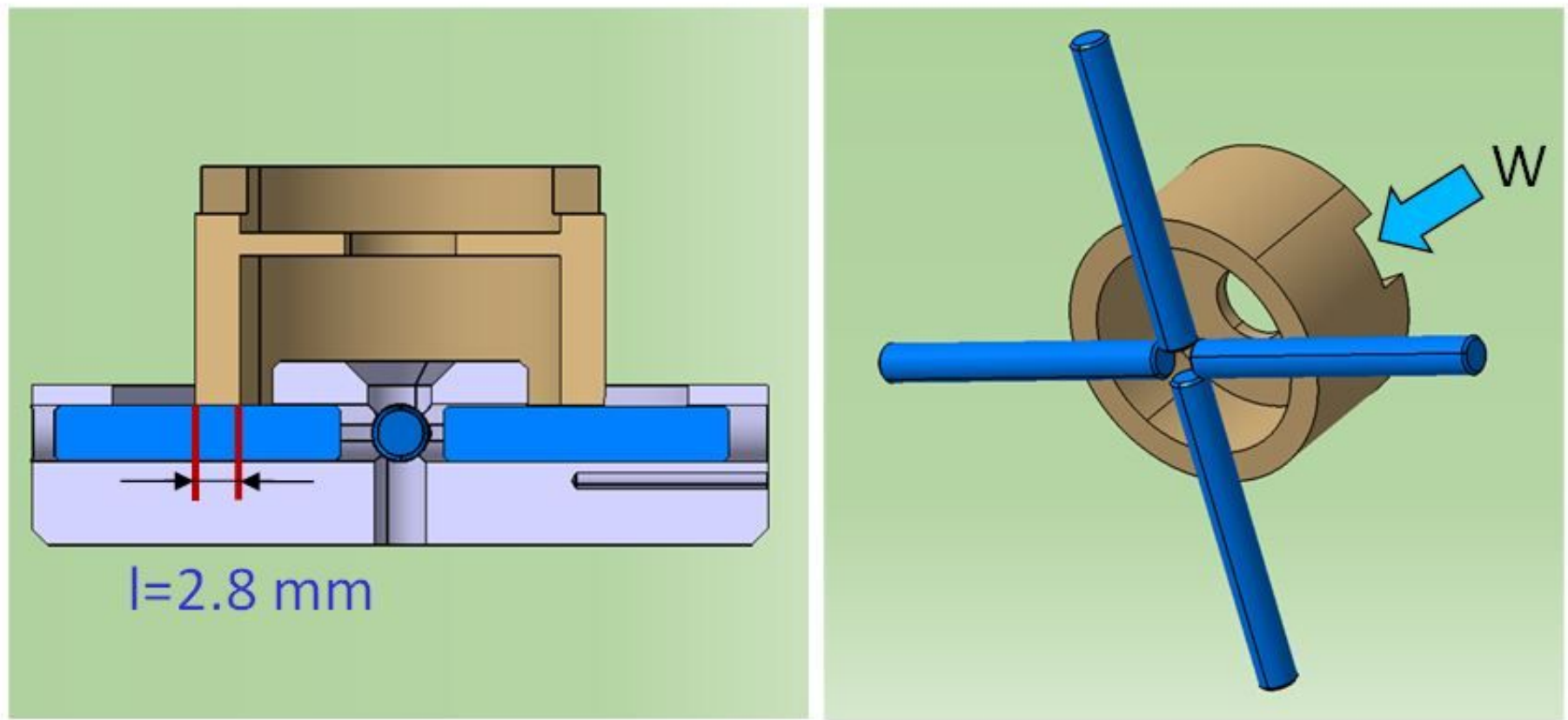

\section{Figure 11}

Contact geometry of sliding test performed with ring specimen and four steel cylinders. 


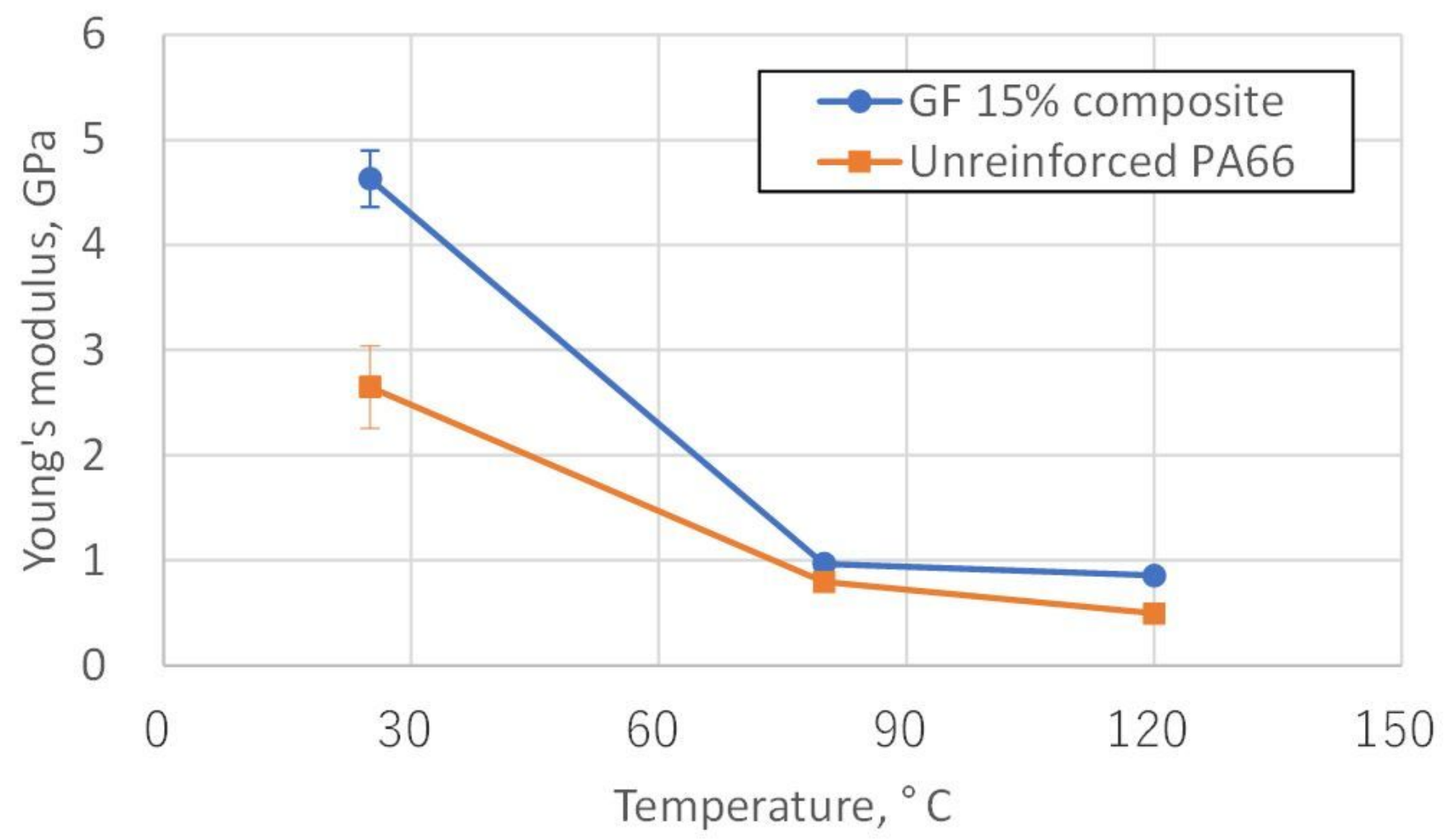

\section{Figure 13}

Young's modulus of unreinforced PA66 and GF composite measured using microindentation at each temperature [29].
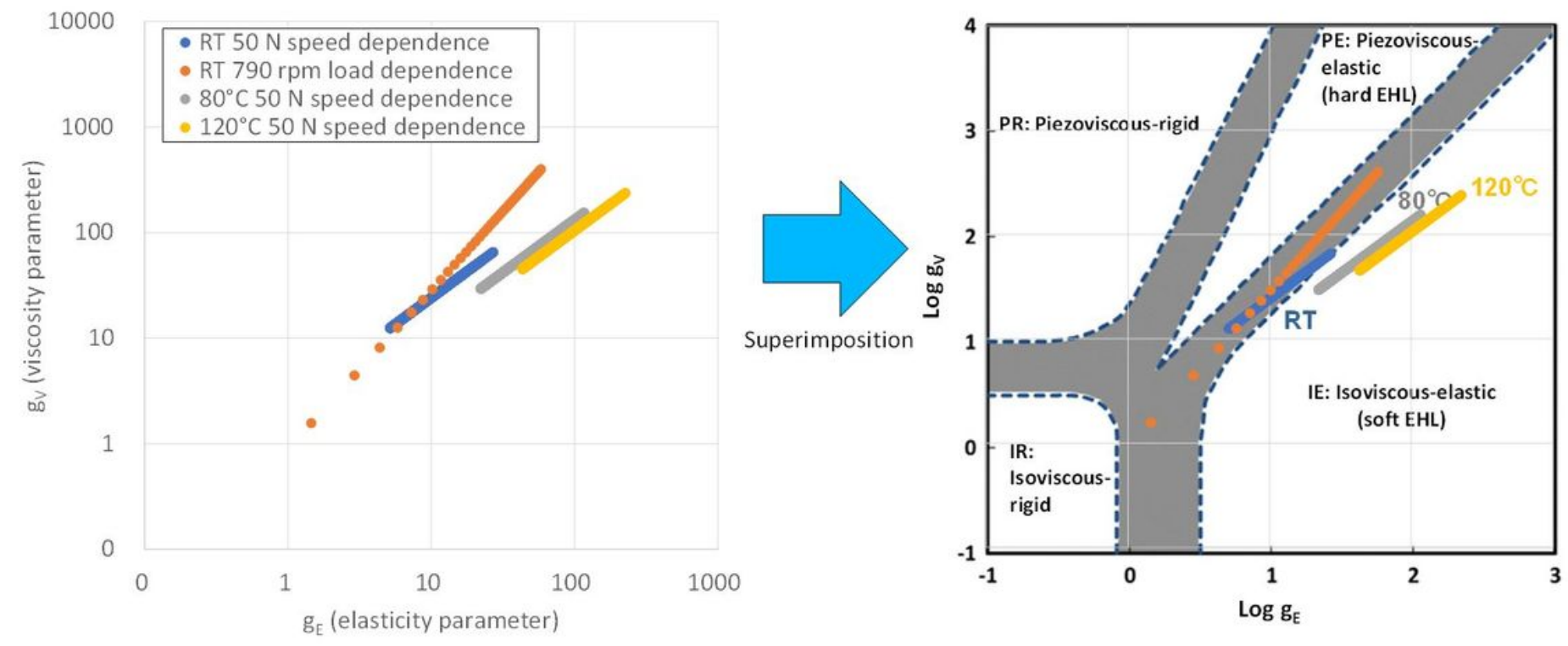

Figure 14

Lubrication regime map showing $\mathrm{gE}$ and $\mathrm{gV}$ estimated under each sliding condition. Colors in both plots correspond to same data points. This original image of the lubrication regime map was reprinted by the 
reference [32] and additional explanation was added.

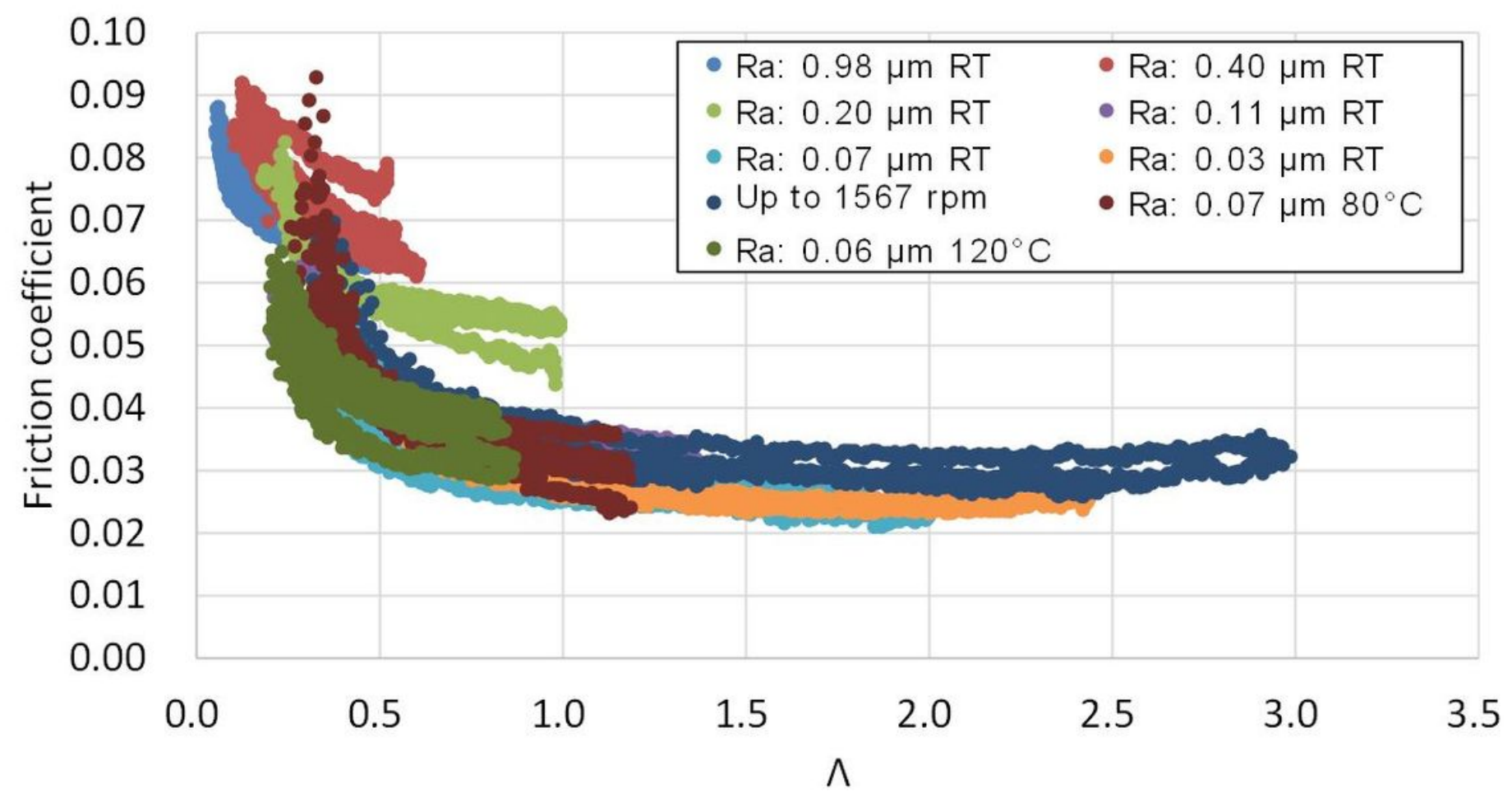

Figure 15

Obtained master $\Lambda-\mu$ curve.

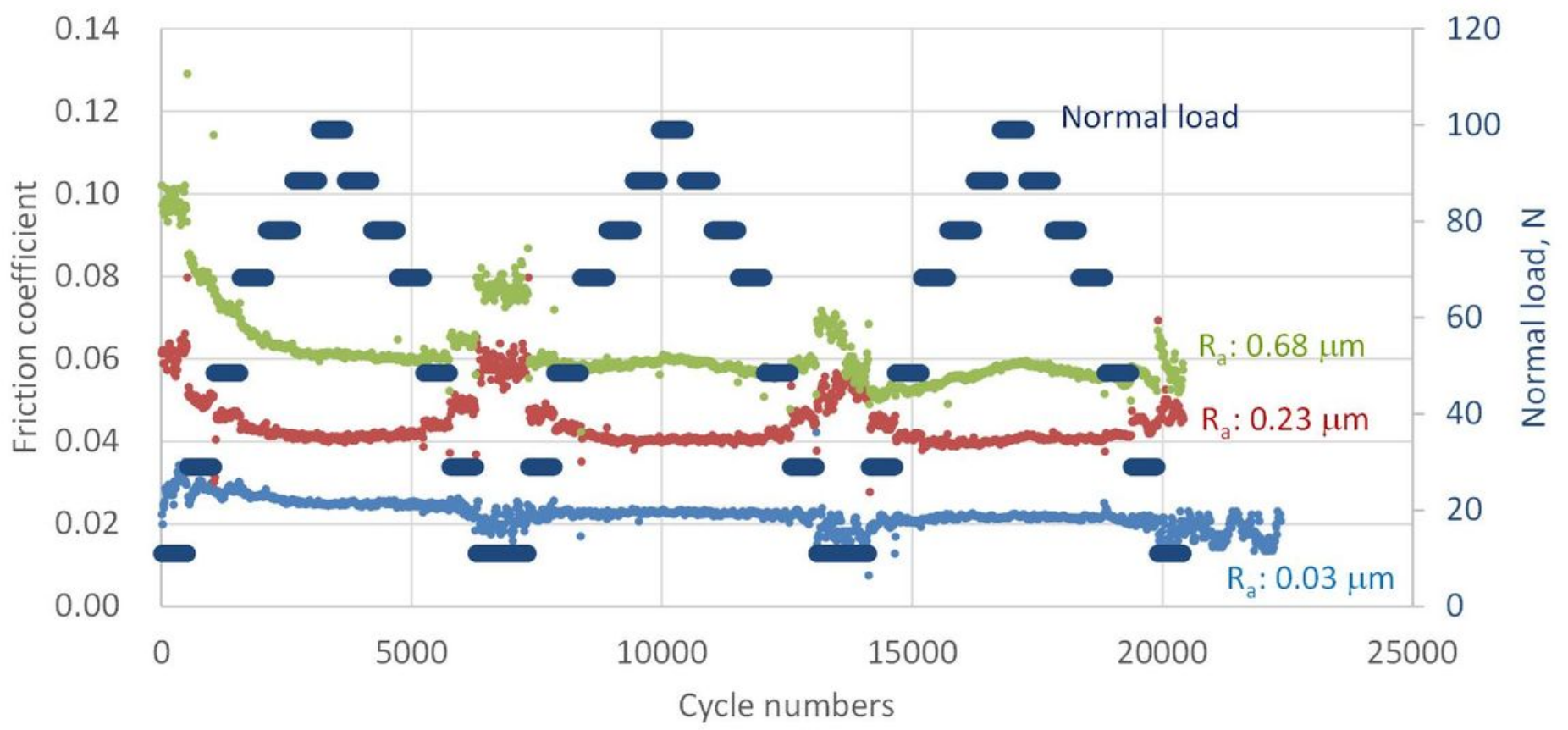

Figure 16 
Friction coefficient evolutions obtained for unreinforced PA66-ring specimens under different normal loads and sliding surface roughness.

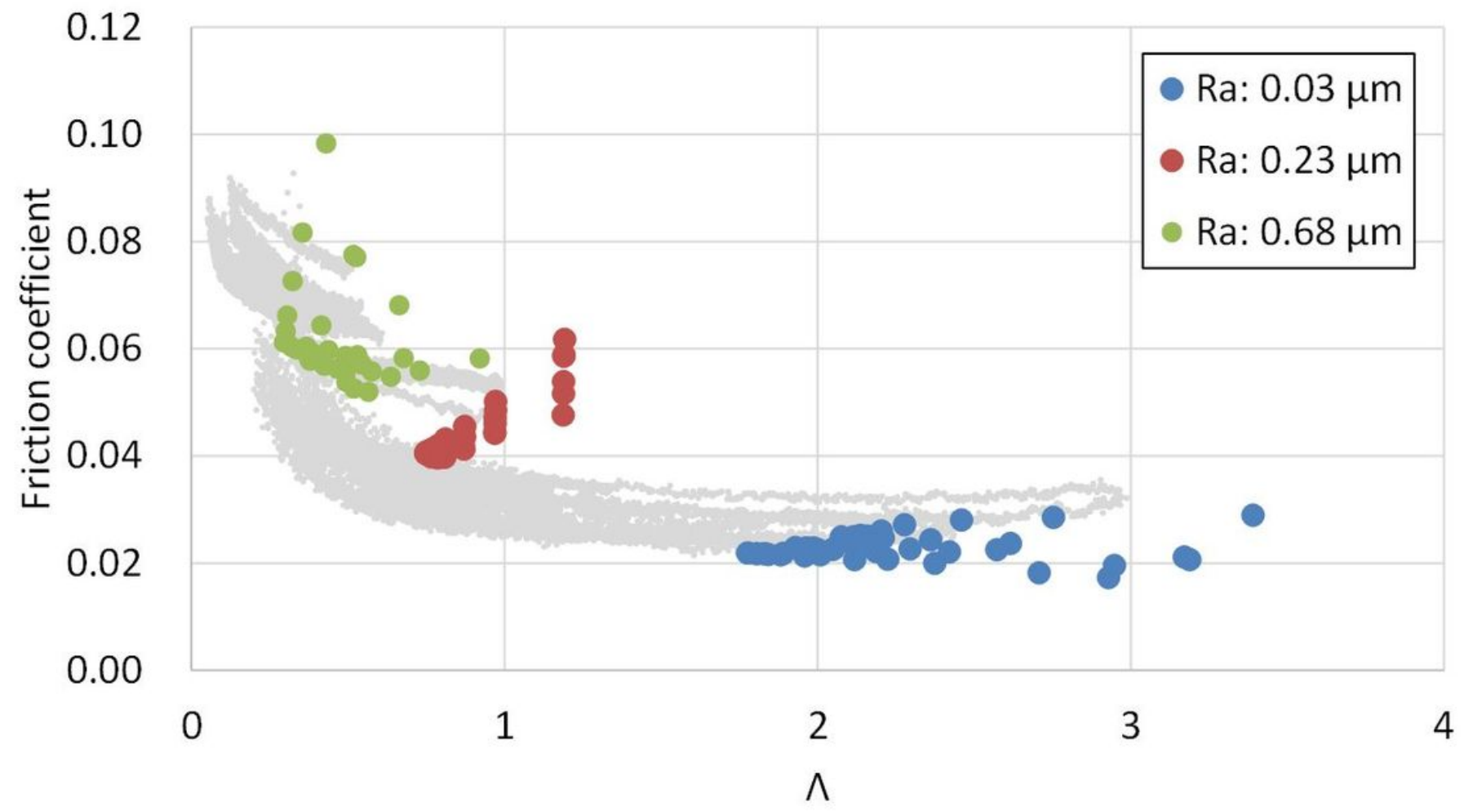

\section{Figure 17}

Relationship between $\Lambda$ and friction coefficient superimposed on $\Lambda-\mu$ master curve (gray) shown in Fig. 15.

(a)

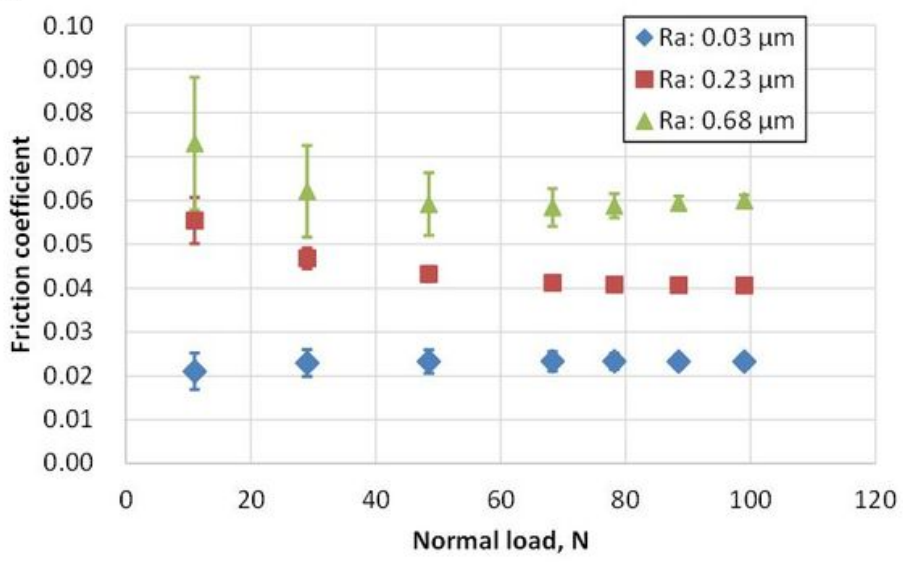

(b)

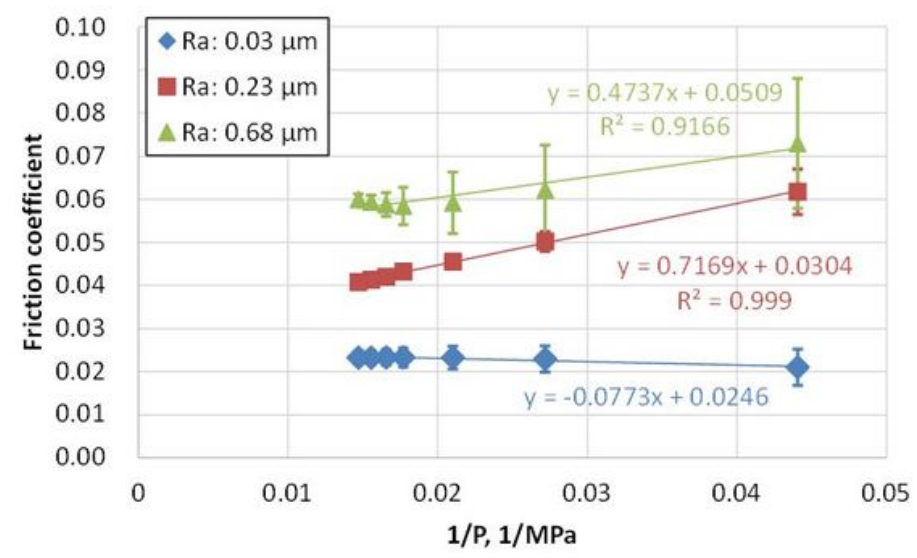

\section{Figure 18}

Relationships between (a) normal load friction coefficient and (b) inverse contact pressure and friction coefficient for different normal loads and surface roughness of unreinforced PA66 ring specimens. 


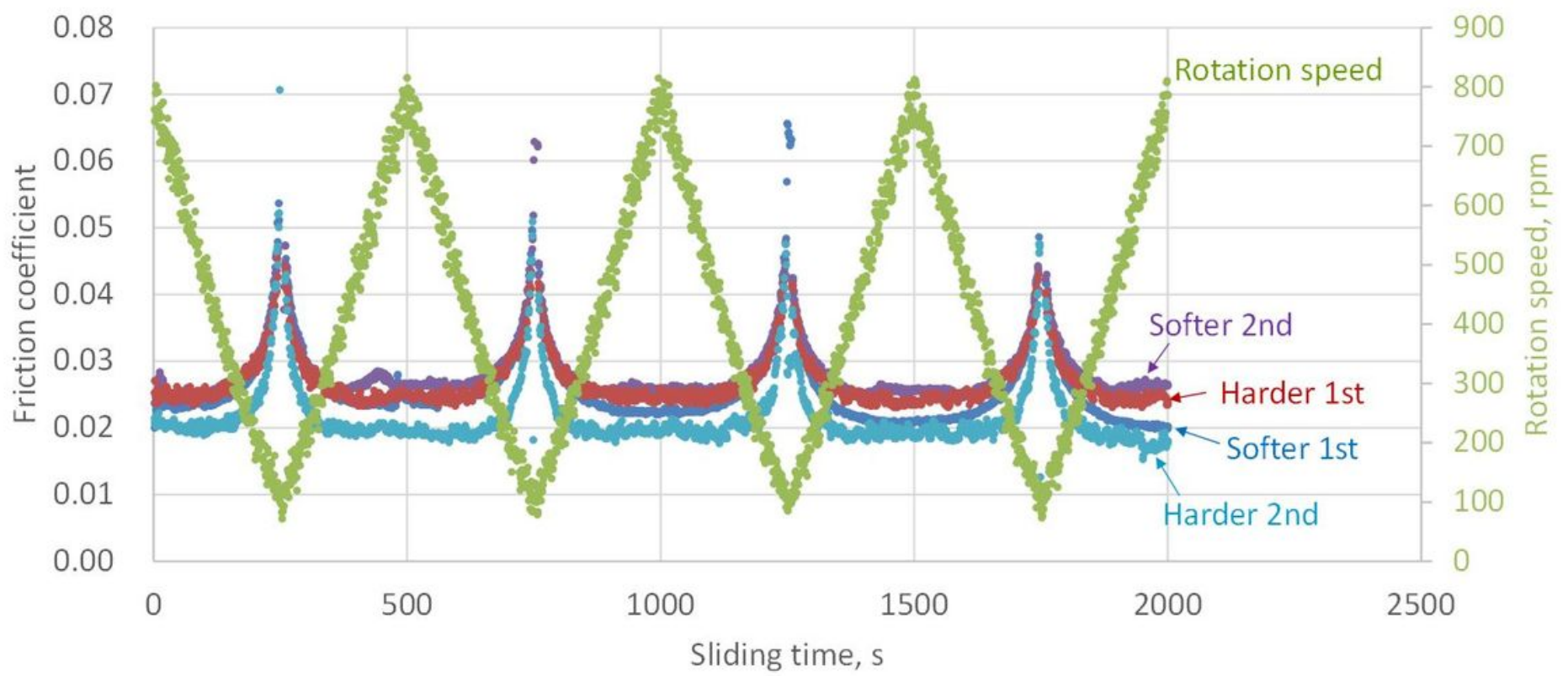

Figure 19

Friction coefficient evolutions obtained for different rotation speeds and counterpart steel harnesses measured using unreinforced PA66. Initial surface Ra $=0.05 \mathrm{Dm}$ (two tests were conducted for each steel hardness).

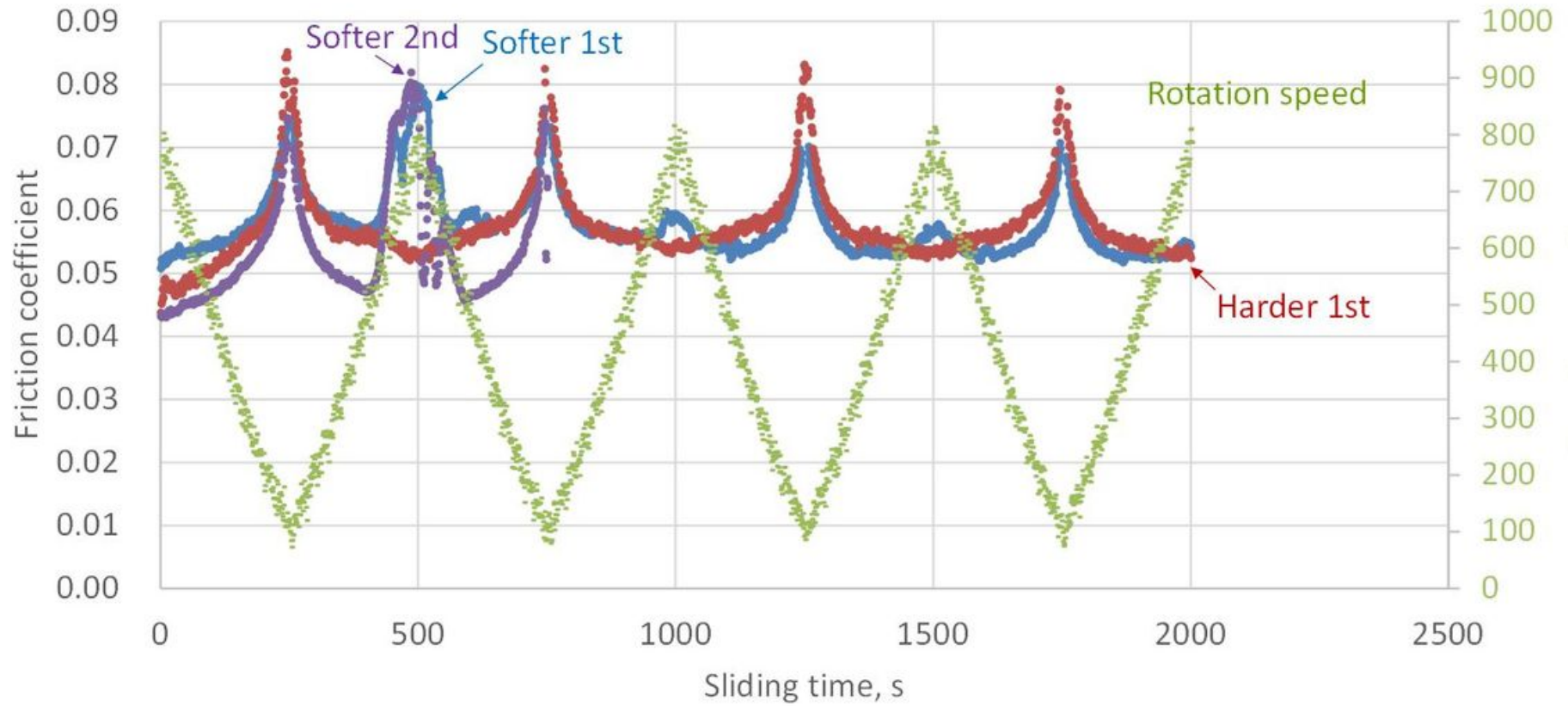

\section{Figure 20}

Friction coefficient evolutions obtained for different rotation speeds and counterpart steel harnesses measured using unreinforced PA66. Initial surface Ra $=0.20 \mu \mathrm{m}$. 
(a)

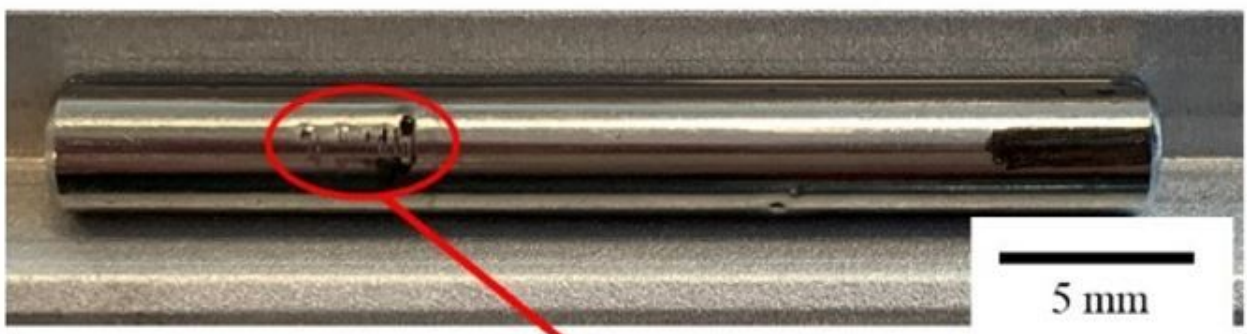

(b)

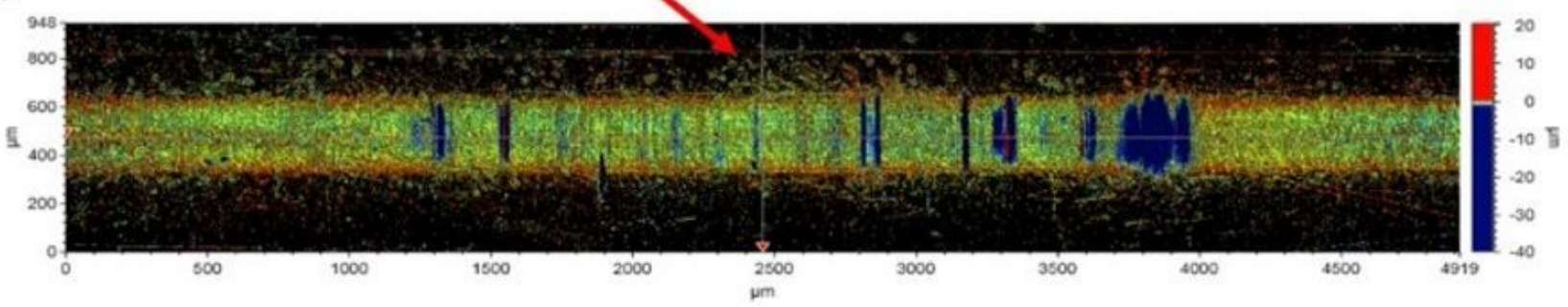

\section{Figure 21}

(a) Optical microscope image and (b) interferometric measurement (after cylinder shape was removed) after softer steel cylinder had slid for $750 \mathrm{~s}$.
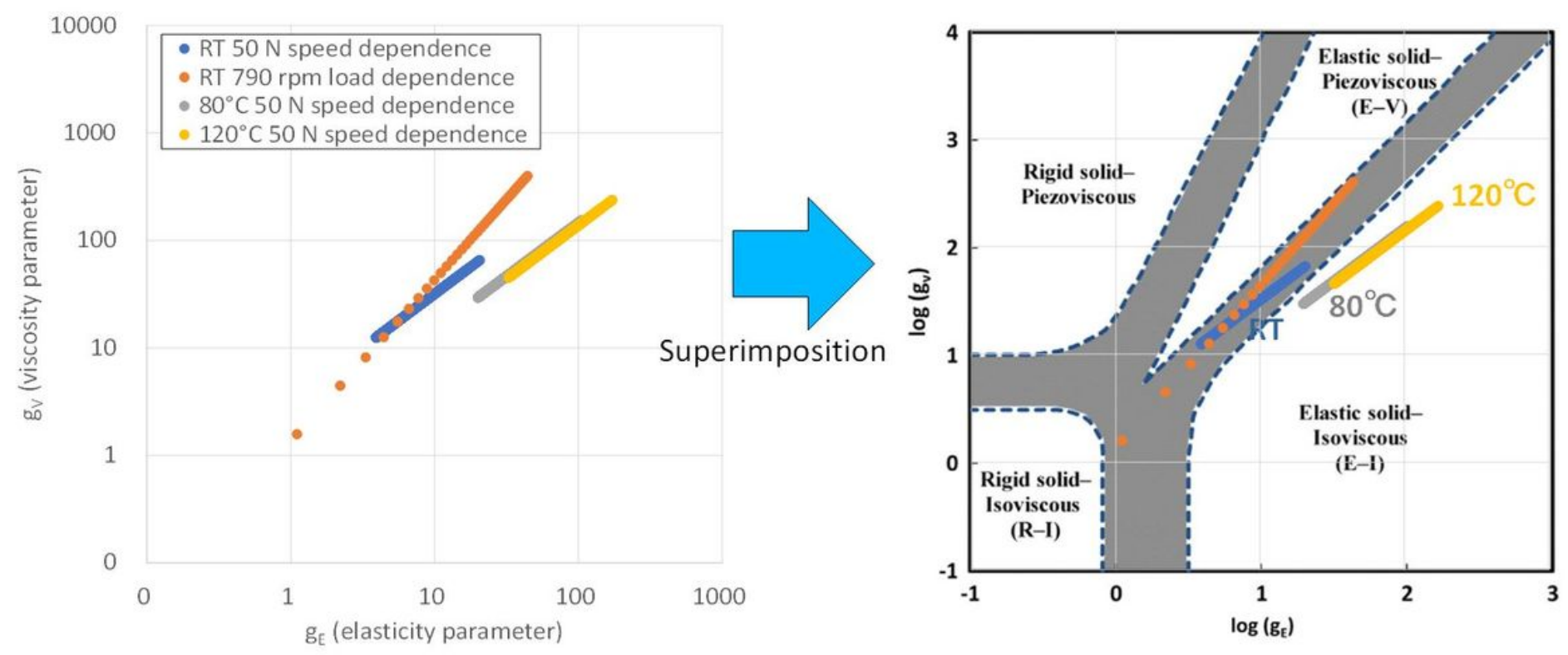

\section{Figure 22}

gE and gV obtained under each sliding-test condition for GF composite and superimposed on lubrication regime map presented in Fig. 9. Colors in both plots correspond to same data points. This original image of the lubrication regime map was reprinted by the reference [32] and additional explanation was added. 
(a)

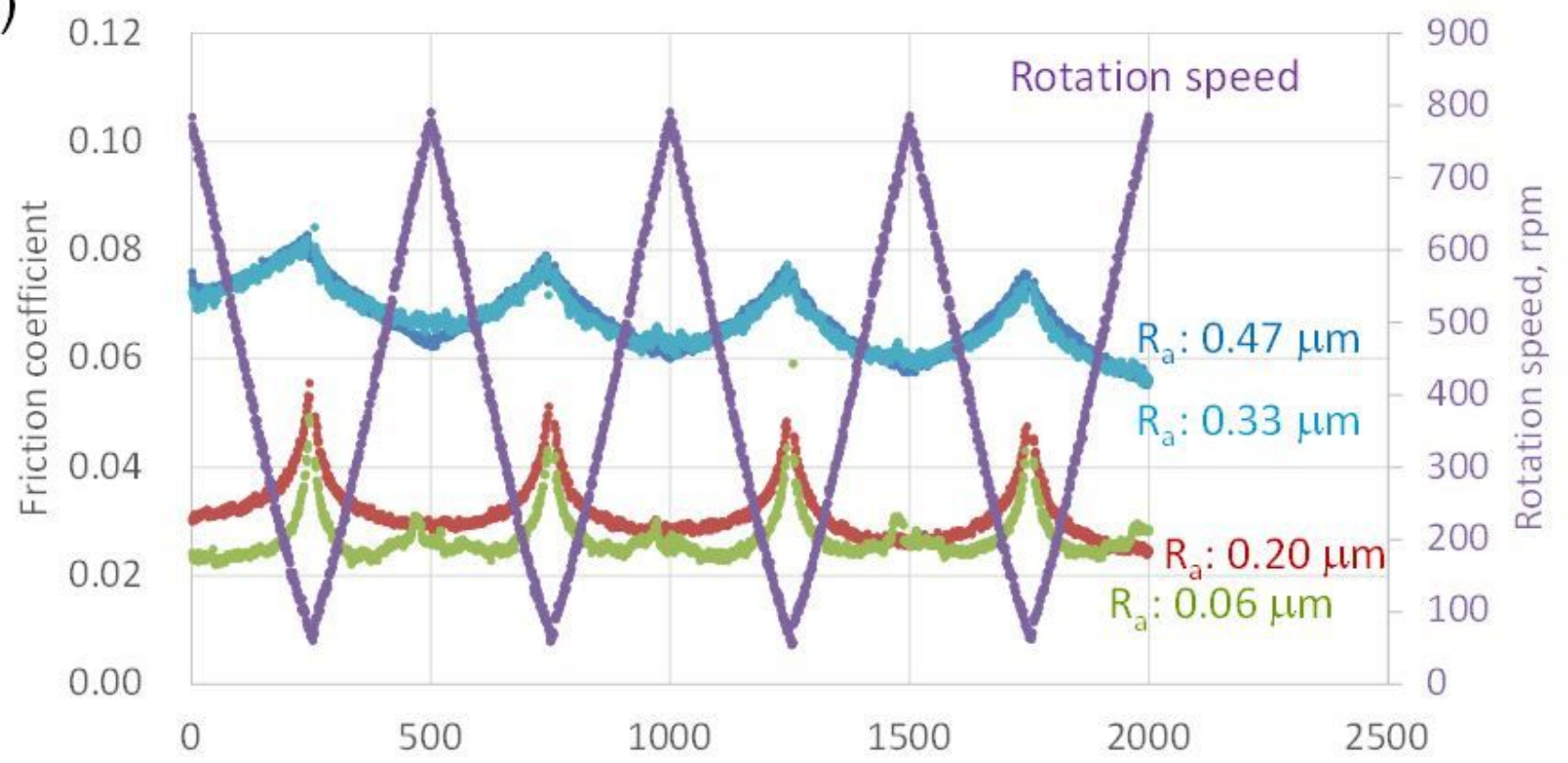

(b)

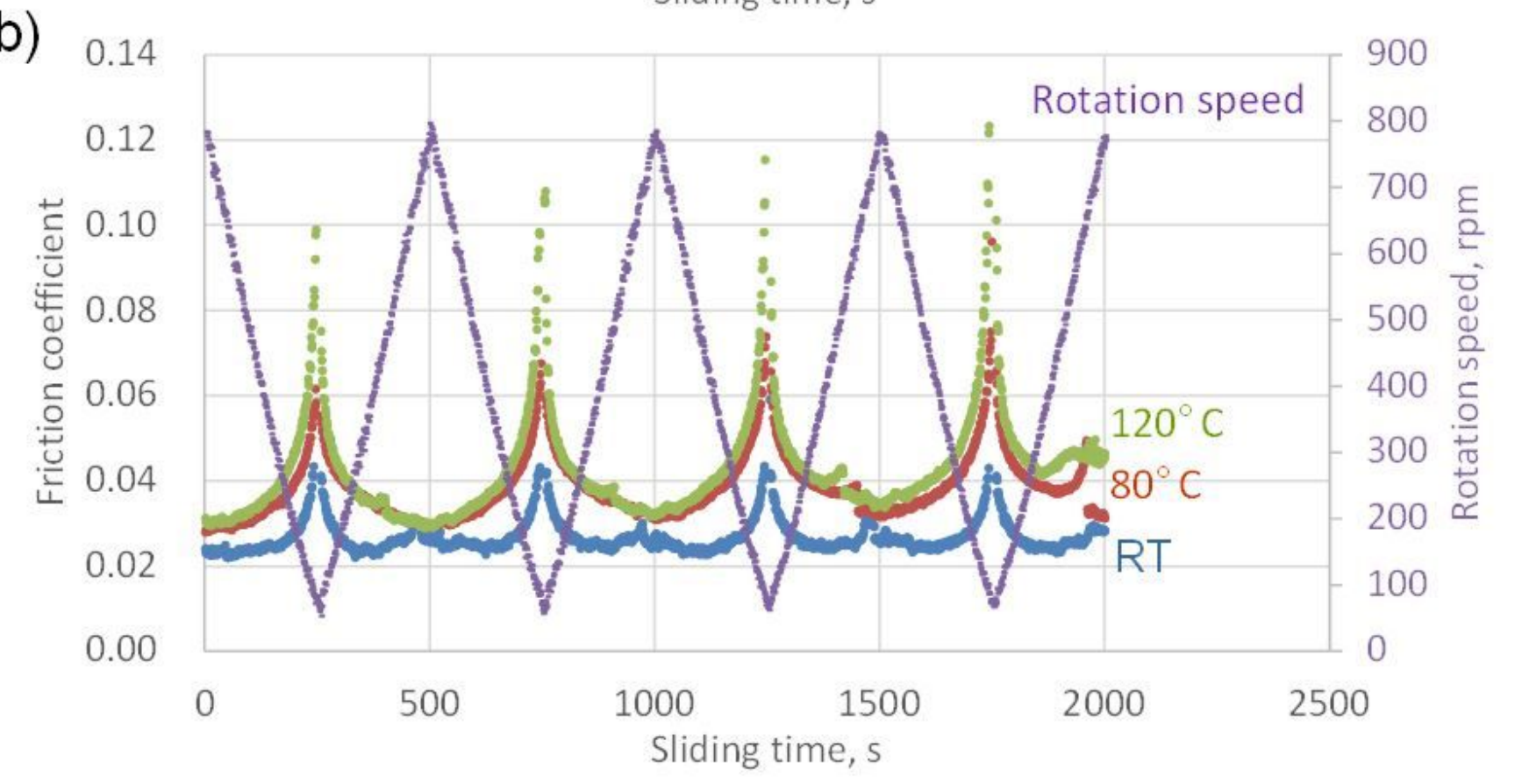

Figure 23

(a) Rotation speed and sliding surface roughness dependences obtained at room temperature and (b) rotation speed and temperature dependences of friction coefficient obtained using smooth GF composite and harder steel. 


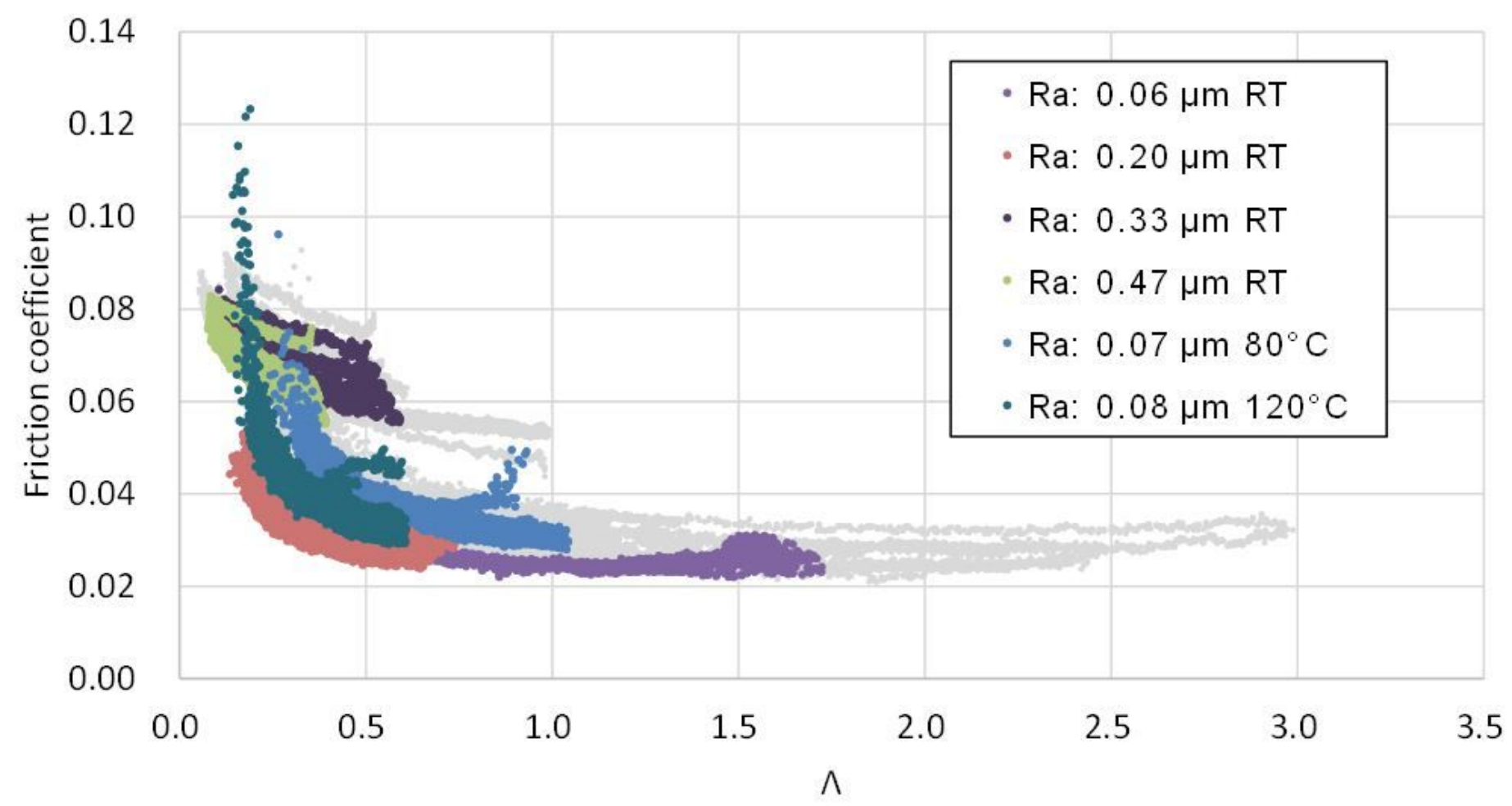

Figure 24

Relationship between calculated $\Lambda$ and friction coefficient obtained using GF composite compared to same relationship obtained using master $\Lambda \rrbracket-\mu$ curve (gray) for unreinforced PA66. 
(a)

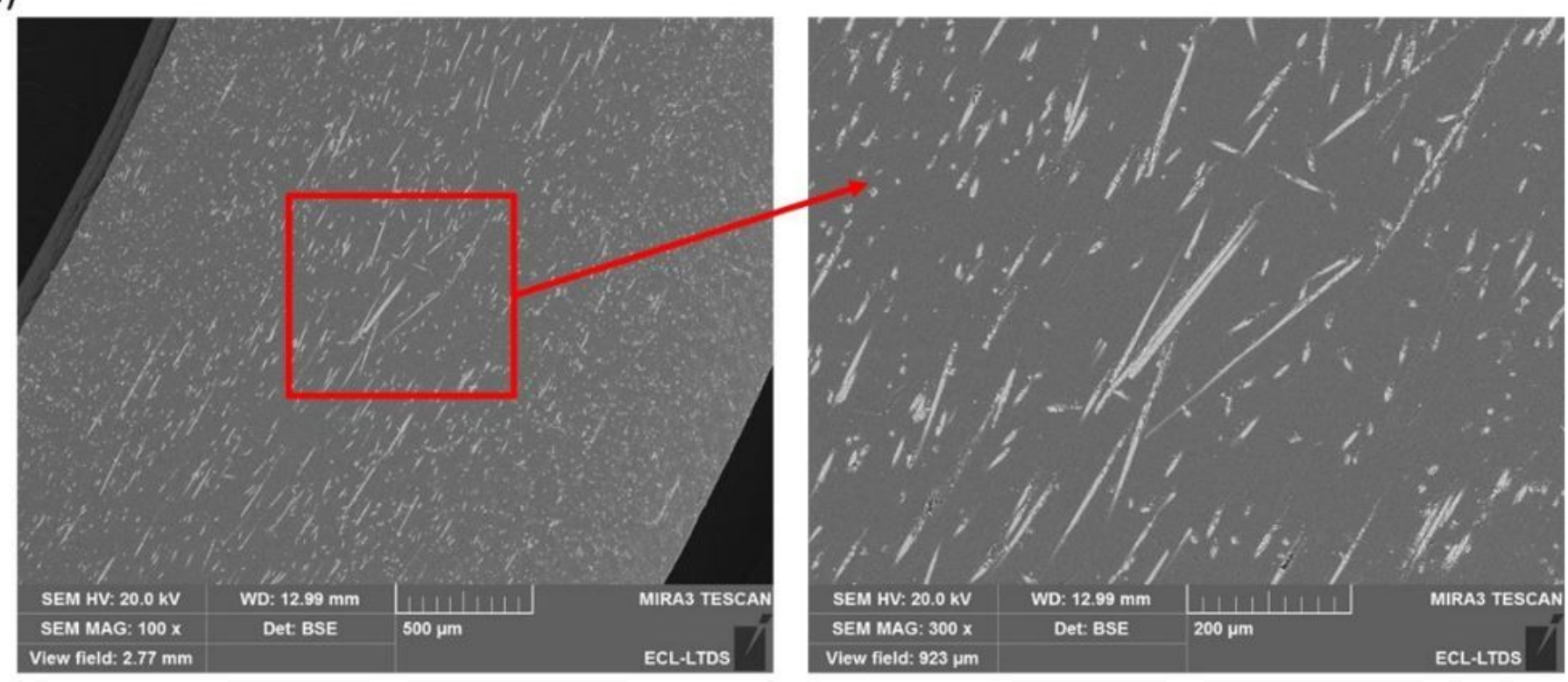

(b)

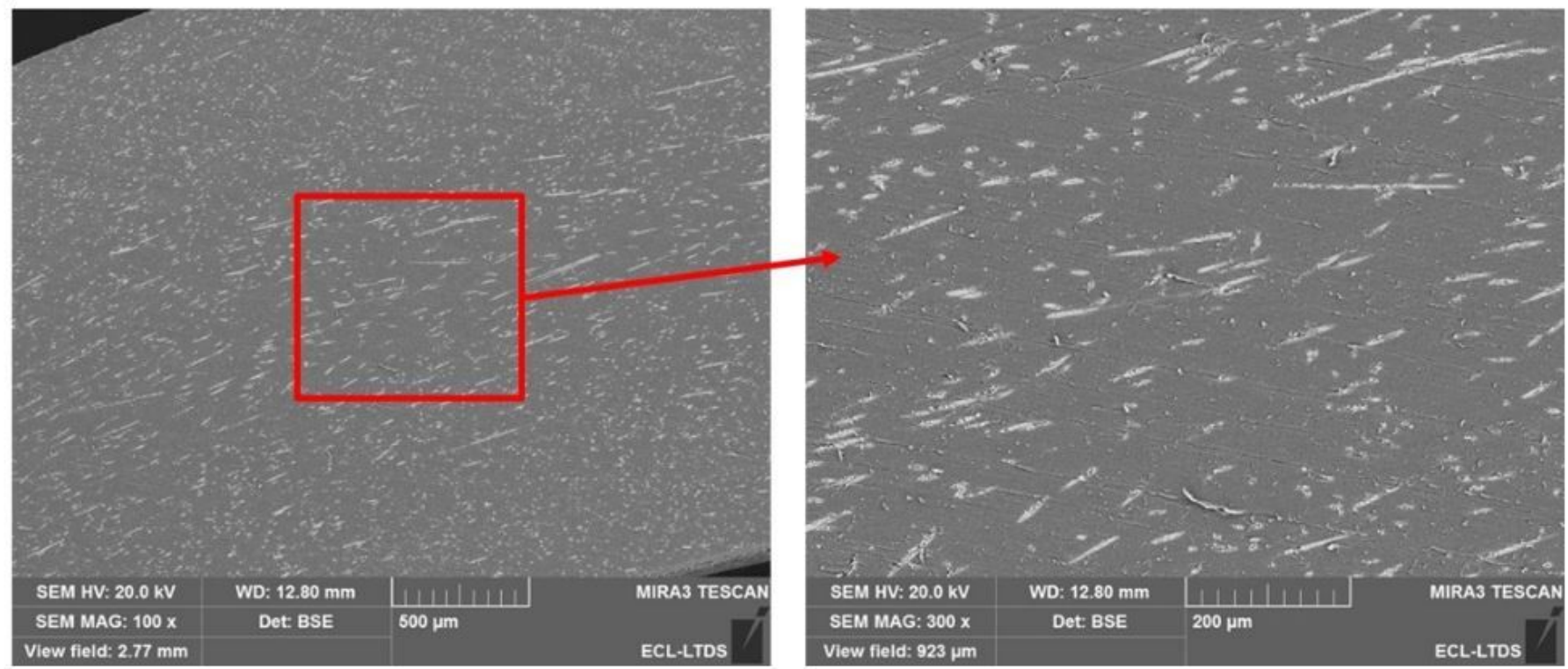

Figure 25

SEM observations of the sliding surface after sliding tests; (a) initial $\mathrm{Ra}=0.06 \mu \mathrm{m}$, (b) initial $\mathrm{Ra}=0.47$ $\mu \mathrm{m}$. 


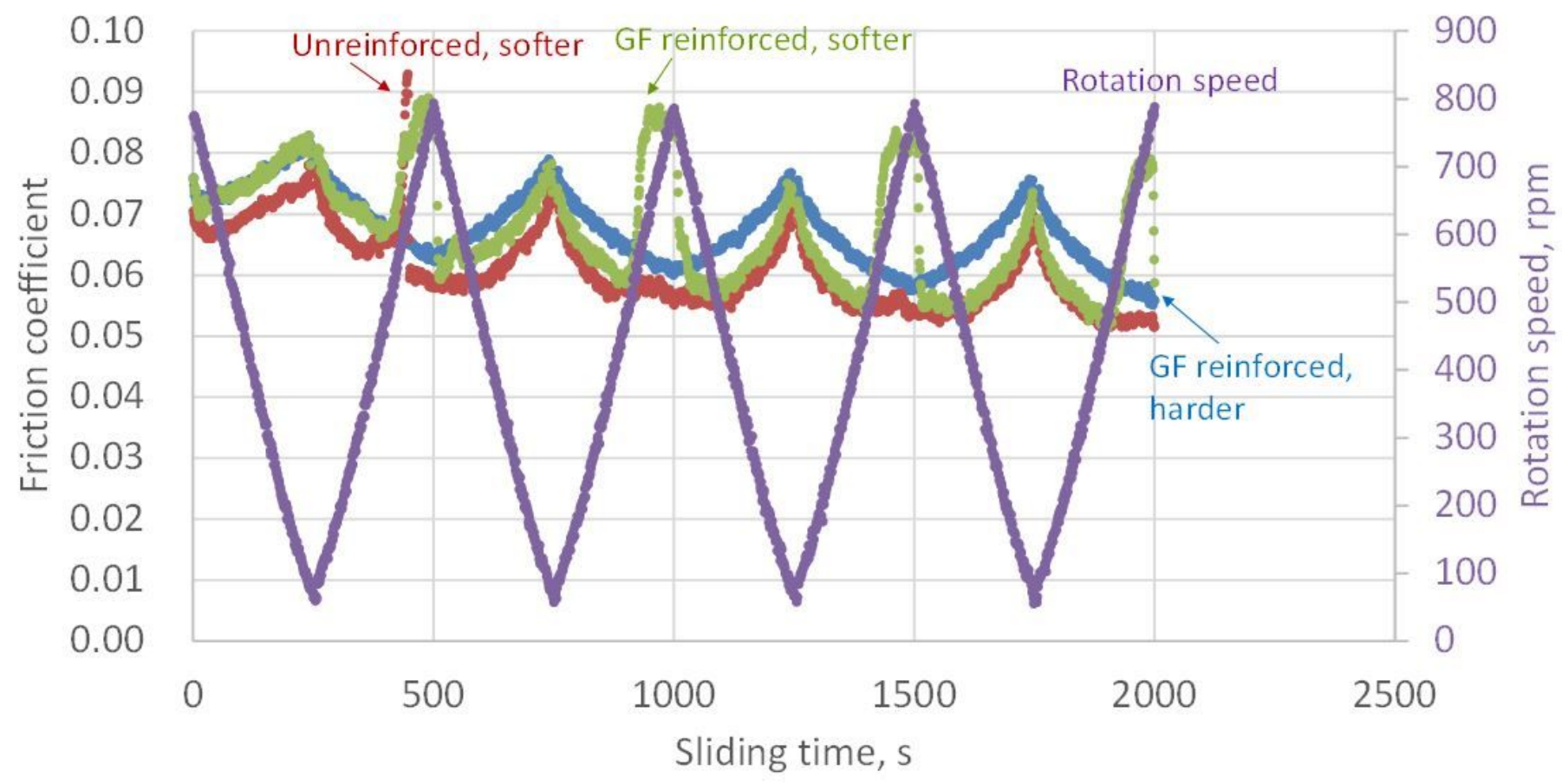

Figure 26

Friction coefficient evolutions obtained at different rotation speeds for either GF composite or unreinforced PA66 and either softer or harder steel.

(a)

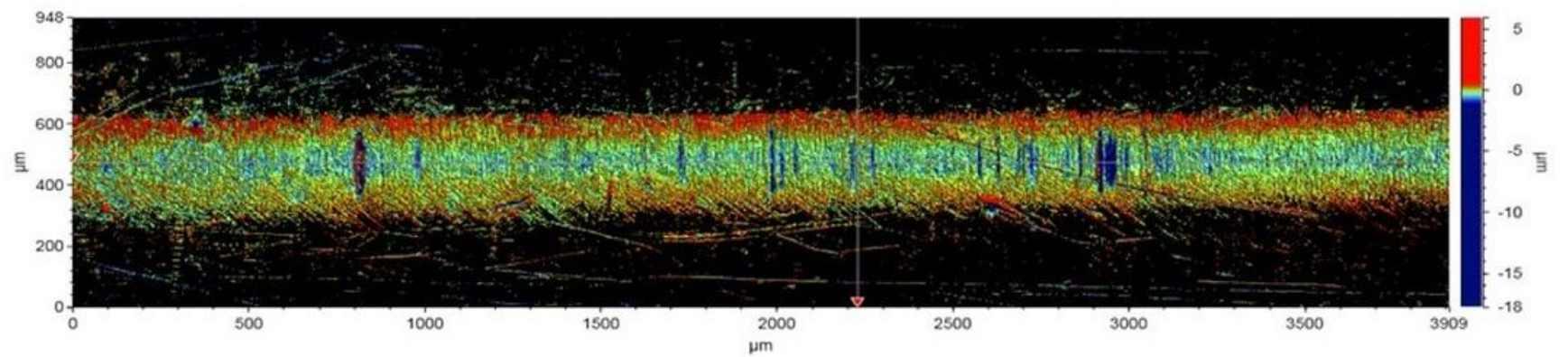

(b)

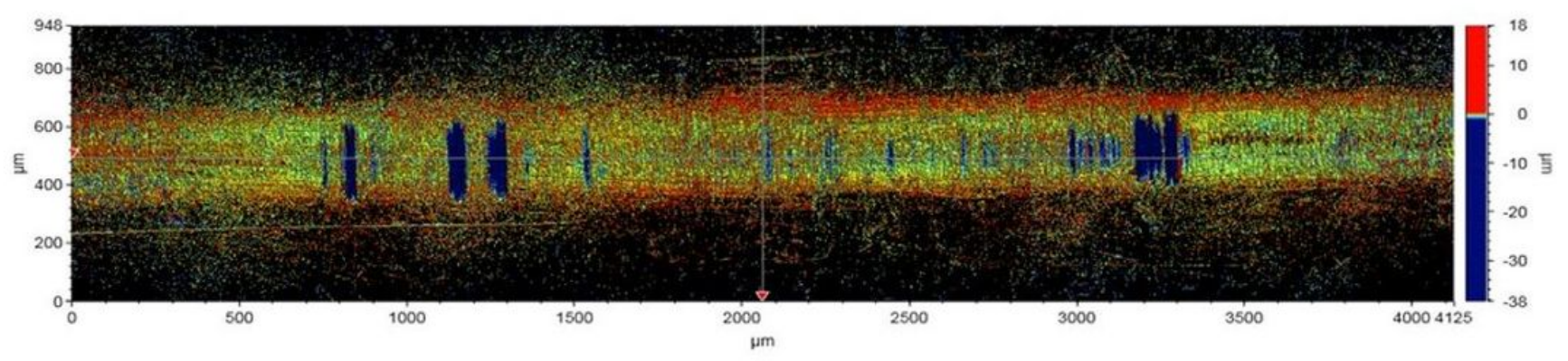

Figure 27 
Interferometric measurements of steel cylinder (after cylindrical shape was removed) after sliding tests in contact with (a) unreinforced PA66 and (b) GF composite.

\section{Supplementary Files}

This is a list of supplementary files associated with this preprint. Click to download.

- SupplementarymaterialTriboogyLetters.docx 